\title{
Global Seabird Response to Forage Fish Depletionò One-Third for the Birds
}

\author{
Philippe M. Cury ${ }^{1, *}$, Ian L. Boyd ${ }^{2, *}$, Sylvain Bonhommeau ${ }^{3}$, Tycho Anker-Nilssen ${ }^{4}$, \\ Robert J. M. Crawford ${ }^{5}$, Robert W. Furness ${ }^{6}$, James A. Mills ${ }^{7}$, Eugene J. Murphy ${ }^{8}$, Henrik Österblom ${ }^{9}$, \\ Michelle Paleczny ${ }^{10}$, John F. Piatt ${ }^{11}$, Jean-Paul Roux ${ }^{12,13}$, Lynne Shannon ${ }^{14}$, William J. Sydeman ${ }^{15}$
}

1 Institut de Recherche pour le Développement, UMR EME-212, Centre de Recherche Halieutique Méditerranéenne et Tropicale, Avenue Jean Monnet, BP 171, 34203 Sète Cedex, France.

${ }^{2}$ Scottish Oceans Institute, University of St Andrews, St Andrews KY16 8LB, UK.

${ }^{3}$ Ifremer, UMR EME 212, Centre de Recherche Halieutique Méditerranéenne et Tropicale, Avenue Jean Monnet, BP 171, 34203 Sète Cedex, France.

${ }_{5}^{4}$ Norwegian Institute for Nature Research, Post Office Box 5685 Sluppen, NO-7485 Trondheim, Norway.

${ }^{5}$ Branch Oceans and Coasts, Department of Environmental Affairs, Private Bag X2, Rogge Bay 8012, South Africa.

${ }^{6}$ College of Medical, Veterinary and Life Sciences, University of Glasgow, Glasgow G12 8QQ, UK.

710527 A Skyline Drive, Corning, NY 14830, USA.

${ }^{8}$ British Antarctic Survey, High Cross, Madingley Road, Cambridge CB3 OET, UK.

9 Baltic Nest Institute, Stockholm Resilience Centre, Stockholm University, SE-106 91 Stockholm, Sweden.

${ }^{10}$ Fisheries Centre, Aquatic Ecosystems Research Laboratory (AERL), 2202 Main Mall, The University of British Columbia, Vancouver, BC, Canada V6T 1 Z4.

${ }_{11}^{1}$ U.S. Geological Survey, Alaska Science Center, 4210 University Drive, Anchorage, AK 99508, USA.

12 Ecosystem Analysis Section, Ministry of Fisheries and Marine Resources, Lüderitz Marine Research, Post Office Box 394, Lüderitz, Namibia.

${ }^{13}$ Animal Demography Unit, Zoology Department, University of Cape Town, Private Bag X3, Rondebosch, Cape Town 7701, South Africa.

${ }^{14}$ Marine Research Institute and Zoology Department, University of Cape Town, Private Bag X3, Rondebosch, Cape Town 7701, South Africa.

${ }^{15}$ Farallon Institute for Advanced Ecosystem Research, Post Office Box 750756 Petaluma, CA 94952, USA.

*: Corresponding authors : Philippe M. Cury, email address : philippe.cury@ird.fr ; Ian L. Boyd, email address : ilb@st-andrews.ac.uk

\section{Abstract :}

Determining the form of key predator-prey relationships is critical for understanding marine ecosystem dynamics. Using a comprehensive global database, we quantified the effect of fluctuations in food abundance on seabird breeding success. We identified a threshold in prey (fish and krill, termed f̃orage fishò abundance below which seabirds experience consistently reduced and more variable productivity. This response was common to all seven ecosystems and 14 bird species examined within the Atlantic, Pacific, and Southern Oceans. The threshold approximated one-third of the maximum prey biomass observed in long-term studies. This provides an indicator of the minimal forage fish biomass needed to sustain seabird productivity over the long term. 


\section{Introduction}

Public and scientific appreciation for the role of top predators in marine ecosystems has grown considerably, yet many upper trophic level (UTL) species, including seabirds, marine mammals and large predatory fish, remain depleted owing to human activities (1-4). Fisheries impacts include direct mortality of exploited species and the more subtle effects of altering trophic pathways and the functioning of marine ecosystem (5). Specifically, fisheries for lower trophic level (LTL) species, primarily small coastal pelagic fish (e.g. anchovies and sardines), euphausiid crustaceans (krill) and squid (hereafter referred to as ñorage fishò), threaten the future sustainability of UTL predators in marine ecosystems (6, 7). An increasing global demand for protein and marine oils contributes pressure to catch more LTL species (8). Thus, fisheries for LTL species are likely to increase while the consequences of such activity remain largely unknown at ecosystem scale. It remains challenging, however, to assess fishing impacts on food webs because numerical relationships between predators and prey are often unknown, even for commercially valuable fish $(9,10)$. Ecosystem models and ecosystem-based fisheries management, for which maintaining predator populations is an objective $(2,11,12)$, will remain controversial until these relationships are more fully quantified.

To improve our understanding of the effects of LTL fisheries on marine ecosystems, more information on predator-prey relationships across a range of species and ecosystems is required (6). Seabirds are conspicuous members of global marine ecosystems. Many aspects of seabird ecology have been measured consistently for decades, encompassing ecosystem change at multiple scales (13). Though substantial long-term datasets on seabird breeding success have been compiled for many taxa in several marine 
ecosystems around the world (14-16), for relatively few has independent information on prey availability been concurrently obtained. For those where prey data are available, temporal covariance in predator and prey parameters suggests that seabirds can be used as indicators of forage fish population fluctuations $(7,16,17)$. In the present study we use data collected contemporaneously over multiple decades from seabirds and forage fish to test the hypothesis that the form of the numerical response between seabird breeding success and forage fish abundance is consistent across species and ecosystems. Data were selected based on the duration of the time series for both seabirds and forage fish, and high spatial and temporal congruence between the seabird data and the fish population data. Seabirds with strong dependencies on the monitored forage fish population were selected. We compiled data from 19 time-series covering 7 marine ecosystems, 9 sites and 14 seabird species and their major prey (Fig. 1, Table S1). The dataset included 438 data points spanning 15-47 colony-years per breeding site (Table S1). The abundance of principal prey for each seabird species was estimated independently of the data collected for the birds, usually as part of population assessments conducted in support of fisheries management (Table S1). 


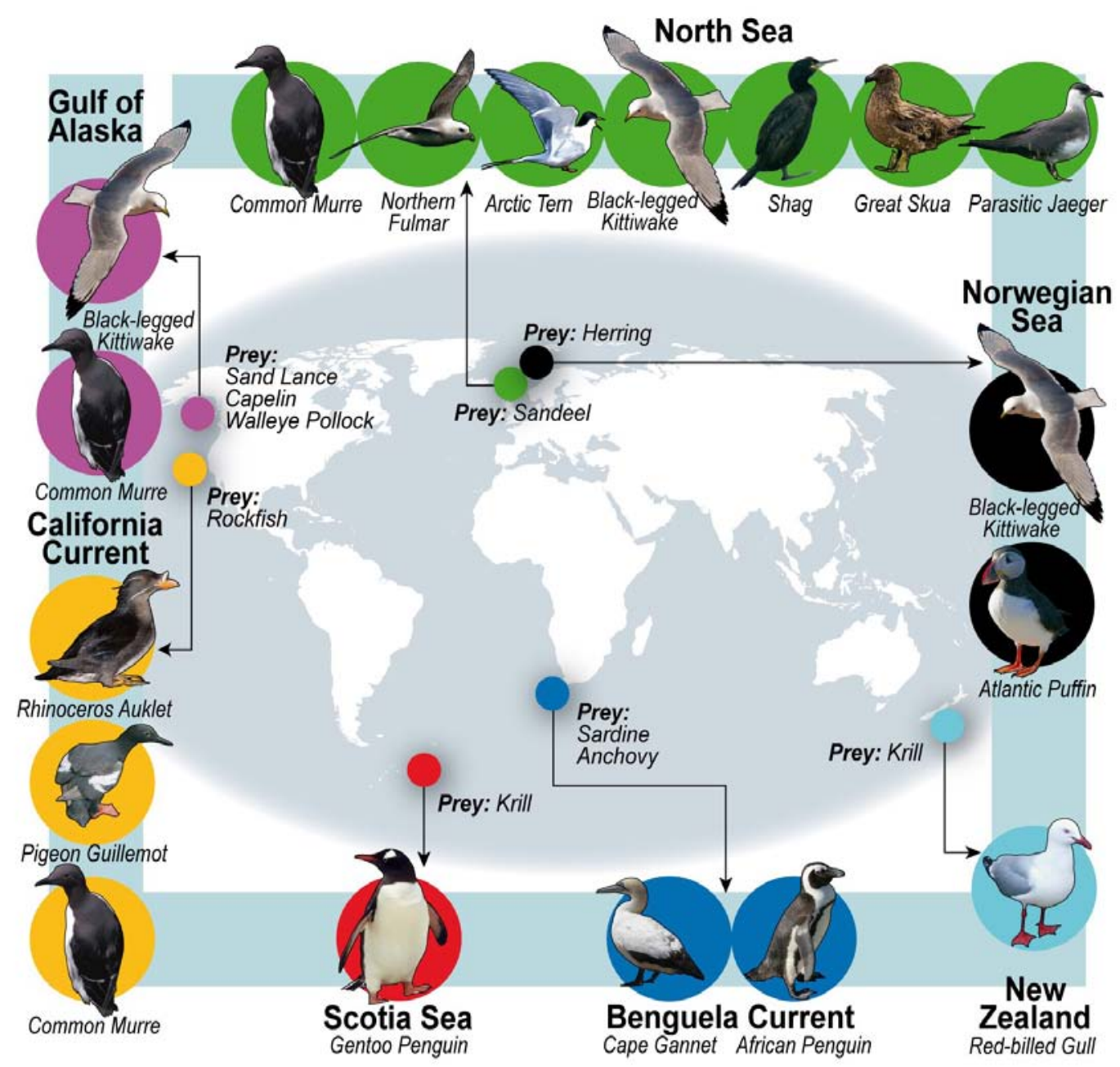

Fig. 1. Map of the distribution of seabird and prey species considered in our analysis.

To examine empirical relationships between seabird breeding success and prey abundance, we used non-parametric statistical methods that facilitate non-linear modeling by making no a priori assumptions about the form of the relationships (Generalized Additive Models or GAMs). Initially, each timeseries (seabird breeding success and prey abundance) was normalized by expressing the measurements as the number of standard deviations from the mean; this enables robust comparisons across species and ecosystems. Once the numerical relationship was established, we used a change-point analysis (sequential t-tests that find the most likely point at which the slope of breeding success changes in relation to prey abundance) to identify thresholds within non-linear relationships (18, Fig. 2A). A bootstrap analysis was used to calculate confidence intervals of the threshold and the variance in seabird 
breeding success was calculated for each prey abundance class. Last, a selection of a priori parametric models ranging from linear, sigmoid, asymptotic to hierarchical (Table S2) was fitted to the general relationship. The most parsimonious model was then used to fit the relationship between seabird breeding success and forage fish population size for each ecosystem (pooling all species) and each seabird species (pooling all ecosystems).

Across ecosystems, seabird breeding success showed a non-linear response to changes in prey abundance (Fig. 2A). The threshold at which breeding success began to decline from the asymptote was not significantly different from the long-term mean of prey abundance (range -0.30 and +0.13 standard deviation of the mean, Fig. 2A). The threshold was $34.6 \%$ (95\% confidence interval $31 \%$ to $39 \%$ ), or approximately one-third of the maximum observed prey abundance. The coefficient of variation between the different thresholds among species and ecosystems was 28\% (Table S1). All time series were of sufficient duration to identify the threshold (detection is possible after 13 years of observation, Fig. S1) and the maximum biomass (detection is possible after 11 years, Fig. S2). Variance in breeding success increased significantly (Ftest, $\mathrm{p}<10^{-4}$ ) below the threshold of prey abundance (Fig. 2B). Fitting parametric models to individual responses showed that there was a similar inflection point and asymptotic values across ecosystems and species (Fig. 2C, Fig. 2D, Fig. 3), indicating that the functional form was a general feature of the seabird-forage fish relationship. 
A

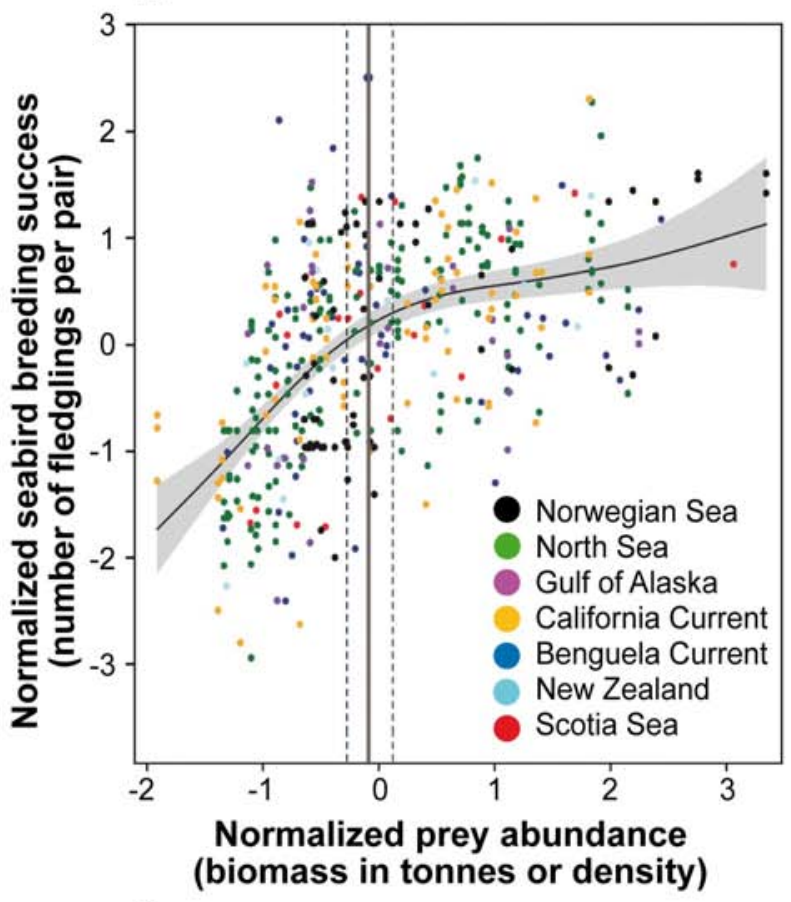

C

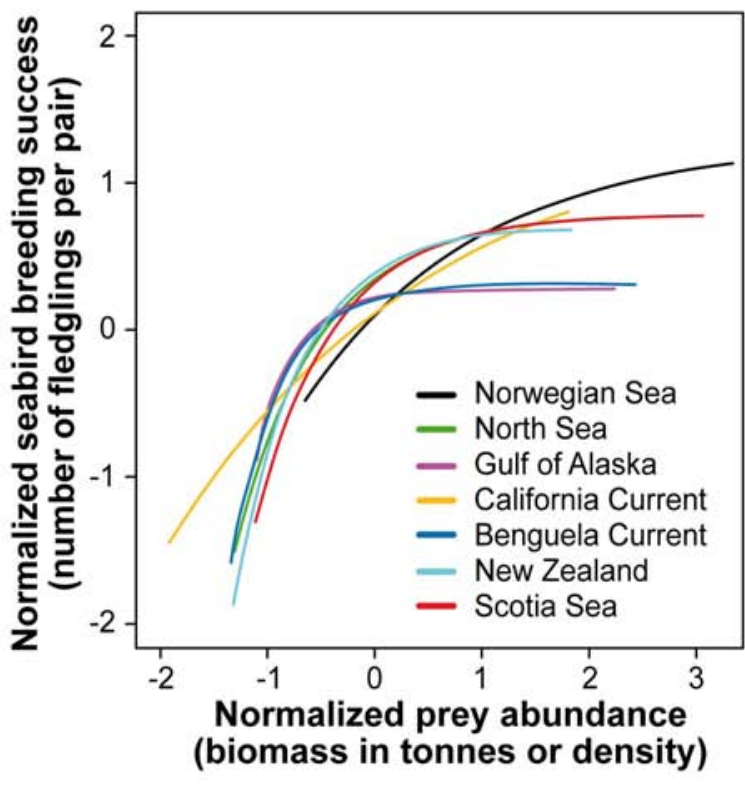

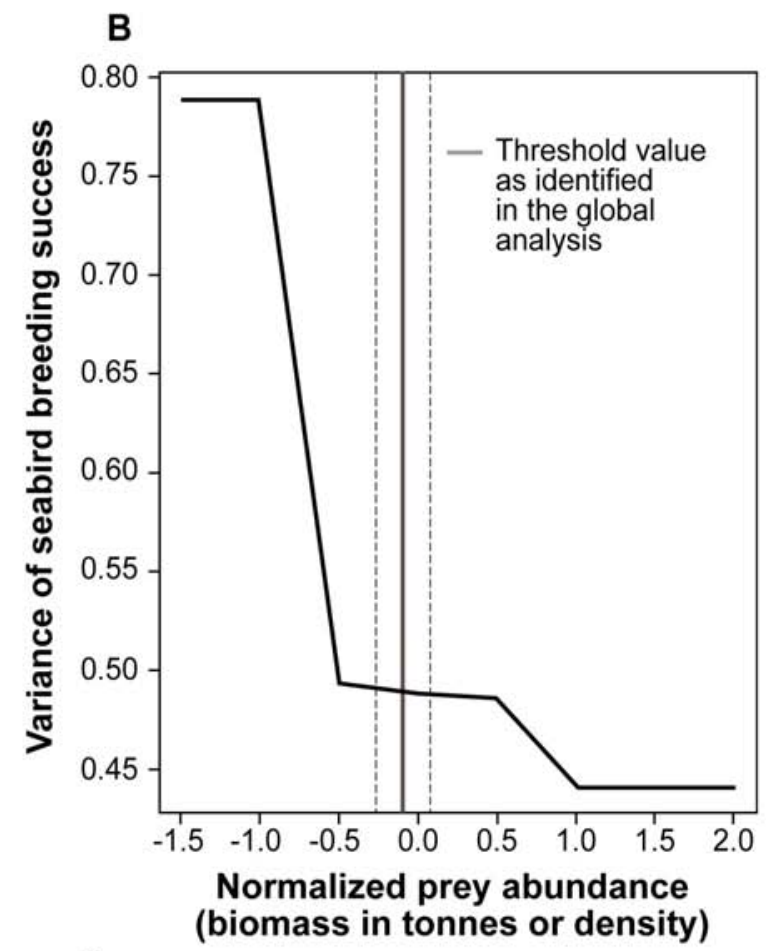

D

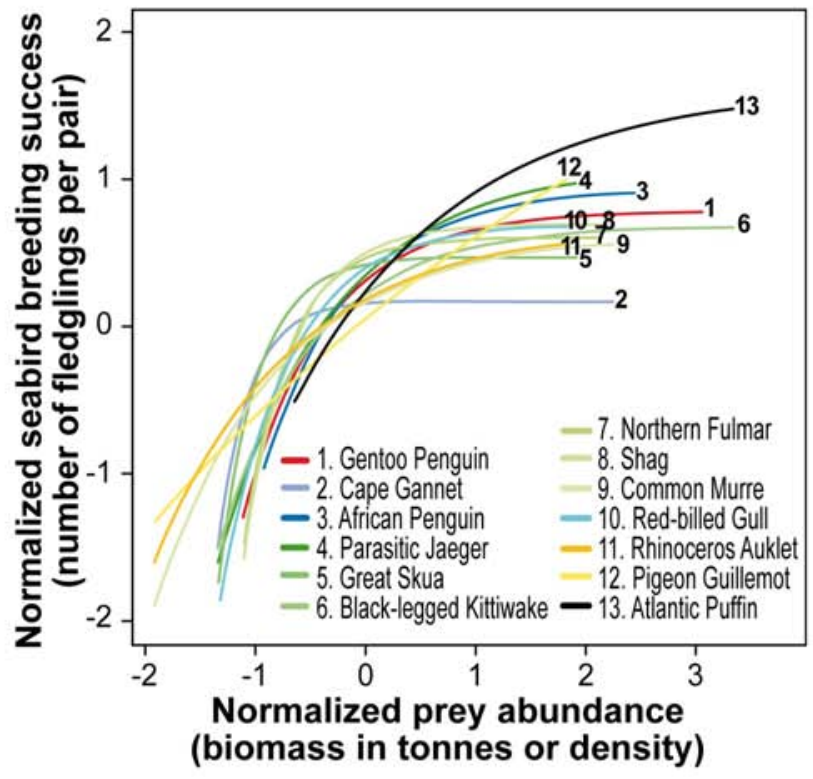

Fig. 2. (A) Relationship between normalized annual breeding success of seabirds and normalized prey abundance. Each data point from all the time series was plotted with the predictions of a Generalized Additive Model (GAM) (solid line). The grey area represents the 95\% confidence interval of the fitted GAM. The threshold in the non-linear relationship (black solid vertical line) and its 95\% confidence interval (black dashed vertical lines) were detected from a change-point analysis. (B) Change in variance across the range of normalized food abundance ranging from -1.5 to 2 standard deviations in 8 classes. 
Variance below the threshold was 1.8 times higher than above it. (C) Similar relationships were present when data were pooled for species within ecosystems and (D) for species pooled among ecosystems using the bestfitting asymptotic model (Table S2). The Arctic Tern (not shown) model fit was not significant (Table S1). Note that the colors in (A) and (C) represent the dataset for each ecosystem and in (D) for each seabird species.

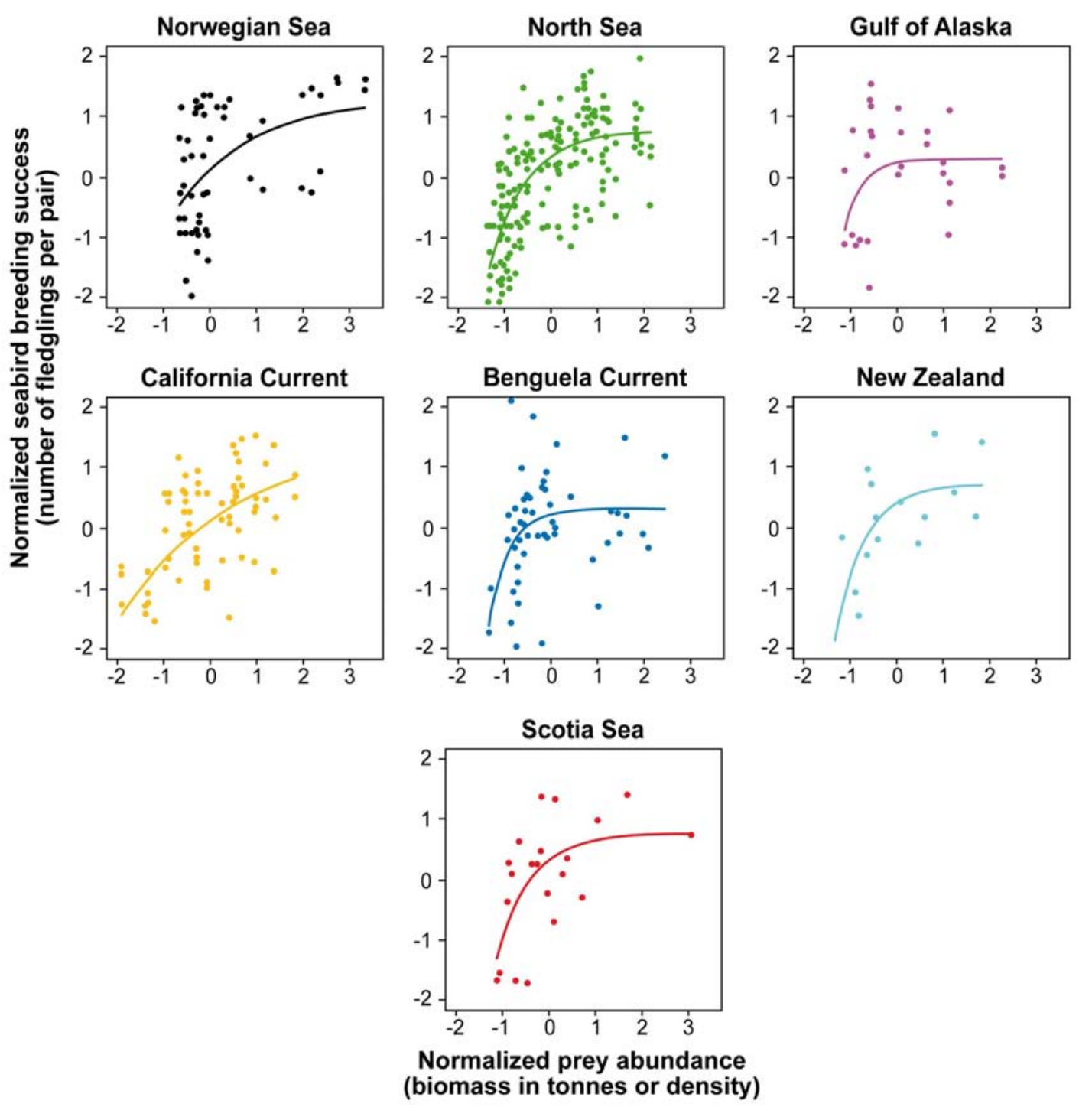

Fig. 3. Relationship between normalized annual breeding success of pooled seabird species and normalized prey abundance for the seven different ecosystems using the most parsimonious asymptotic model (Table S2).

The asymptotic form of the relationship between seabird breeding success and forage fish abundance has been reported previously $(15,16,19-24)$, but 
the common scaling across species and ecosystems and the consistency of threshold values are new observations. The global pattern shows a threshold below which the numerical response declines strongly as food abundance decreases and above which it reaches a plateau and does not change even as food abundance increases. This pattern is apparently robust to the varying life history strategies, habitat preferences, and population sizes of the seabird species considered. Nonetheless, we acknowledge that a range of factors may interact to weaken or possibly accentuate the relationship between seabird breeding performance and prey species abundance. Alternative drivers of change in breeding success include changes in habitat characteristics or predation pressures, or complex inter-colony dynamics. Predators may also show more or less capacity to switch to alternative prey items, which may buffer productivity or other parameters against declines in any single prey species (25).

Periods of consistently high or low breeding success, or occasional complete breeding failures, are normal in seabirds and most species are adapted to fleeting anomalous environmental conditions. However, chronic food scarcity, as potentially defined by prey abundance below the threshold described here for seabirds, could compromise long-term breeding success, and eventually affect recruitment with population consequences. Thus food scarcity that could result from chronic over-exploitation reduces adult survival in seabirds (26), with immediate population-level impacts. Whether caused by persistent overfishing, or directional or stochastic environmental change that reduces ecosystem carrying capacity, recruitment and survival will probably have thresholds of prey abundance shifted to the left of that for breeding success $(15,16)$. Consequently, the threshold for breeding success is likely to provide a precautionary guideline to what level of food reduction might seriously impact seabird populations.

The threshold defined by our study suggests that if management objectives include balancing predator-prey interactions to sustain healthy UTL predator populations and ecosystem functions (2), a practical indicator would be to 
maintain forage fish biomass above one-third of the maximum observed longterm biomass. The application of such a management guideline will depend upon local circumstances, such as the need to implement spatial management around breeding colonies or the conservation status of species (27). Although we cannot assume similarity between all taxa in the value of the predator-prey threshold, our study demonstrates consistency among a broad range of seabirds. There exists also evidence that some marine mammals and predatory fish share the general form of the relationship $(17,19,25,28)$.

Tuning management goals to ensure sufficient biomass of forage fish for seabird reproduction may be a useful step towards ensuring sustainability of predator-prey interactions for other, less well-studied predators in marine ecosystems. Even for predators not showing high dependency on exploited species, this is likely to provide a precautionary step. The "one-third for the birds" guiding principle could be applied widely to help manage forage fisheries to benefit ecosystem resilience. Indeed, predator responses of this type are already included in some specific management systems (29). While such a guideline might be difficult for new fisheries, where there are few data to determine the maximum biomass, most of the economically important coastal pelagic fish populations have sufficient data to define the threshold in many ecosystems (e.g. in the Benguela, California and Humboldt Currents) (Fig. S1, Fig. S2).

The generality of the asymptotic form of the predator-prey relationship suggests that it is rooted in fundamental life history and ecological theory (e.g. demographic trade-offs and functional responses). In a practical context, "onethird for the birds" is a simple, empirically-derived guiding principle that embraces the ecosystem approach to management aimed at sustaining the integrity of predator-prey interactions and marine food webs for the benefit of both natural predators and humans.

References and Notes

1. J.B.C. Jackson et al., Science 293, 629 (2001) 
2. E. K. Pikitch et al., Science 305, 346 (2004).

3. H. K. Lotze, B. Worm, Trends Ecol. Evol. 24, 254 (2009).

4. M. Hoffmann et al., Science 330, 1503 (2010).

5. M. Coll et al., PLoS One 3 (12), e3881 (2008).

6. A. D. M. Smith et al., Science 333, 1147 (2011)

7. P. Cury et al., ICES J. Mar. Sci. 57, 603 (2000).

8. R. L. Naylor et al., PNAS 106, 1510 (2009).

9. P. A. Abrams, L. R. Ginzburg, Trends Ecol. Evol. 15, 337 (2000).

10. L. C. Stige et al., Proc. R. Soc. London 277, 3411 (2010).

11. H. M. Pereira et al., Science 330, 1496 (2010).

12. T. P. Dawson, et al., Science 332, 53 (2011).

13. R. D. Wooller et al., Trends Ecol. Evol. 7, 111 (1992).

14. R. W. Furness, K. Camphuysen, ICES J. Mar. Sci. 54, 726 (1997).

15. D. K. Cairns. Biol. Oceanogr. 5, 261 (1987).

16. J. F. Piatt et al., Mar. Ecol. Prog. Ser. 352, 221 (2007).

17. I. L. Boyd, Aquat. Conser. 12, 119 (2002).

18. T. Andersen et al., Trends Ecol. Evol. 24, 49 (2008).

19. I. L. Boyd, A. W. A. Murray, J. Anim. Ecol. 70, 747 (2001).

20. J. M. Durant et al., Proc. R. Soc. Lond. B 270, 1461 (2003).

21. K. Reid et al. ICES J. Mar. Sci. 62, 366 (2005).

22. R.W. Furness, J. Ornithol. 148, S247 (2007).

23. J. A. Mills et al., J. Anim. Ecol. 77, 1129 (2008).

24. J. C. Field et al., Current. Ecol. Appl. 20, 2223 (2010).

25. M. E. Hunsicker, et al., Ecol. Lett. doi:10.1111/j.14610248.2011.01696.x (2011).

26. A.S. Kitaysky et al., Ecology, 24625 (2010).

27. L. Pichegru et al., Biol. Lett. 6, 498 (2010).

28. J. F. Piatt, D.A. Methven, Mar. Ecol. Prog. Ser. 84, 205 (1992).

29. D.J. Agnew. Antarct, Sci. 9, 235 (1997).

Acknowledgments: This work was partly funded by Eur-Oceans Consortium, the Institut de Recherche pour le Développement, the Lenfest Forage Fish Task Force, the Swedish Environmental Protection Agency, the Sea Around us Project and by the South African Research Chair Initiative. All supporting 
institutions and collaborators are acknowledged in the SOM. Data and methods that are used can be accessed through a web site referenced in the SOM. 


\section{Supporting Online Material for}

Global seabird response to forage fish depletion - one-third for the birds

Philippe M. Cury, Ian L. Boyd, Sylvain Bonhommeau, Tycho Anker-Nilssen, Robert J.M. Crawford, Robert W. Furness, James A. Mills, Eugene J. Murphy, Henrik Österblom, Michelle Paleczny, John F. Piatt, Jean-Paul Roux, Lynne Shannon and William J. Sydeman 


\section{Supporting Online Material}

\section{Contents}

\section{Materials and Methods}

1. Data set: times series used and narrative description of seabirds and their prey in the different marine ecosystems (table S1)

2. Statistical methods, threshold determination and model fitting

a. Empirical analyses of the dataset: tests of normality and pooling data across ecosystems

b. Testing alternative forms of the global (asymptotic) model using parametric models (table S2)

\section{Figures S1-S4}

Figure S1: Number of years of observation required for estimating the threshold.

Figure S2: Number of years of observation required to evaluate the maximum observed biomass.

Figure S3: Generalized Additive Mixed Model (GAMM) analysis to account for the 'ecosystem effect' in the relationship between breeding success and prey abundance.

Figure S4: Quantile GAM analysis to account for extreme values of the relationship between breeding success and prey abundance.

\section{Tables S1-S2}

Table S1 - Time-series used in the meta-analysis

Table S2 - Parametric models considered for the predator-prey relationship

\section{References and Notes}

\section{Data and Codes}




\section{Data set: narrative description of seabirds and their prey in the different marine ecosystems (table S1)}

A total of 19 time series from 7 ecosystems and 14 seabird species was used in the present analysis (table S1). Data are available at the end of the SOM.

Time series were selected based upon the following procedure and criteria during a first workshop held in Sète (France):

1. The time-series was of sufficient duration (> 10 years or "bird years").

2. The time-series was representative of an ecosystem.

3. The variables were collected using comparable methods resulting in comparable metrics (i.e. breeding success expressed as the number of fledglings per pair and prey abundance estimated using biomass or density)

4. There were reliable data about the populations of the main prey species of the predator concerned and these were collected, independently from seabird data, but at similar spatial and temporal scales.

5. The seabird species involved were known, either directly or indirectly, to depend upon the abundance of low-trophic level species during reproduction. The case of indirect dependence included kleptoparasitic species (such as skuas) and species that feed substantially on discarded fish. In most studies, predation impacted fledging success to some extent. However, in the case of Western Gull (Larus occidentalis) studied in the Californian Current, excessive predation was the main factor determining breeding success rather than food, so we excluded this population from the analysis in order to avoid misinterpretation about causal links.

During the second and final workshop held in Cape Town (South Africa) the selected database was analyzed using the different statistical methods presented below.

The following are descriptions of the data sets classified by region:

\section{Gulf of Alaska - Cook Inlet}

Alaska's marine waters support more than 100 million seabirds (30). In the Gulf of Alaska, seabird colony populations have fluctuated widely in recent decades and declined markedly at a few sites (31). The Exxon Valdez oil spill (EVOS) of 1989 had an immediate and lingering impact on some species of seabirds $(32,33)$, adding to other anthropogenic factors influencing populations (e.g., gill-net by-catch, fisheries removals, introduced predators) (30). Variability in the marine environment, however, had an even greater impact on seabird populations in the Gulf of Alaska during the same period. Most notably, a major regime shift occurred in the late 1970s, causing marked changes in oceanography, plankton production, marine fish communities and diets of marine birds and mammals, leading to reproductive failures and population declines at some colonies $(33,34)$. In particular, populations of small forage fish species, with high energy density, such as capelin (Mallotus 
villosus) declined precipitously, while populations of forage fish species having lower energy density (0-age class), such as walleye pollock (Theragra chalcogramma) and cod (Gadus macrocephalus), increased and this change was reflected in the diets of seabirds $(33,35)$. These population fluctuations of forage fish populations could not be explained by direct effects of fisheries, because most declining forage species such as capelin were never harvested in Alaska, and a few species such as pollock increased for environmental reasons $(34,35)$.

Ecosystem studies were initiated a few years after the EVOS to assess whether environmental conditions that persisted after the climate-induced regime shift could delay the recovery of seabirds from impacts of the EVOS. In particular, a hypothesis was advanced that food stress brought on by climate change might limit seabird reproductive success. In lower Cook Inlet, Alaska, a natural experiment was devised to examine the response of seabirds to fluctuations in prey density around three neighboring colonies (36) and determine the prey density threshold for breeding success. Historical studies had shown that food supplies and breeding success of common murres (CM, Uria aalge) and Black-legged Kittiwakes (BK, Rissa tridactyla) were poor at Chisik Island, excellent at Gull Island, and average at the Barren Islands (16). Oceanography, plankton, forage fish ecology and seabird distribution at sea were studied in waters around each colony (e.g., 16, 3739). Absolute forage fish abundance was measured by echo-integration of the hydroacoustic biomass, after adjusting for catch composition and target strengths of forage species in mid-water trawl catches $(16,40)$. Seabird foraging behavior, diets, time-budgets, chick growth rates, physiological condition, reproductive success, population trends and adult survival rates were measured concurrently at each of the three colonies (e.g., 16, 37, 41, 42).

These studies revealed that diets of murres and kittiwakes were broadly similar within and among colonies, and reflected the relative abundance of forage species in marine waters around each colony $(26,36,38-42)$. Diets of adults were composed largely of oily schooling fishes such as Pacific sand lance (Ammodytes hexapterus; CM 47\%, BK 51\%) and osmerids such as capelin (CM 24\%, BK 18\%), and to a lesser extent of gadids such as pollock (CM 20\%, BK 14\%). In contrast to some of the other studies reported below, there were no major changes between years in diet composition or in relative fish community composition around each colony. However, as expected, forage fishes were consistently 1-2 orders of magnitude less abundant around Chisik, and most abundant around Gull Island during each year of study. Seabirds at all colonies responded to variation in prey abundance among years not by switching to alternate prey, but by reducing rates of food delivery to chicks, thereby reducing breeding success $(16,26,41-42)$. In general, the response in seabird foraging behaviors and reproductive success to spatio-temporal variability in food supplies was non-linear (16). 


\section{Norwegian Sea - Røst}

Røst $\left(67^{\circ} 30^{\prime} \mathrm{N} 12^{\circ} 00^{\prime} \mathrm{E}\right)$ is an offshore archipelago situated at the southwestern tip of the Lofoten Islands in North Norway. Its population of Atlantic puffins (Fratercula arctica) is still one of the largest in the world, but decreased from about 1.44 million to 410,000 breeding pairs over the 31-year period 1979-2010 (43-46). As the survival of adult puffins at Røst is not different from that at other European colonies, which have not shown equivalent declines (47), the decrease at Røst $(72 \%)$ is attributed to the extraordinarily poor breeding success of this colony, which includes 18 years of virtually complete breeding failures since 1975 (20,44-46). The breeding success has been closely linked to the abundance, quality and timing of first-year herring (Clupea harengus) from the Norwegian spring-spawning (NSS) stock, which drift past Røst in summer on their way to their Barents Sea nursery areas (20, 48-50). This herring stock collapsed in the late 1960s due to an extensive and increasing fishery during a period of poor recruitment (51). The stock remained at an extremely low level for two decades before it gradually rebuilt its numbers. The recovery happened as a result of both strict regulations of herring fishing and an improved ocean climate that increased the production of strong year classes and later recruitment to the breeding stock (52). In the only 11 seasons since 1975 with high breeding success $(71 \%-96 \%$ of chicks fledged) for the Røst puffins, first-year herring contributed an average of $56 \%$ by mass of the chick diet, while non-schooling fish (mainly first-year Gadidae) contributed $25 \%$. In the seasons when breeding failed almost completely (0$8 \%$ of chicks fledged), these proportions (when measurable) were reversed (to $27 \%$ and $53 \%$ of first-year herring and mainly first-year Gadidae, respectively, $n=12$ years) $(44,46)$. The availability of first-year herring also explains much of the inter-annual variation in survival of breeding birds (5355). The 1.5 million pairs of puffins breeding in the western parts of North Norway, where this herring is available in the breeding season, are able to consume $5-15 \%$ of a reasonably good herring year-class (56). When converted to newly metamorphosed fish in June-July, this corresponds to 1545 million metric tons of herring fry. The breeding success of puffins in Røst is a good predictor of NSS herring year-class strength at the age 0 stage (57).

More than $90 \%$ of the black-legged kittiwakes (Rissa tridactyla) in Røst, the second-most numerous seabird in the archipelago, breed in a colony that decreased from about 25,000 pairs to 7,500 pairs over the same 31-year period $(44,46)$. Since 2007 , based on regurgitations collected annually from black-legged kittiwake chicks and adults, first-year herring was a regular but small component of the kittiwake diet (45). In all these years kittiwake breeding success was very poor, although the data are insufficient to indicate the normal diet composition. Until the mid 1990s, however, breeding success of the Røst kittiwakes correlated well with the abundance of young herring (58), but this relationship was later affected by extensive harassment and predation of kittiwake chicks from a booming population of non-breeding white-tailed eagles (Haliaeetus albicilla) summering in the area (59).

Breeding numbers and reproductive success of kittiwakes and puffins were monitored annually in study plots, and food loads of adult puffins were 
collected regularly throughout the chick period using mist nets $(43,60)$. Annual estimates of first-year abundance and spawning stock biomass of NSS herring were provided by ICES (61). No sufficiently long-term data exists on the breeding success of other seabirds feeding on this food source.

\section{North Sea - Shetland}

Shetland is an archipelago in the northwest corner of the North Sea, strongly influenced by inflowing North Atlantic water. Most islands are bounded by sea cliffs and provide ideal nesting habitat for many seabird species (62). Seas around Shetland hold stocks of lesser sandeels Ammodytes marinus and adult herring Clupea harengus (but no juveniles), and are visited seasonally by adult mackerel Scomber scombrus (63). Since only northern gannets Morus bassanus, great black-backed gulls Larus marinus and great skuas Stercorarius skua are large enough to swallow adult herring and mackerel (64), most seabirds in Shetland feed predominantly on sandeels while breeding $(22,65)$. Larus gulls, great skuas, gannets and fulmars Fulmarus glacialis, also scavenge on trawl fishery offal and discards $(64,66,67)$, but even in those species, sandeels represent most of the diet in years when standeel abundance is high $(66,68-70)$. Due to the lack of alternative small pelagic fish species at Shetland, most small seabirds (including Arctic skuas Stercorarius parasiticus and kittiwakes Rissa tridactyla) have little opportunity for prey switching when sandeels are scarce, but either increase effort searching for sandeels (71-73) or abandon breeding $(62,74)$.

Seabird consumption and diet composition data (75) refer to the period when the Shetland sandeel stock was large (ca. 120,000 tonnes) in the late 1970s and early 1980s. When the sandeel stock collapsed in the late 1980s, some seabirds switched diet (sandeels almost disappeared from diet of northern fulmars, northern gannets, great black-backed gulls, great skuas and herring gulls), and all except northern gannet declined in breeding numbers.

The Shetland stock of sandeels is considered to be quite distinct from others in the North Sea, with independent dynamics (76-78). Shetland sandeel stock biomass was assessed by Virtual Population Analysis (VPA) during the period when there was a sandeel fishery at Shetland and by research trawl surveys after the fishery closed $(22,78)$. Seabird breeding success at Foula was monitored by RWF and colleagues from the early 1970s, under contract to Shetland Oil Terminal Environmental Advisory Group (SOTEAG), following standard methods used for UK seabirds, as established by Walsh et al. (79). Seabird breeding success at many other Shetland colonies was monitored since 1986 by the national seabird monitoring program coordinated by the Joint Nature Conservation Committee (JNCC) as reported in their annual reports (80). We therefore included in the analysis all seabird species from Foula for which there was a time series of breeding success data matching that of the Shetland sandeel stock. This included species that feed by scavenging on fishery discards as well as on sandeels, since in years of sandeel abundance these birds feed predominantly on sandeels, and mainly switch to discards when preferred small pelagic fish are scarce $(66,68-70)$. 
Shetland sandeel stock biomass was high in the 1970s when a fishery on sandeels began for the first time, and declined rapidly during the 1980s as large catches of sandeels were taken (22). The fishery was closed in 1990 due to low stock biomass and associated concerns about seabird breeding failures, and although sandeel recruitment was good in 1991 immediately following closure, the stock biomass showed only partial recovery. Stock biomass fell again very rapidly after 2000. Causes of stock decline are not fully understood $(22,75-78)$, but may relate to a combination of sequential fishery exploitation of stocks on local sandbanks, effects of increasing sea temperatures, changes in currents, and (especially since 2000) impacts of predation by an increasing stock of adult herring (81).

\section{California Current - Southeast Farallon Island}

The California Current Ecosystem (CCE) is one of 4 highly productive eastern boundary current systems in the world. Exceptional, yet variable productivity of forage fish arises from transport of sub-arctic water from the north via the California Current, transport of sub-tropical waters from the south relative to $\mathrm{El}$ Niño/La Niña events and regional wind-driven coastal upwelling (vertical transport) currents that supply nutrients to the light-penetrating upper ocean, thereby stimulating photosynthesis and food web development (82). Interannual and inter-decadal variability in forage fish have been related to water temperature, upwelling indices, and large-scale climatic factors such as the Southern Oscillation Index (SOI) and the Pacific Decadal Oscillation Index (PDO). Generally speaking, when upwelling and southward transport are strong, waters are colder and primary productivity is higher, with corresponding effects at higher trophic levels.

In the CCE, the upper trophic level predator community includes $\sim 2-7 \mathrm{M}$ individuals of $\sim 100$ seabird species (83), though recent population declines of dominant species (e.g., shearwaters) have been documented $(84,85)$. Seabird prey in this ecosystem consists largely of forage fish, including age- 0 predatory fish, such as hake (Merluccius productus) and rockfishes (Sebastes spp.), and coastal pelagic species such as northern anchovy (Engraulis mordax) and Pacific sardine (Sardinops sagax). Market squid (Loligo opalescens) and mesozooplankton, primarily euphausiid crustaceans, also are important diet items $(86,87)$. Roth et al. (88) provide estimates of consumption (MT) of various prey species by common murres (Uria aalge) in the central-northern portion of the CCE.

To study the reproductive success of seabirds, focal breeding pairs were sampled throughout each nesting season by PRBO Conservation Science at Southeast Farallon Island, Farallon National Wildlife Refuge $\left(37^{\circ} 42^{\prime} \mathrm{N}, 123^{\circ} \mathrm{W}\right)$ $(89,90)$. The species monitored were western gull (Larus occidentalis), Brandt's cormorant (Phalacrocorax penicillatus), common murre, pigeon guillemot (Cepphus columba), pelagic cormorant (Phalacrocorax pelagicus), Cassin's auklet (Ptychoramphus aleuticus), ashy storm-petrel (Oceanodroma homochroa) and rhinoceros auklet (Cerorhinca monocerata). For each species, individual nest sites were monitored $(n=15-500$ nests per species per year) at 1-7 day intervals for breeding activity. Reproductive performance 
was defined as the number of offspring departing the colony per breeding pair per year (or "jumping" for murres) (90). As Cassin's auklet and ashy stormpetrel are planktivorous $(91,92)$, and limited spatially and temporally congruent data about plankton (krill) population abundance was available (2002-2008), they have not been included in this analysis. Western gull breeding success has largely been determined by predation (93), so similarly they have not been included in the analysis. The breeding success of Brandt's cormorant is now largely determined by the abundance of northern anchovy (Engraulis mordax) for which we did not have a time series on prey abundance. The breeding success of Pelagic cormorant is driven largely by the abundance of benthic, neritic prey, another prey group for which there was no data. Thus, we selected for our analysis Common murre, Rhinoceros Auklet and Pigeon Guillemot, 3 species for which we had appropriately sampled prey data.

The availability of juvenile rockfish is the single most important determinant of seabird breeding success at Southeast Farallon Island, at least through the period in which we have overlapping time series of seabird breeding success and independent measures of prey availability, 1983-2007. There is substantial inter-annual variability in the consumption of juvenile rockfish. For the period 1975-2007, juvenile rockfish comprised from $1 \%$ to $94 \%$ (mean $=43 \%$ ) of the offspring diet of murres. For the period 1989-2006, juvenile rockfish comprised $1 \%$ to $56 \%$ (mean=20\%) of the chick diet for guillemots, and for the period 1987-2007, juvenile rockfish comprised $0 \%$ to $59 \%$ (mean $=16 \%$ ) of the diet for rhinoceros auklet young.

Juvenile rockfish relative abundance was estimated from annual trawl surveys conducted by the National Marine Fisheries Service (NMFS) in May and early June from 1983 to 2007 (94), in the region of central California that closely approximates the foraging range of the seabird species studied (24). Pelagic juvenile rockfish experience high mortality from predation so abundance was calculated after the raw catch had been adjusted to a standard age of 100 days (95). To develop an annual index of age-0 abundance, we used towspecific catch rate and a delta-general linear model (GLM) approach (24).

The relationship between juvenile rockfish in the offspring diet of murres, guillemots and rhinoceros auklets relative to the estimated abundance of these forage fish in the environment based on the NMFS surveys $(87,93,96)$ is asymptotic (87). There was substantial inter-annual variation in the covariance of rockfish abundance and seabird consumption (96). Amongst murres, $81 \%$ of the variation in juvenile rockfish in the diet was explained by juvenile rockfish relative abundance in the environment (96). Declines in predation of juvenile rockfish by the birds as well as abundance in the environment $(87,90)$ were related to upwelling and other oceanographic factors as well as fishing (24). Rockfish fisheries in the region targeted adults, so the link to the abundance of juveniles (age-0) which constitutes the seabird's diet is difficult to assess. However, across this assemblage, there have been substantial declines in rockfish populations (24). One of the primary species predated by seabirds, the shortbelly rockfish (Sebastes jordanii), is not fished directly, although it may be by-caught in other fisheries. 


\section{Benguela Current - Lambert's Bay, Malgas Island, Robben Island}

The Benguela ecosystem off south-western Africa is one of the world's four major eastern-boundary-current upwelling ecosystems. It supports high biomasses of anchovy Engraulis encrasicolus and sardine Sardinops sagax, which are the main prey of a wide spectrum of predators and are also exploited by purse-seine fisheries (97). Amongst the predators that feed mainly on anchovy and sardine are four seabirds: African penguin Spheniscus demersus, Cape gannet Morus capensis, Cape cormorant Phalacrocorax capensis and swift (or crested) tern Thalasseus bergii $(98,99)$. The first three of these seabirds are endemic to southern Africa, as also is the nominate race of swift tern (100). The other main eastern-boundary-current upwelling ecosystem of the southern hemisphere is the Humboldt system off western South America (101). In that system, anchovy Engraulis ringens and sardine again are the dominant forage fishes and it also has an endemic penguin, sulid, cormorant and tern that subsist mainly on these two prey species (100). In the Benguela ecosystem, there have been large fluctuations in the abundances of both anchovy and sardine (102), as well as shifts in their distributions $(103,104)$, which provide opportunity to investigate relationships between the population sizes and demographic parameters of predators, or their diet, and the abundance or availability of their prey. For example, numbers of African penguins and Cape gannets breeding in Namibia were significantly correlated with the biomass of small epipelagic fish, mostly sardine, off that country (99). Off South Africa, in the 2000s, a large increase in the number of swift terns breeding coincided with an increased abundance of anchovy and sardine (105). At Robben Island, South Africa, the breeding success of African penguins was significantly correlated with the combined biomass of anchovy and sardine (106). Off South Africa's Western Cape, from 1984-1993 the contribution of anchovy to the diet of Cape gannets was significantly related to the biomass of anchovy (107). The causes of the large fluctuations in the abundance and distribution of anchovy and sardine in the Benguela ecosystem are not fully understood but are thought to have been influenced by both environmental factors and fishing, with some major collapses of stocks attributed to over-exploitation (108).

For African penguins at Robben Island we used information on breeding success (chicks fledged per pair) and prey abundance for 1989-2004 published by Crawford et al. (106). For Cape gannets at Lambert's Bay and Malgas Islands, we used information on breeding success from Adams et al. (107), and unpublished records of Department of Environmental Affairs, South Africa and annual estimates of the spawner biomass of anchovy and sardine (combined) found west of Cape Agulhas (kindly provided by $\mathrm{J}$ Coetzee of Department of Agriculture, Fisheries and Forestry, see also 102). Most Cape gannets breeding at Lambert's Bay and Malgas Island feed west of Cape Agulhas. When breeding, African penguins and Cape gannets at these localities feed mainly on anchovy and sardine; outside the breeding season Cape gannets may scavenge substantial quantities of hakes Merluccius spp. that have been discarded by trawlers (108). 


\section{New Zealand - Kaikoura Peninsula}

The coastal water off Kaikoura on the east coast of New Zealand is a highly productive system (109) that supports a variety of sea birds and marine mammals (110). The hydrology is relatively complex as it is a region of interaction of warm northern water from the East Cape Current and cooler southern water of the Southland Current $(111,112)$. The continental shelf off the coast is relatively narrow and incursions of warm or cold water have a major impact on the productivity of the region (109).

The Kaikoura Peninsula is home to the third largest breeding population of red-billed gulls (Larus novaehollandiae scopulinus). Adults can often sustain themselves on alternative foods such as earthworms, small fish, garbage and kelp flies (23), but they are dependent upon an abundant and regular supply of Nyctiphanes australis (krill), their preferred food for successful breeding.

The availability of krill varies annually in response to changes in climate and oceanography. Prior to the gulls' breeding season, the critical period for growth and productivity of krill is winter-early spring when egg formation occurs. Nitrogen enrichment in the coastal water at this time is greatest when there is no influx of warm offshore water $(23,106)$. During the breeding season the relative availability of krill was correlated positively with the Southern Oscillation Index and the frequency of occurrence of NE winds which induce upwelling (23). Incursions of warm oceanic water, often induced by westerly winds, which are characteristic of El Niño years, were associated with reduced euphausiid availability and reduced breeding success. Strong incursions sometimes displaced the coastal water column with lower nutrient water, and less dramatic incursions resulted in warm water overlying the colder water, preventing the migration of euphausiids to the surface $(23,109$, 112).

The reproductive success of the red-billed gull has been monitored at Kaikoura for the past 47 years and the abundance of euphausiids available to the birds was determined for 35 years during the period (1975-2010). Between 1993 and 2003, the population declined by 51\% (85). The availability of $N$. australis to the red-billed gull was assessed by calculating the proportion of breeders and non-breeders which regurgitated the euphausiid when captured (23). Between 1975 and 2010, 62\% of 7215 adult red-billed gulls regurgitated $N$. australis during the breeding season. The contribution of $N$. australis to the diet reached up to $84 \%$ (23). The relationships between food availability and the number of pairs that bred, laying date, clutch size, fledging success and age of first breeding were different before and after the population decline (23). The underlying cause appears to have been a compensatory density-dependent mechanism that reduced interspecific competition for food. The index of availability measures the frequency the bird obtained euphausiids. When the population declined by $51 \%$ after 1993 from 19,000 to 9,000 individuals, competition for food at the irregular surface forming swarms lessened and consequently the food index changed and was 
not comparable to the index when the population was stable at the higher level. The data set therefore needed to be partitioned into pre- and postdecline phases (23). The analysis of the impact of food on breeding success in the present paper was restricted to the pre-period from1975 to 1994 when the population was stable. The prey availability index was calculated from different red-billed gulls than the individually colour-marked birds that were studied to ascertain the reproductive performance; so these can be considered as two independent data sets.

\section{Scotia Sea - Bird Island}

The Scotia Sea is part of the Southern Ocean and is bounded in the west by Drake Passage, while to the south, east and north, it is surrounded by the Scotia Arc. The oceanographic regime is dominated by the easterly flow through Drake Passage of the Antarctic Circumpolar Current (ACC) and by northerly outflows from the Weddell Sea. To the east of Drake Passage the ACC is deflected northwards by the Scotia Arc, which brings high nutrient waters north and eastwards into areas of high natural iron concentration, making it one of the more productive regions of the Southern Ocean (113). The northward flowing currents also transport Antarctic krill (Euphausia superba) from ice dominated areas in the south into the region around the Island of South Georgia, in a process that is considered to be crucial in maintaining the local krill population (114-116). The high production and northward dispersal generate a high biomass of krill around the island, where it is the prey for many upper-trophic level predators. Climate related fluctuations in oceanic and sea ice conditions across the Scotia Sea affect krill recruitment and dispersal generating large inter-annual variations in krill biomass around South Georgia (113, 116, 117-119). A series of acoustic estimates of krill biomass was maintained at South Georgia for over 20 years and provided an annual index of krill availability $(113,119)$.

Seabirds and seals that breed at South Georgia are important predators of krill and their responses to changes in prey abundance have been used to monitor the ecosystem $(29,118,120)$. Two or three times in a decade krill abundance has been very low and the foraging and breeding performance of a range of predators has been affected $(113,117,118,121)$. The response of particular species to variations in food availability has depended on the magnitude of the variation and the flexibility of their feeding, foraging and breeding strategies (121). The quantitative responses of predators to changes in krill abundance depend upon the characteristics of the variable being measured. Those involving population changes had greatest buffering and lowest variance compared with those associated with breeding behaviour (122). Those with highest variance were most sensitive to inter-annual variation in indices of krill abundance, and breeding behaviour and diet during the breeding season showed non-linear functional relationships between independently-collected krill density estimates (19). Behavioural and short term responses can, therefore, allow buffering of life history responses to variation, which can mask population responses to change in food availability $(123,124)$. In years of low krill availability the fish component in particular tends to increase, but this is set against a decrease in overall breeding 
success (125). The gentoo penguin (Pygoscelis papua) is one of the species monitored at South Georgia and its breeding success was significantly reduced in periods of low krill availability $(118,121)$. The measured responses to inter-annual changes in food availability at South Georgia occurred within a context of significant decadal change in the Scotia Sea ecosystem and in the dynamics of predator populations across the Southern Ocean (126).

The major fluctuations in krill abundance around South Georgia have been related to Southern Hemisphere scale atmospheric fluctuations that affected Scotia Sea oceanic and sea ice conditions, which in turn directly impact the krill population dynamics. The fishery for krill in the Southern Ocean is currently operating at a lower level than during the 1980s and 1990s and even peak catches were far below the current maximum allowable catch levels (127). The fishery around South Georgia operated mainly during winter months, outside the main breeding season for most predators. There has been a rapid increase over the last few years in overall krill catch levels from the fishery, which reflects changes in gear and the development of new krillbased products. This rapid expansion is causing concern, although current catches are still well below the peak catches previously recorded. In addition to Gentoo penguins, a range of other species at South Georgia depends on krill as a major component of the diet (121) including Macaroni penguins, fur seals and black-browed and grey-headed albatrosses. These species show different levels of dependence on krill in their diets and in their responses to changes in availability $(21,121,128)$, and may be affected differently by a future intensification of the krill fishery.

\section{Statistical methods, threshold determination and model fitting}

The data analysis was designed to optimize across the constraints presented by the data. We made no a priori assumptions about the distribution of the data or about the form of any functional relationships between seabird breeding success and prey availability. We used generalized additive models (GAMs) to explore the shape (also described as "form" in the main text) of the functional relationships. GAMs are the similar to generalized linear models in that they relate a single dependent variable to one or more independent variables but they also have the property of exploring non-linearity in the relationships using smoothers with no a priori assumption on the shape of the relationship. We then applied a parametric approach using model selection criteria (AIC) across a range of deterministic models to verify and reinforce the results revealed by the GAM. All the statistical methods were assessed using a hierarchical modeling framework to account for the repetition of the same relationship in each ecosystem. All the R-codes that were used are available at the end of the SOM. 


\section{a) Empirical analyses of the dataset: tests of normality and pooling data across ecosystems}

To enable comparison of the data between ecosystems and species groups, we first normalized each time series by subtracting the mean and dividing by the standard deviation for each time series. The Shapiro test for normality was applied to each time-series of prey abundance and seabird breeding success to investigate if the data were normally distributed Sixteen of 19 (table S1), prey abundance time-series and 12 seabird series were normally distributed. We also ensured that the normalization did not affect the shape of the relationship between breeding success and prey abundance, especially for non-normally distributed data. Consequently, we used a non-parametric approach, generalized additive models (GAM) fitted to the pooled normalized data to explore the functional form of the relationship between seabird breeding success and the abundance of forage fish (Fig. 2A). $\boldsymbol{R}$ package "gam" was used (129).

\section{Identification of a threshold from non-parametric GAM analysis}

To identify and quantify a threshold in the functional relationship between prey abundance and breeding success of predators, a change-point analysis was performed (130). We used the function "cpt.reg" of the $\boldsymbol{R}$ package "changepoint" (131). This function enabled calculation of the optimal positioning of a change-point. This analysis was performed on the predicted values based on the GAM.

To test the validity and robustness of the calculated threshold we estimated potential bias in threshold estimates with respect to the sample size (number of years analyzed). The aim was also to estimate the number of years required to estimate the threshold. From the pooled dataset, we randomly drew " $X$ " consecutive years from the breeding success and prey time-series, where " $X$ " is comprised between 5 and 42 years. From this subset we calculated the threshold and compare it to its value as estimated from the global dataset. We repeated this operation 1000 times to test a wide range of subsets and calculated a confidence interval for the estimated threshold from the subset of " $X$ " consecutive years. The minimum number of years required to estimate the threshold was determined using the significance of the mean value of the threshold, given the confidence intervals for both the subset and global dataset, i.e. the minimum number of consecutive years where the threshold value estimated from the subset dataset was within the confidence interval of the threshold estimated from the global dataset (fig. S1). To evaluate the number of years of observations needed to determine the maximum observed biomass in prey time series, we calculated the number of years between the beginning of the data collection and the year when the maximum biomass was observed (fig. S2). 


\section{Estimation of the threshold confidence interval}

We used a bootstrap procedure to estimate the confidence interval of the threshold estimate. We sampled the global dataset 1000 times to estimate the value of the threshold. The values of the $2.5 \%$ and $97.5 \%$ quantiles of the 1000 estimates of the threshold were considered as the $95 \%$ confidence interval $(\mathrm{Cl})$ for the threshold.

\section{Accounting for "ecosystem" variation using a general additive mixed model}

To test the hypothesis that systematic ecosystem by ecosystem variation may have resulted in the apparent asymptotic (saturation) relationship between predators and prey based on the pooled global dataset, we added a random effect to the GAM formulation, i.e. a general additive mixed model (GAMM); this accounted for the potential 'ecosystem effect'. This approach corresponds to generalized linear mixed model (GLMM), in which the linear predictor depends linearly on unknown smooth functions of some of the covariates. We used the $\boldsymbol{R}$ package "gamm4" (132).

Using the GAMM, the asymptotic form of the pooled data was validated. Moreover, the threshold value $(-0.12)$ obtained using this method was not different from the result obtained using the simple GAM analysis (-0.092; fig. S3). Uncertainties for the extreme values were larger, but not unreasonably so. We followed the GAMM with the bootstrap analysis to verify the $\mathrm{Cl}$. This analysis provided a larger confidence interval than the simple GAM, but Cls were remarkably similar. We think that these minor differences stemmed from the fact that inclusion of "ecosystem" in the model created another source of variability around the main pattern. The similar results in terms of threshold identification and uncertainty illustrate the robustness of our analyses (Fig. 2A).

\section{Accounting for stochasticity in the identified globally-coherent pattern of the predator-prey relationship}

The GAM analysis revealed an average asymptotic relationship between seabird breeding success and prey abundance. We investigated whether the form of this relationship was influenced by extreme values (very high/low breeding success) using quantile GAMs. Our aim here was to examine whether the variability driving the "average" asymptotic relationship could be replicated using just extreme values from our data distribution. We used the $\boldsymbol{R}$ package "vgam" for this test $(133,134)$, with quantile values at $10 \%$ and $90 \%$. The quantile GAM performs as a GAM model which is fitted on the quantiles of the response variable (here the $10 \%$ and $90 \%$ of the seabird breeding success). This analysis reveals that a very similar pattern is obtained using the extreme values. In other words, for an analysis using only low/high breeding success, there still exists a threshold value (fig. S4). This analysis demonstrated that our results are robust while accounting for the stochasticity over the average relationship. This shows robustness of the threshold to the accuracy of measurement of breeding success. The identified threshold using 
these quantiles is very similar to the threshold calculated using all data ( 0.14 for the quantile 10 and $90 \%$, and -0.92 for the simple GAM analysis Fig. 2A) and is within the $\mathrm{Cl}$ of the simple GAM analysis.

\section{Calculating the variance in the breeding success relative to prey abundance}

The variance in seabird breeding success was calculated for each prey abundance class (every 0.5 from -1.5 to 2 ; Fig. 2B). Prey biomass values ( 6 data points) that were either below and above those extreme values were not included in the variance analysis to avoid "edge" effects as they were too few data points for each class to calculate the variance. An F-test was used to test for significant differences in variance from low to high levels of prey abundance. This test showed significant difference in variance $\left(p<10^{-5}\right)$ as well as mean breeding success.

\section{b) Testing alternative forms of the global (asymptotic) model (table S2)}

\section{Model fitting}

We used a series of parametric models to evaluate possible inconsistency in the global asymptotic model. We examined 11 equations that covered a range of log-linear relationships (table S2); we fit these equations to the pooled dataset using the "nls" function in $\boldsymbol{R}(135)$. To select the best model, we used the Akaike Information Criterion (AIC). The model 4 in table S2 $\left(y=c+a \cdot\left(1-e^{-}\right.\right.$ b.x) ) was selected as the "best" model. In order to validate the global analysis and to examine the robustness of the fitted functional relationships, we fitted this parametric model to the data for each ecosystem (Fig 2C \& Fig 3) and for each seabird species (Fig. 2D). To examine effects at the ecosystem level, data were pooled across the seabird species within each ecosystem.

\section{Hierarchical model fitting}

Using the same basic procedure we used for the GAM/GAMM analysis, we added "ecosystem" as a random effect to the model showing the lowest AIC value. We used the "nlme" function of the $\boldsymbol{R}$ package (136). We added two random effects for the parameters $a$ and $c\left(r_{i, 1}\right.$ and $r i, 2$ where $i$ is the ecosystem) using the procedure described in (136) (table S2). Fitting this hierarchical model to data showed that the results were similar between ecosystems (table S2). Resulting values were, however, slightly different from the fixed-effect model. Autocorrelation in the data was checked with an analysis of the model residuals. Residuals were randomly distributed and the qqnorm plot showed that they did not differ from the normality assumption. 
Figures $\mathrm{S} 1$ to $\mathrm{S} 4$

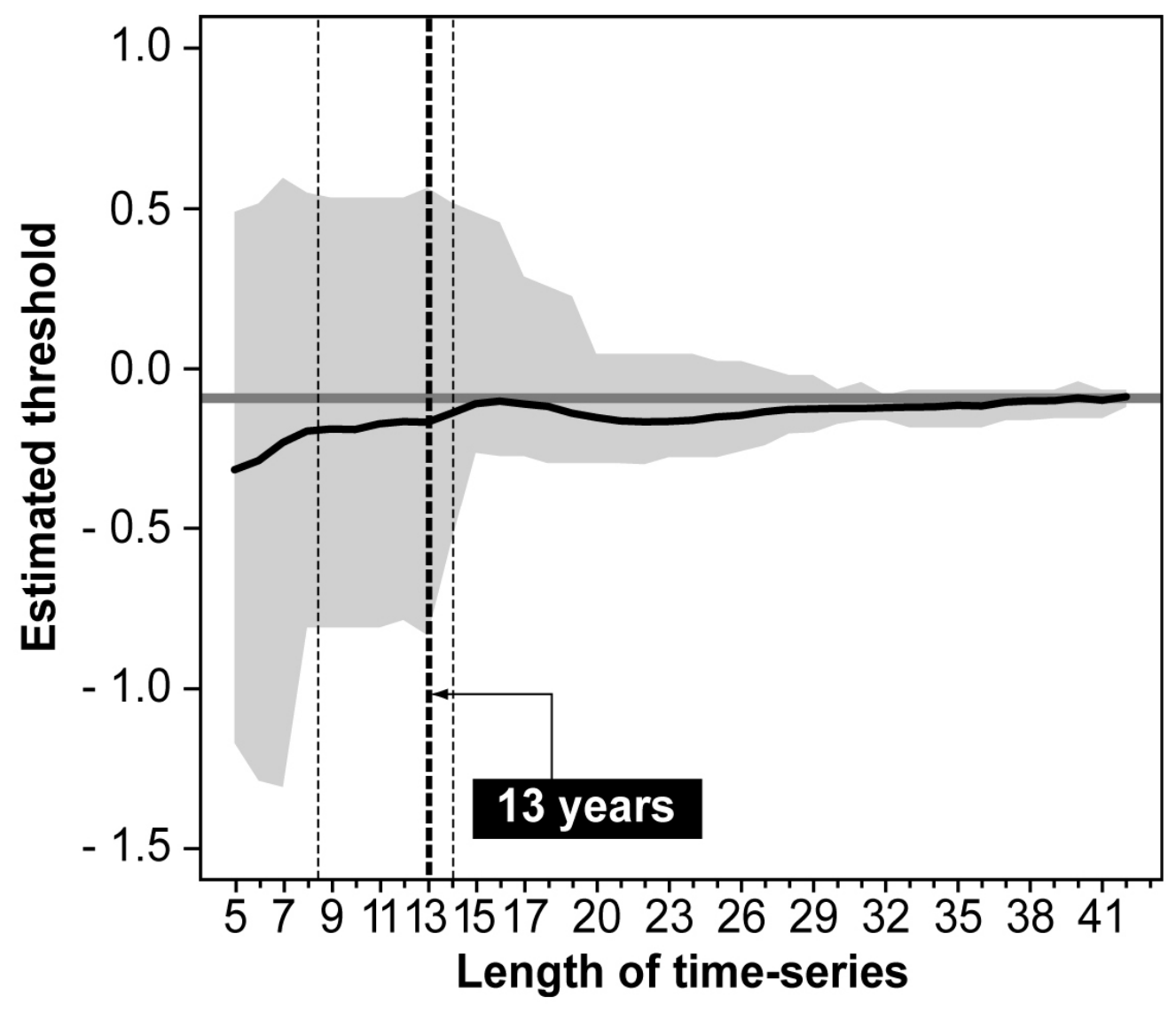

Fig. S1: Minimum number of years required for estimating the threshold. The horizontal grey line represents the threshold estimated from the global dataset while the solid black line is the threshold estimated from a subset of the global dataset. The subset was obtained from the pooled dataset where we randomly drew " $X$ " consecutive years from the breeding success and prey time-series, where " $X$ " is comprised between 5 and 42 years ( $X$-axis). The minimum number of years required for estimating the threshold was determined using the significance of the mean value of the threshold, given the confidence interval for both the subset and global dataset. We repeated this computation 1000 times to obtain a confidence interval over the estimate of the minimum number of years required to calculate the threshold. The vertical dashed line indicates that 13 years of data (the confidence Interval is between 8.5 and 14 years, vertical thin dashed lines) were necessary to detect on average the threshold defined in Fig. 2A (i.e., the value of the estimated threshold is not significantly different from the threshold for the global dataset). All time-series in the global data set of our meta-analysis were between 15 and 47 years long, which makes the detection of the threshold possible in all cases. 


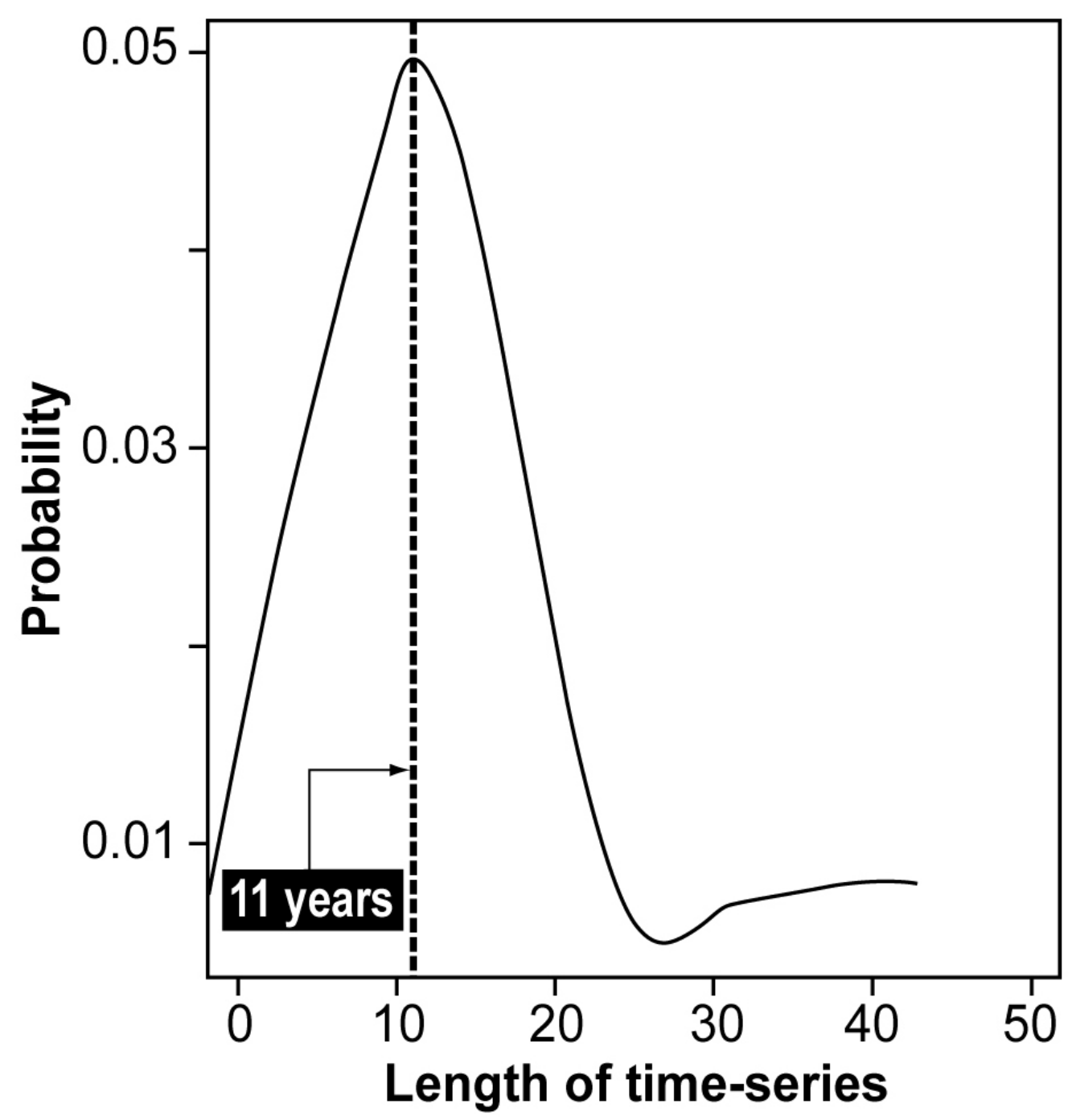

Fig. S2: Probability distribution of the maximum observed biomass detected in the prey abundance time series as a function of the length of the time series. The vertical dashed line indicates that after 11 years of observation most of prey time series revealed the maximum prey biomass. All times series in the global data set of our meta-analysis were between 15 and 47 years long, which makes the detection of the maximum prey biomass possible in all cases. 


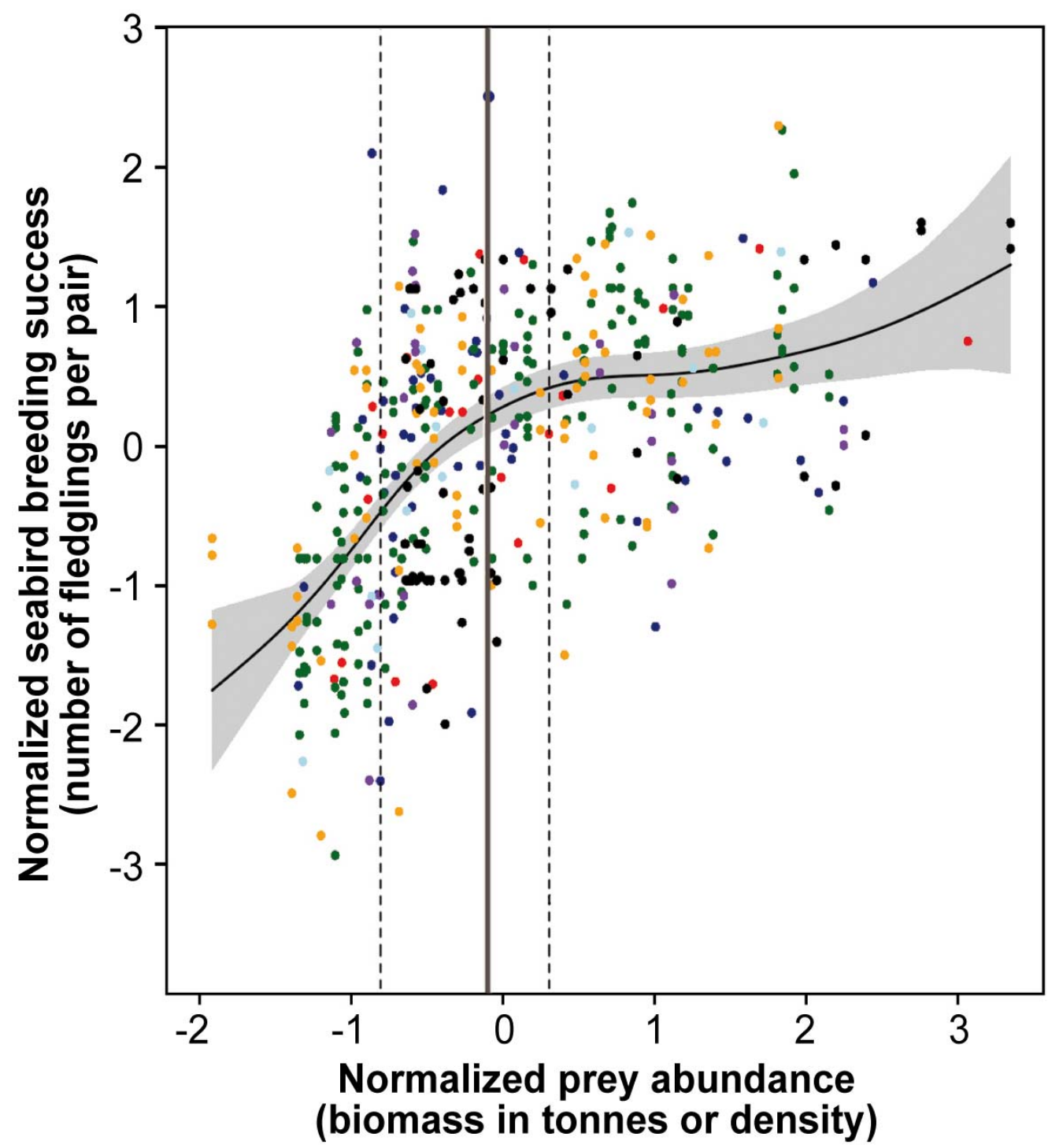

Fig. S3: Relationship between normalized annual breeding success of seabirds and normalized prey abundance. Each data point from all the time series was plotted together with the predictions of a General Additive Mixed Model (GAMM) (solid line) to account for the 'ecosystem effect'. The grey area represents the $95 \%$ confidence interval of the fitted GAMM. The threshold in the non-linear relationship (solid vertical line) was detected from a changepoint analysis and its confidence interval (black dashed vertical lines) was estimated from a bootstrap analysis. When accounting for the "ecosystem effect" using the GAMM analysis, the results are similar to the GAM analysis (respectively the threshold value is -0.12 here instead of -0.09 in Fig. $2 A$ ). 


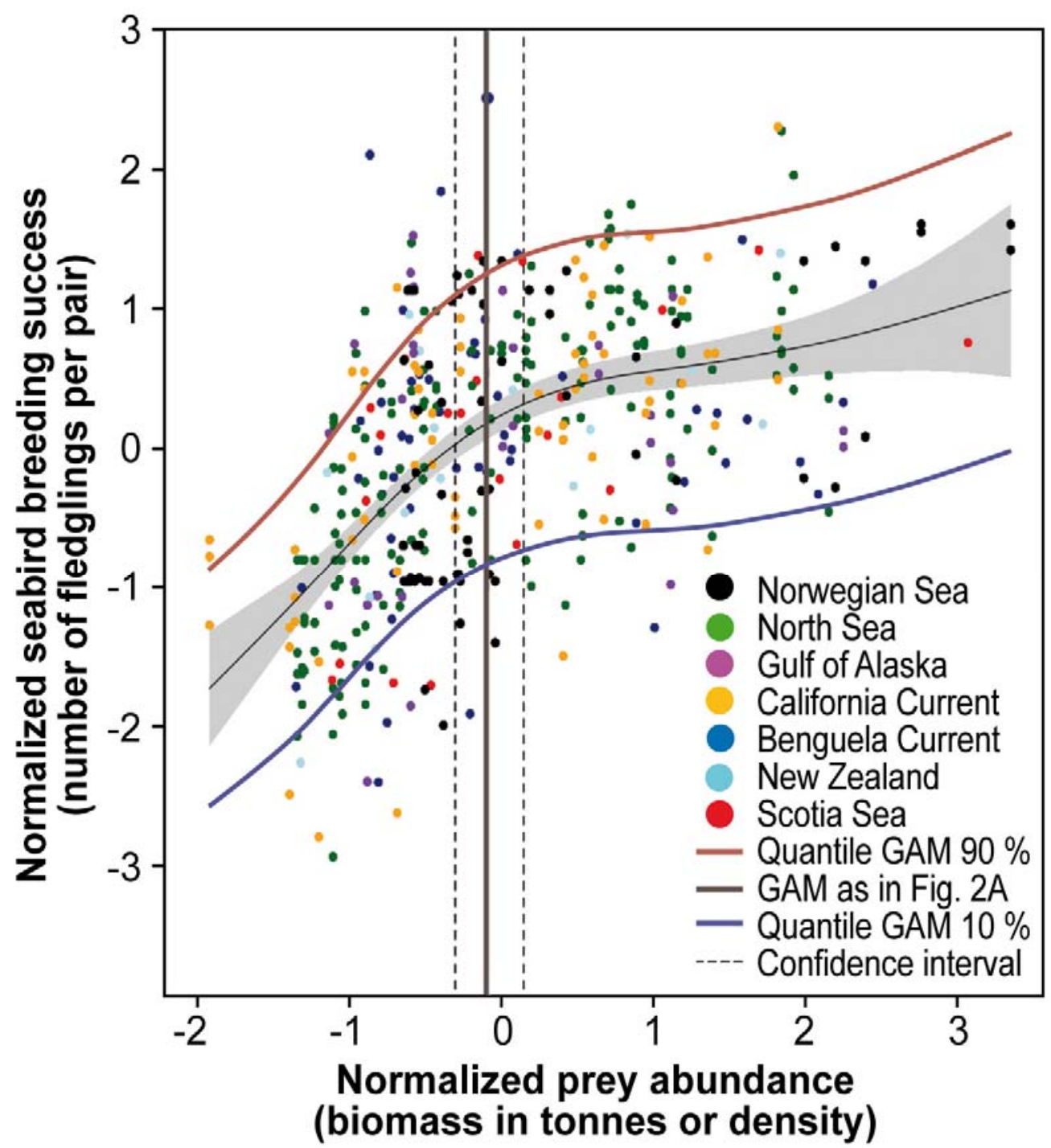

Fig. S4: Relationship between normalized annual breeding success of seabirds and normalized prey abundance. Each data point from all the time series was plotted together with the prediction of a General Additive Model (GAM) (solid black line) and of a quantile GAM (for the 10 and 90\% quantile; blue and red solid line respectively). The grey area represents the $95 \%$ confidence interval of the fitted GAMM. The threshold in the non-linear relationship (solid vertical line) was detected from a change-point analysis and its confidence interval (black dashed vertical lines) was estimated from a similar bootstrap analysis to Fig. 2A. This analysis showed that a similar pattern can be observed for extreme values. In other words, for a low/high breeding success (10 or $90 \%$ quantile resp.), there still exists a threshold below which the breeding success starts to decline. The threshold identified for the two quantile GAM predictions is close to the GAM analysis (respectively the threshold value is -0.14 here instead of -0.09 in Fig. 2A). 
Table S1: Time-series used in the global analysis of seabird-forage fish relationships. Each time series is one bird species at one location.

Breeding success and prey abundance units are shown. Thresholds for each time series, as computed using Generalized Additive Models, are expressed as a percentage (\%) of the maximum prey abundance in the time series considered.

\begin{tabular}{|c|c|c|c|c|c|c|c|c|c|c|c|c|c|}
\hline $\mathrm{N}^{\circ}$ & Ecosystem & Location & $\begin{array}{l}\text { Bird } \\
\text { species } \\
\text { (scientific } \\
\text { name) }\end{array}$ & $\begin{array}{l}\text { Bird } \\
\text { species } \\
\text { (common } \\
\text { name) }\end{array}$ & $\begin{array}{l}\text { Prey } \\
\text { species } \\
\text { (scientific } \\
\text { name) }\end{array}$ & $\begin{array}{l}\text { Prey } \\
\text { species } \\
\text { (common } \\
\text { name) }\end{array}$ & $\begin{array}{l}\text { Time } \\
\text { Series }\end{array}$ & $\begin{array}{l}\text { Seabird } \\
\text { breeding } \\
\text { success }\end{array}$ & $\begin{array}{l}\text { Prey } \\
\text { abundance } \\
\text { (unit) }\end{array}$ & $\begin{array}{l}\text { Prey } \\
\text { in the } \\
\text { diet } \\
(\% \\
\text { total } \\
\text { mass) }\end{array}$ & $\begin{array}{l}\text { Thres- } \\
\text { hold } \\
\text { (\%) }\end{array}$ & $\begin{array}{l}\text { Notes on } \\
\text { data }\end{array}$ & $\begin{array}{l}\text { Reference } \\
\text { to data }\end{array}$ \\
\hline \multirow[t]{2}{*}{1} & $\begin{array}{l}\text { Norwegian } \\
\text { Sea }\end{array}$ & Røst & $\begin{array}{l}\text { Fratercula } \\
\text { arctica }\end{array}$ & $\begin{array}{l}\text { Atlantic } \\
\text { puffin }\end{array}$ & $\begin{array}{l}\text { Clupea } \\
\text { harengus }\end{array}$ & Herring & $\begin{array}{l}1964- \\
2010\end{array}$ & $\begin{array}{l}\text { Fledging } \\
\text { success } \\
\text { (proportion } \\
\text { fledged of } \\
\text { chicks } \\
\text { hatched) }\end{array}$ & $\begin{array}{l}\text { Herring } \\
\text { age } 0 \\
\text { abundance }\end{array}$ & $\begin{array}{l}23 \% \\
\text { to } \\
89 \%\end{array}$ & $22 \%$ & $\begin{array}{l}\text { Categorical } \\
\text { data (good, } \\
\text { poor, very } \\
\text { poor, no } \\
\text { fledging } \\
\text { success) } \\
\text { until } 1976\end{array}$ & 44,45 \\
\hline & - & Røst & $\begin{array}{l}\text { Rissa } \\
\text { tridactyla }\end{array}$ & Kittiwake & $\begin{array}{l}\text { Clupea } \\
\text { harengus }\end{array}$ & Herring & $\begin{array}{l}1981- \\
2010\end{array}$ & $\begin{array}{l}\text { Number of } \\
\text { fledglings/ } \\
\text { pair }\end{array}$ & $\begin{array}{l}\text { Herring } \\
\text { age } 0 \\
\text { abundance }\end{array}$ & $\begin{array}{l}\text { Not } \\
\text { availa- } \\
\text { ble }\end{array}$ & $26 \%$ & $\begin{array}{l}1984-1987 \\
\text { missing }\end{array}$ & 45 \\
\hline \multirow[t]{3}{*}{2} & $\begin{array}{l}\text { North Sea - } \\
\text { Shetland }\end{array}$ & Shetland & $\begin{array}{l}\text { Phalacro- } \\
\text { corax } \\
\text { aristotelis }\end{array}$ & Shag & $\begin{array}{l}\text { Ammodytes } \\
\text { marinus }\end{array}$ & Sandeel & $\begin{array}{l}1986- \\
2005\end{array}$ & $\begin{array}{l}\text { Number of } \\
\text { fledglings/ } \\
\text { pair }\end{array}$ & $\begin{array}{l}\text { Sandeel } \\
\text { biomass }(\mathrm{t}) \\
\text { in the } \\
\text { Shetland } \\
\text { stock }\end{array}$ & $100 \%{ }^{*}$ & $39 \%$ & & 75,79 \\
\hline & - & Foula & $\begin{array}{l}\text { Sterna } \\
\text { paradisaea }\end{array}$ & Arctic Tern & $\begin{array}{l}\text { Ammodytes } \\
\text { marinus }\end{array}$ & Sandeel & $\begin{array}{l}1972- \\
2005\end{array}$ & $\begin{array}{l}\text { Number of } \\
\text { fledglings/ } \\
\text { pair }\end{array}$ & $\begin{array}{l}\text { Sandeel } \\
\text { biomass }(\mathrm{t}) \\
\text { in the } \\
\text { Shetland } \\
\text { stock }\end{array}$ & $100 \%{ }^{*}$ & $\begin{array}{l}\text { No } \\
\text { thresh- } \\
\text { old }\end{array}$ & & 22,75 \\
\hline & - & Foula & $\begin{array}{l}\text { Stercora- } \\
\text { rius } \\
\text { parasiticus }\end{array}$ & Arctic skua & $\begin{array}{l}\text { Ammodytes } \\
\text { marinus }\end{array}$ & Sandeel & $\begin{array}{l}1976- \\
2005\end{array}$ & $\begin{array}{l}\text { Number of } \\
\text { fledglings/ } \\
\text { pair }\end{array}$ & $\begin{array}{l}\text { Sandeel } \\
\text { biomass (t) } \\
\text { in the } \\
\text { Shetland } \\
\text { stock }\end{array}$ & $100 \% *$ & $36 \%$ & & 22,75 \\
\hline
\end{tabular}




\begin{tabular}{|c|c|c|c|c|c|c|c|c|c|c|c|c|c|}
\hline & - & Foula & $\begin{array}{l}\text { Stercora- } \\
\text { rius } \\
\text { skua }\end{array}$ & Great skua & $\begin{array}{l}\text { Ammodytes } \\
\text { marinus }\end{array}$ & Sandeel & $\begin{array}{l}1972- \\
2005\end{array}$ & $\begin{array}{l}\text { Number of } \\
\text { fledglings/ } \\
\text { pair }\end{array}$ & $\begin{array}{l}\text { Sandeel } \\
\text { biomass }(\mathrm{t}) \\
\text { in the } \\
\text { Shetland } \\
\text { stock }\end{array}$ & $\begin{array}{l}38 \% \\
\text { to } \\
80 \%\end{array}$ & $31 \%$ & & 22,75 \\
\hline & - & Shetland & $\begin{array}{l}\text { Fulmarus } \\
\text { glacialis }\end{array}$ & Fulmar & $\begin{array}{l}\text { Ammodytes } \\
\text { marinus }\end{array}$ & Sandeel & $\begin{array}{l}1986- \\
2005\end{array}$ & $\begin{array}{l}\text { Number of } \\
\text { fledgings/ } \\
\text { regularly } \\
\text { occupied } \\
\text { site. }\end{array}$ & $\begin{array}{l}\text { Sandeel } \\
\text { biomass (t) } \\
\text { in the } \\
\text { Shetland } \\
\text { stock }\end{array}$ & $\begin{array}{l}50 \% \\
\text { to } \\
70 \%\end{array}$ & $30 \%$ & & 75,79 \\
\hline & - & Foula & $\begin{array}{l}\text { Rissa } \\
\text { tridactyla }\end{array}$ & $\begin{array}{l}\text { Black- } \\
\text { legged } \\
\text { kittiwake }\end{array}$ & $\begin{array}{l}\text { Ammodytes } \\
\text { marinus }\end{array}$ & Sandeel & $\begin{array}{l}1974- \\
2005\end{array}$ & $\begin{array}{l}\text { Number of } \\
\text { fledglings/ } \\
\text { pair }\end{array}$ & $\begin{array}{l}\text { Sandeel } \\
\text { biomass (t) } \\
\text { in the } \\
\text { Shetland } \\
\text { stock }\end{array}$ & $100 \%{ }^{*}$ & $51 \%$ & & $22,75,137$ \\
\hline & - & Shetland & Uria aalge & $\begin{array}{l}\text { Guillemot } \\
\text { (Common } \\
\text { Murre) }\end{array}$ & $\begin{array}{l}\text { Ammodytes } \\
\text { marinus }\end{array}$ & Sandeel & $\begin{array}{l}1989- \\
2005\end{array}$ & $\begin{array}{l}\text { Number of } \\
\text { fledglings }{ }^{\star \star} / \\
\text { pair }\end{array}$ & $\begin{array}{l}\text { Sandeel } \\
\text { biomass }(\mathrm{t}) \\
\text { in the } \\
\text { Shetland } \\
\text { stock }\end{array}$ & $\begin{array}{l}90 \% \\
\text { to } \\
100 \%\end{array}$ & $30 \%$ & & 75,79 \\
\hline 3 & $\begin{array}{l}\text { Gulf of } \\
\text { Alaska }\end{array}$ & Cook Inlet & $\begin{array}{l}\text { Rissa } \\
\text { tridactyla }\end{array}$ & $\begin{array}{l}\text { Black- } \\
\text { legged } \\
\text { kittiwake }\end{array}$ & $\begin{array}{l}\text { Ammodytes } \\
\text { hexapterus, } \\
\text { Mallotus } \\
\text { villosus, } \\
\text { Theragra } \\
\text { chalcogram- } \\
\text { ma, }\end{array}$ & $\begin{array}{l}\text { Sand } \\
\text { Lance, } \\
\text { Capelin, } \\
\text { walleye } \\
\text { pollock }\end{array}$ & $\begin{array}{l}1995- \\
1999\end{array}$ & $\begin{array}{l}\text { Number of } \\
\text { fledglings/ } \\
\text { pair }\end{array}$ & $\begin{array}{l}\text { Fish } \\
\text { biomass } \\
\left(\mathrm{g} \cdot \mathrm{m}^{-3}\right)\end{array}$ & $83 \%$ & $36 \%$ & $\begin{array}{l}\text { Prey } \\
\text { biomass } \\
\text { measured } \\
\text { around } 3 \\
\text { colonies in } \\
\text { each of } 5 \\
\text { years for } 15 \\
\text { "colony- } \\
\text { years" }\end{array}$ & $16,36,41$ \\
\hline & - & Cook Inlet & Uria aalge & $\begin{array}{l}\text { Guillemot } \\
\text { (Common } \\
\text { Murre) }\end{array}$ & $\begin{array}{l}\text { Ammodytes } \\
\text { hexapterus, } \\
\text { Mallotus } \\
\text { villosus, } \\
\text { Theragra } \\
\text { chalcogram- } \\
\text { ma, }\end{array}$ & $\begin{array}{l}\text { Sand } \\
\text { lance, } \\
\text { Capelin, } \\
\text { walleye } \\
\text { pollock }\end{array}$ & $\begin{array}{l}1995- \\
1999\end{array}$ & $\begin{array}{l}\text { Number of } \\
\text { fledglings }{ }^{\star *} / \\
\text { pair }\end{array}$ & 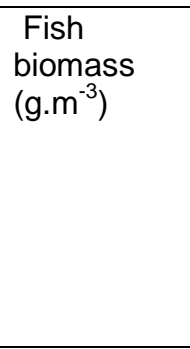 & $91 \%$ & $50 \%$ & $\begin{array}{l}\text { Prey } \\
\text { biomass } \\
\text { measured } \\
\text { around } 3 \\
\text { colonies in } \\
\text { each of } 5 \\
\text { years for } 15 \\
\text { colony-years } \\
\text { per species }\end{array}$ & $16,36,41$ \\
\hline 4 & $\begin{array}{l}\text { California } \\
\text { Current }\end{array}$ & $\begin{array}{l}\text { Southeast } \\
\text { Farallon } \\
\text { Island }\end{array}$ & Uria aalge & $\begin{array}{l}\text { Guillemot } \\
\text { (Common } \\
\text { Murre) }\end{array}$ & $\begin{array}{l}\text { Sebastes } \\
\text { spp. }\end{array}$ & $\begin{array}{l}\text { Juvenile } \\
\text { rockfish }\end{array}$ & $\begin{array}{l}1983- \\
2007\end{array}$ & $\begin{array}{l}\text { Number of } \\
\text { fledglings/ } \\
\text { pair }\end{array}$ & $\begin{array}{l}\text { Juvenile } \\
\text { rockfish } \\
\text { abundance } \\
\text { (index) }\end{array}$ & $43 \%$ & $51 \%$ & & $90,95,96$ \\
\hline
\end{tabular}




\begin{tabular}{|c|c|c|c|c|c|c|c|c|c|c|c|c|c|}
\hline & - & $\begin{array}{l}\text { Southeast } \\
\text { Farallon } \\
\text { Island }\end{array}$ & $\begin{array}{l}\text { Cepphus } \\
\text { columba }\end{array}$ & $\begin{array}{l}\text { Pigeon } \\
\text { Guillemot }\end{array}$ & $\begin{array}{l}\text { Sebastes } \\
\text { spp. }\end{array}$ & $\begin{array}{l}\text { Juvenile } \\
\text { rockfish }\end{array}$ & $\begin{array}{l}1983- \\
2007\end{array}$ & $\begin{array}{l}\text { Number of } \\
\text { fledglings/ } \\
\text { pair }\end{array}$ & $\begin{array}{l}\text { Juvenile } \\
\text { rockfish } \\
\text { abundance } \\
\text { (index) }\end{array}$ & $20 \%$ & $31 \%$ & & $90,95,96$ \\
\hline & - & $\begin{array}{l}\text { Southeast } \\
\text { Farallon } \\
\text { Island }\end{array}$ & $\begin{array}{l}\text { Cerorhinca } \\
\text { mono- } \\
\text { cerata }\end{array}$ & $\begin{array}{l}\text { Rhinoceros } \\
\text { Auklet }\end{array}$ & $\begin{array}{l}\text { Sebastes } \\
\text { spp. }\end{array}$ & $\begin{array}{l}\text { Juvenile } \\
\text { rockfish }\end{array}$ & $\begin{array}{l}1986- \\
2007\end{array}$ & $\begin{array}{l}\text { Number of } \\
\text { fledglings/ } \\
\text { pair }\end{array}$ & $\begin{array}{l}\text { Juvenile } \\
\text { rockfish } \\
\text { abundance } \\
\text { (index) }\end{array}$ & $16 \%$ & $29 \%$ & & $90,95,96$ \\
\hline 5 & $\begin{array}{l}\text { Benguela } \\
\text { Current }\end{array}$ & Malgas & $\begin{array}{l}\text { Morus } \\
\text { capensis }\end{array}$ & $\begin{array}{l}\text { Cape } \\
\text { Gannet }\end{array}$ & $\begin{array}{l}\text { Engraulis } \\
\text { encrasicolus, } \\
\text { Sardinops } \\
\text { sagax }\end{array}$ & $\begin{array}{l}\text { Anchovy, } \\
\text { Sardine }\end{array}$ & $\begin{array}{l}1988- \\
2009\end{array}$ & $\begin{array}{l}\text { Number of } \\
\text { fledglings/ } \\
\text { pair }\end{array}$ & $\begin{array}{l}\text { Prey } \\
\text { biomass in } \\
\text { W Agulhas } \\
\text { (Mt) }\end{array}$ & $49 \% \%^{* \star \star}$ & $44 \%$ & & 138 \\
\hline & - & $\begin{array}{l}\text { Lambert's } \\
\text { Bay }\end{array}$ & $\begin{array}{l}\text { Morus } \\
\text { capensis }\end{array}$ & $\begin{array}{l}\text { Cape } \\
\text { Gannet }\end{array}$ & $\begin{array}{l}\text { Engraulis } \\
\text { encrasicolus, } \\
\text { Sardinops } \\
\text { sagax }\end{array}$ & $\begin{array}{l}\text { Anchovy, } \\
\text { Sardine }\end{array}$ & $\begin{array}{l}1991- \\
2009\end{array}$ & $\begin{array}{l}\text { Number of } \\
\text { fledglings/ } \\
\text { pair }\end{array}$ & $\begin{array}{l}\text { Prey } \\
\text { biomass in } \\
\text { W Agulhas } \\
\text { (Mt) }\end{array}$ & $73 \%{ }^{* * *}$ & $43 \%$ & $\begin{array}{l}\text { No data were } \\
\text { collected in } \\
2006 \text { in order } \\
\text { to minimize } \\
\text { disturbance } \\
\text { at the colony } \\
\text { after all birds } \\
\text { abandoned } \\
\text { the colony in } \\
\text { late } 2005\end{array}$ & 138 \\
\hline & - & $\begin{array}{l}\text { Robben } \\
\text { Island }\end{array}$ & $\begin{array}{l}\text { Sphenis- } \\
\text { cus } \\
\text { demersus }\end{array}$ & $\begin{array}{l}\text { African } \\
\text { penguin }\end{array}$ & $\begin{array}{l}\text { Engraulis } \\
\text { encrasicolus, } \\
\text { Sardinops } \\
\text { sagax }\end{array}$ & $\begin{array}{l}\text { Anchovy, } \\
\text { Sardine }\end{array}$ & $\begin{array}{l}1989- \\
2004\end{array}$ & $\begin{array}{l}\text { Number of } \\
\text { fledglings/ } \\
\text { pair }\end{array}$ & $\begin{array}{l}\text { Prey } \\
\text { biomass in } \\
\text { W Agulhas } \\
\text { (Mt) }\end{array}$ & $86 \%$ & $32 \%$ & $\begin{array}{l}\text { Year } 2000 \\
\text { was } \\
\text { excluded } \\
\text { because an } \\
\text { oil spill in that } \\
\text { year resulted } \\
\text { in most birds } \\
\text { at the colony } \\
\text { terminating } \\
\text { breeding at } \\
\text { an early } \\
\text { stage }\end{array}$ & 106 \\
\hline
\end{tabular}




\begin{tabular}{|c|c|c|c|c|c|c|c|c|c|c|c|c|c|}
\hline 6 & New Zealand & $\begin{array}{l}\text { Kaikoura } \\
\text { Peninsula }\end{array}$ & $\begin{array}{l}\text { Larus } \\
\text { novaehol- } \\
\text { landiae } \\
\text { scopulinus }\end{array}$ & $\begin{array}{l}\text { Red-billed } \\
\text { gull }\end{array}$ & $\begin{array}{l}\text { Nyctiphanes } \\
\text { australis }\end{array}$ & Krill & $\begin{array}{l}1975- \\
1993\end{array}$ & $\begin{array}{l}\text { Number of } \\
\text { fledglings/ } \\
\text { pair }\end{array}$ & $\begin{array}{l}\text { Krill } \\
\text { availability } \\
\text { index } \\
\text { (proportion } \\
\text { of adult } \\
\text { birds which } \\
\text { regurgitated } \\
N \text {. australis } \\
\text { when } \\
\text { captured) }\end{array}$ & $\begin{array}{l}84 \% \\
\text { (\% of } \\
\text { adult } \\
\text { eating } \\
\text { krill) }\end{array}$ & $61 \%$ & $\begin{array}{l}1977,1978, \\
1989 \text { are } \\
\text { missing } \\
\text { data after } \\
1994 \text { not } \\
\text { considered } \\
\text { for ecological } \\
\text { reasons }\end{array}$ & 23 \\
\hline 7 & Scotia Sea & $\begin{array}{l}\text { Bird } \\
\text { Island }\end{array}$ & $\begin{array}{l}\text { Pygoscelis } \\
\text { papua }\end{array}$ & $\begin{array}{l}\text { Gentoo } \\
\text { penguin }\end{array}$ & $\begin{array}{l}\text { Euphausia } \\
\text { superba }\end{array}$ & Krill & $\begin{array}{l}1983- \\
2009\end{array}$ & $\begin{array}{l}\text { Number of } \\
\text { fledglings/ } \\
\text { pair }\end{array}$ & $\begin{array}{l}\text { Krill } \\
\text { biomass } \\
\left(\mathrm{g} \cdot \mathrm{m}^{-2}\right)\end{array}$ & $\begin{array}{l}42 \% \\
\text { to } \\
63 \%\end{array}$ & $30 \%$ & $\begin{array}{l}\text { 1984, } 1985, \\
1987,1988 \\
\text { are missing }\end{array}$ & $\begin{array}{l}19,125, \\
121\end{array}$ \\
\hline
\end{tabular}

* the percentage of sandeel in the diet fell after 1985 when the sandeel stock declined, so these values represent the diet in years when food supply was good.

**Fledgings/pair for Uria aalge reflect the number of offspring raised to "jumping stage". Unlike most seabirds, Uria aalge male parents take the chick to sea when 2/3 grown.

Thus, for this species, the variable measured is number of chicks/pair raised to the age of colony-departure (typically 20-25 days old).

${ }^{* * *}$ For gannets, their dependence on anchovy and sardine is greater during the breeding period. 
Table S2: Details of the parametric models tested to fit to the global relationship of normalized breeding success with normalized prey abundance (Fig. 2A). A wide range of linear to nonlinear models was tested. Model number 4 was selected as the best model (lowest AIC value). The hierarchical model is a version of model 4 in which the implication of including ecosystems as a random effect is considered.

\begin{tabular}{|c|c|c|c|c|c|c|c|c|c|}
\hline \multirow{2}{*}{\multicolumn{2}{|c|}{ Model }} & \multicolumn{3}{|c|}{$\begin{array}{l}\text { Parameter } \\
\text { estimates }\end{array}$} & \multicolumn{3}{|c|}{ Standard error } & \multirow[t]{2}{*}{ AIC } & \multirow[t]{2}{*}{ Threshold } \\
\hline & & a & b & c & a & b & c & & \\
\hline & Linear models & & & & & & & & \\
\hline 1 & $y=b$ & 0.005 & & & 0.04 & & & 1228.6 & - \\
\hline \multirow[t]{2}{*}{2} & $y=a x+b$ & 0.51 & 0.005 & - & 0.04 & 0.04 & - & 1091.5 & - \\
\hline & Asymptotic models & & & & & & & & \\
\hline 3 & $\mathrm{y}=\mathrm{a} * e^{-\mathrm{bx}}$ & 1,2 & 0,5 & - & 0,3 & 0,1 & - & 1072,3 & 0,1 \\
\hline 4 & $y=c+a *\left(1-e^{-b x}\right)$ & 0,7 & 0,8 & 0,2 & 0,2 & 0,1 & 0,05 & 1059,9 & $-0,3$ \\
\hline 5 & $y=c+a *\left(1-b^{x}\right)$ & 1,2 & 1,6 & - & 0,3 & 0,2 & - & 1072,3 & 0,1 \\
\hline 6 & $y=a x /(b+x)$ & 0,3 & 1,5 & - & 0,05 & 0,04 & - & 1127,7 & $-1,5$ \\
\hline 7 & $y=c+(a x / b+x)$ & 0,3 & 1,5 & 0,2 & 0,05 & 0,03 & 0,04 & 1112,6 & $-1,5$ \\
\hline 8 & $y=a x /(b+x)+c x$ & 0,1 & 1,5 & 0,4 & 0,05 & 0,1 & 0.05 & 1066,3 & $-1,5$ \\
\hline 9 & $y=a x /(1+b x)$ & $-0,002$ & 1,5 & - & 0,004 & 0,01 & - & 1229,9 & $-0,7$ \\
\hline \multirow[t]{2}{*}{10} & $y=x /(a+b x)$ & 1,8 & 0,4 & - & 0,1 & 0,1 & - & 1072,4 & $-0,2$ \\
\hline & Sigmoidal model & & & & & & & & \\
\hline 11 & $\mathrm{y}=\mathrm{a} /\left(1+e^{-(\mathrm{x}-\mathrm{c} / \mathrm{b})}\right)$ & 0,6 & 0,1 & 0,2 & 0,1 & 0,2 & 0,1 & 1174,9 & 0,1 \\
\hline & Hierarchical model & & & & & & & & \\
\hline 12 & $\begin{array}{l}y=\left(c+r_{i, 1}\right)+\left(a+r_{i, 2}\right) \\
*\left(1-e^{-b x}\right)\end{array}$ & 0.48 & 1.04 & 0.23 & 0.13 & 0.18 & 0.05 & 1063.9 & -0.3 \\
\hline
\end{tabular}




\section{References and Notes}

1. J. B. C. Jackson et al., Historical overfishing and the recent collapse of coastal ecosystems. Science 293, 629 (2001).

2. E. K. Pikitch et al., Ecology. Ecosystem-based fishery management. Science 305, 346 (2004).

3. H. K. Lotze, B. Worm, Historical baselines for large marine animals. Trends Ecol. Evol. 24, 254 (2009).

4. M. Hoffmann et al., The impact of conservation on the status of the world's vertebrates. Science 330 , 1503 (2010).

5. M. Coll, S. Libralato, S. Tudela, I. Palomera, F. Pranovi, Ecosystem overfishing in the ocean. PLoS ONE 3, e3881 (2008).

6. A. D. M. Smith et al., Impacts of fishing low-trophic level species on marine ecosystems. Science 333, 1147 (2011).

7. P. Cury et al., Small pelagics in upwelling systems: patterns of interaction and structural changes in “wasp-waist” ecosystems. ICES J. Mar. Sci. 57, 603 (2000).

8. R. L. Naylor et al., Feeding aquaculture in an era of finite resources. Proc. Natl. Acad. Sci. U.S.A. 106, 15103 (2009).

9. P. A. Abrams, L. R. Ginzburg, The nature of predation: Prey dependent, ratio dependent or neither? Trends Ecol. Evol. 15, 337 (2000).

10. L. C. Stige et al., Direct and indirect climate forcing in a multi-species marine system. Proc. R. Soc. Lond. 277, 3411 (2010).

11. H. M. Pereira et al., Scenarios for global biodiversity in the 21st century. Science 330, 1496 (2010).

12. T. P. Dawson, S. T. Jackson, J. I. House, I. C. Prentice, G. M. Mace, Beyond predictions: biodiversity conservation in a changing climate. Science 332, 53 (2011).

13. R. D. Wooller, J. S. Bradley, J. P. Croxall, Long-term population studies of seabirds. Trends Ecol. Evol. 7, 111 (1992).

14. R. W. Furness, K. Camphuysen, Seabirds as monitors of the marine environment. ICES J. Mar. Sci. 54, 726 (1997).

15. D. K. Cairns, Seabirds as indicators of marine food supplies. Biol. Oceanogr. 5, 261 (1987).

16. J. F. Piatt et al., Seabirds as indicators of marine food supplies: Cairns revisited. Mar. Ecol. Prog. Ser. 352, 221 (2007).

17. I. L. Boyd, Integrated environment-prey-predator interactions off South Georgia: implications for management of fisheries. Aquat. Conserv. 12, 119 (2002).

18. T. Andersen, J. Carstensen, E. Hernández-García, C. M. Duarte, Ecological thresholds and regime shifts: Approaches to identification. Trends Ecol. Evol. 24, 49 (2009).

19. I. L. Boyd, A. W. A. Murray, Monitoring a marine ecosystem using responses of upper trophic level predators. J. Anim. Ecol. 70, 747 (2001).

20. J. M. Durant, T. Anker-Nilssen, N. C. Stenseth, Trophic interactions under climate fluctuations: The Atlantic puffin as an example. Proc. Biol. Sci. 270, 1461 (2003). 
21. K. Reid, J. Croxall, D. Briggs, E. Murphy, Antarctic ecosystem monitoring: quantifying the response of ecosystem indicators to variability in Antarctic krill. ICES J. Mar. Sci. 62, 366 (2005).

22. R. W. Furness, Responses of seabirds to depletion of food fish stocks. J. Ornithol. 148 (suppl. 2), 247 (2007).

23. J. A. Mills et al., The impact of climate fluctuation on food availability and reproductive performance of the planktivorous red-billed gull Larus novaehollandiae scopulinus. J. Anim. Ecol. 77, 1129 (2008).

24. J. C. Field, A. D. MacCall, R. W. Bradley, W. J. Sydeman, Estimating the impacts of fishing on dependent predators: A case study in the California Current. Ecol. Appl. 20, 2223 (2010).

25. M. E. Hunsicker et al., Functional responses and scaling in predator-prey interactions of marine fishes: contemporary issues and emerging concepts. Ecol. Lett. 14, 1288 (2011).

26. A. S. Kitaysky et al., Food availability and population processes: severity of nutritional stress during reproduction predicts survival of long-lived seabirds. Funct. Ecol. 24, 625 (2010).

27. L. Pichegru, D. Grémillet, R. J. Crawford, P. G. Ryan, Marine no-take zone rapidly benefits endangered penguin. Biol. Lett. 6, 498 (2010).

28. J. F. Piatt, D. A. Methven, Threshold foraging behavior of baleen whales. Mar. Ecol. Prog. Ser. 84, 205 (1992).

29. D. J. Agnew, Review-The CCAMLR Ecosystem Monitoring Programme. Antarct. Sci. 9, 235 (1997).

30. S. A. Hatch, J. F. Piatt, in Our Living Resources: A Report to the Nation, E. T. LaRoe, G. S. Farris, C. E. Puckett, P. D. Doran, M. J. Mac, Eds. (U.S. Department of the Interior, National Biological Service, Washington, DC), pp. 49-52 (1995).

31. D. E. Dragoo, G. V. Byrd, D. B. Irons, Breeding status, population trends and diets of seabirds in Alaska, 2007 (U.S. Fish and Wildlife Service Report AMNWR 2010/08, Homer, Alaska, 2010).

32. J. F. Piatt, C. J. Lensink, Exxon Valdez bird toll. Nature 342, 865 (1989).

33. J. F. Piatt, P. J. Anderson, in Exxon Valdez Oil Spill Symposium Proceedings, S. D. Rice, R. B. Spies, D. A. Wolfe, B. A. Wright, Eds. (American Fisheries Society Symposium 18, Bethesda, MD), pp. 720-737 (1996).

34. R. C. Francis, S. R. Hare, A. B. Hollowed, W. S. Wooster, Effects of interdecadal climate variability on the oceanic ecosystems of the NE Pacific. Fish. Oceanogr. 7, 1 (1998).

35. P. J. Anderson, J. F. Piatt, Community reorganization in the Gulf of Alaska following ocean climate regime shift. Mar. Ecol. Prog. Ser. 189, 117 (1999).

36. J. F. Piatt, Ed., Response of Seabirds to Fluctuations in Forage Fish Density [Final Report to Exxon Valdez Oil Spill Trustee Council (Restoration Project 00163M) and Minerals Management Service (Alaska OCS Report 2002-068), Alaska Science Center, U.S. Geological Survey, Anchorage, Alaska, 2002].

37. A. M. A. Harding et al., Prey density and the behavioral flexibility of a marine predator: the common murre (Uria aalge). Ecology 88, 2024 (2007).

38. M. D. Robards, J. F. Piatt, A. B. Kettle, A. A. Abookire, Temporal and geographic variation in fish communities of lower Cook Inlet, Alaska. Fish Bull. 97, 962 (1999). 
39. A. A. Abookire, J. F. Piatt, Oceanographic conditions structure forage fishes into lipid-rich and lipid-poor communities in lower Cook Inlet, Alaska, USA. Mar. Ecol. Prog. Ser. 287, 229 (2005).

40. S. Speckman, J. F. Piatt, C. Minte-Vera, J. Parrish, Parallel structure among environmental gradients and three trophic levels in a subarctic estuary. Prog. Oceanogr. 66, 25 (2005).

41. J. F. Piatt, A. M. A. Harding, in Long-term Ecological Change in the Northern Gulf of Alaska, R. B. Spies, Ed. (Elsevier, Amsterdam, 2007), pp. 335-352.

42. M. T. Shultz, J. F. Piatt, A. M. A. Harding, A. B. Kettle, T. I. Van Pelt, Timing of breeding and reproductive performance in murres and kittiwakes reflect mismatched seasonal prey dynamics. Mar. Ecol. Prog. Ser. 393, 247 (2009).

43. T. Anker-Nilssen, O. W. Røstad, Census and monitoring of puffins Fratercula arctica on Røst, N Norway, 1979-1988. Ornis Scand. 24, 1 (1993).

44. T. Anker-Nilssen, T. Aarvak, "Long-term studies of seabirds in the municipality of Røst, Nordland. Results with focus on 2004 and 2005” (NINA Report 133, Norwegian Institute for Nature Research, Trondheim, 2006).

45. T. Anker-Nilssen, “Key-site monitoring in Røst in 2009” (SEAPOP Short Report 12-2010, Norwegian Institute for Nature Research, Trondheim, 2010).

46. T. Anker-Nilssen, Ed., Seabirds in Norway 2010. Results from the SEAPOP programme” (SEAPOP annual report pamphlet, www.seapop.no/no/, 2011).

47. M. P. Harris et al., Effect of wintering area and climate on the survival of adult Atlantic puffins Fratercula arctica in the eastern Atlantic. Mar. Ecol. Prog. Ser. 297, 283 (2005).

48. T. Anker-Nilssen, thesis, Trondheim University, Norway (1992).

49. J. M. Durant et al., Timing and abundance as key mechanisms affecting trophic interactions in variable environments. Ecol. Lett. 8, 952 (2005).

50. J. M. Durant, T. Anker-Nilssen, N. C. Stenseth, Ocean climate prior to breeding affects the duration of the nestling period in the Atlantic puffin. Biol. Lett. 2, 628 (2006).

51. O. Dragesund, J. Hamre, O. Ulltang, Biology and population dynamics of the Norwegian springspawning herring. Rapp. P.-V. Reun.- Cons. Int. Explor. Mer 177, 43 (1980).

52. R. Toresen, O. J. Østvedt, Variation in abundance of Norwegian springspawning herring (Clupea harengus, Clupeidae) throughout the 20th century and the influence of climatic fluctuations. Fish Fish. 1, 231 (2000).

53. V. Grosbois et al., Modeling survival at multi-population scales using mark-recapture data. Ecology 90, 2922 (2009).

54. O. Gimenez, T. Anker-Nilssen, V. Grosbois, Exploring causal pathways in demographic parameter variation: Path analysis of mark-recapture data. Methods Ecol. Evol. 10.1111/j.2041210X.2011.00150.x (2011).

55. T. Anker-Nilssen, T. Aarvak, Satellite telemetry reveals post-breeding movements of Atlantic puffins Fratercula arctica from Røst, North Norway. Polar Biol. 32, 1657 (2009).

56. R. T. Barrett, T. Anker-Nilssen, G. W. Gabrielsen, G. Chapdelaine, Food consumption by seabirds in Norwegian waters. ICES J. Mar. Sci. 59, 43 (2002). 
57. R. Sætre, R. Toresen, T. Anker-Nilssen, Factors affecting the recruitment variability of the Norwegian spring-spawning herring (Clupea harengus L.). ICES J. Mar. Sci. 59, 725 (2002).

58. T. Anker-Nilssen, R. T. Barrett, J. V. Krasnov, in Forage Fishes in Marine Ecosystems. Proceedings of the International Symposium on the Role of Forage Fishes in Marine Ecosystems (Alaska Sea Grant College Program Report No. 97-01, Univ. of Alaska, Fairbanks, 1997), pp. 683-698.

59. T. Anker-Nilssen, T. Aarvak, Effects of White-tailed Eagles on the Reproductive Performance of Black-legged Kittiwakes; Indications from a 26-year Study in North Norway, paper presented at the Seabird Group 10th International Conference Brugge, Belgium, 27-30 March (2009).

60. T. Anker-Nilssen, The breeding performance of puffins Fratercula arctica on Røst, northern Norway in 1979-1985. Fauna norv. Ser. C. Cinclus 10, 21 (1987).

61. ICES, "Report of the Working Group on Widely Distributed Stocks (WGWIDE), 28 August-3 September 2010, Vigo, Spain” (ICES CM 2010/ACOM:15, Copenhagen, 2010).

62. M. Pennington et al., The Birds of Shetland (Christopher Helm, London, 2004).

63. R. W. Furness, M. L. Tasker, Seabird-fishery interactions: Quantifying the sensitivity of seabirds to reductions in sandeel abundance and identification of key areas for sensitive seabirds in the North Sea. Mar. Ecol. Prog. Ser. 202, 253 (2000).

64. A. V. Hudson, R. W. Furness, Utilisation of discarded fish by scavenging seabirds behind whitefish trawlers in Shetland. J. Zool. (Lond.) 215, 151 (1988).

65. R. W. Furness, Management implications of interactions between fisheries and sandeel-dependent seabirds and seals in the North Sea. ICES J. Mar. Sci. 59, 261 (2002).

66. S. C. Votier et al., Changes in fisheries discard rates and seabird communities. Nature 427, 727 (2004).

67. S. C. Votier, S. Bearhop, R. Fyfe, R. W. Furness, Temporal and spatial variation in the diet of a marine top predator-links with commercial fisheries. Mar. Ecol. Prog. Ser. 367, 223 (2008).

68. R. W. Furness, C. M. Todd, Diets and feeding of Fulmars Fulmarus glacialis during the breeding season: A comparison between St Kilda and Shetland colonies. Ibis 126, 379 (1984).

69. A. R. Martin, The diet of Atlantic Puffin Fratercula arctica and Northern gannet Sula bassana chicks at a Shetland colony during a period of changing prey availability. Bird Study 36, 170 (1989).

70. K. C. Hamer, R. W. Furness, R. C. Caldow, The effects of changes in food availability on the breeding ecology of great skuas Catharacta skua in Shetland. J. Zool. (Lond.) 223, 175 (1991).

71. K. C. Hamer, P. Monaghan, J. D. Uttley, P. Walton, M. D. Burns, The influence of food supply on the breeding ecology of kittiwakes (Rissa tridactyla) in Shetland. Ibis 135, 255 (1993).

72. R. A. Phillips, R. W. G. Caldow, R. W. Furness, The influence of food availability on the breeding effort and reproductive success of Arctic skuas Stercorarius parasiticus. Ibis 138, 410 (1996).

73. S. E. Davis, R. G. Nager, R. W. Furness, Food availability affects adult survival as well as breeding success of parasitic jaegers. Ecology 86, 1047 (2005).

74. P. Monaghan, J. D. Uttley, M. D. Burns, C. Thaine, J. Blackwood, The relationship between food supply, reproductive effort and breeding success in Arctic terns Sterna paradisaea. J. Anim. Ecol. 58, 261 (1989). 
75. R. W. Furness, A preliminary assessment of the quantities of Shetland sandeels taken by seabirds, seals, predatory fish and the industrial fishery in 1981-83. Ibis 132, 205 (1990).

76. P. J. Wright, M. C. Bailey, Timing of hatching in Ammodytes marinus from Shetland waters and its significance to early growth and survivorship. Mar. Biol. 126, 143 (1996).

77. S. A. Pedersen, P. Lewy, P. Wright, Assessment of the lesser sandeel (Ammodytes marinus) in the North Sea based on revised stock divisions. Fish. Res. 41, 221 (1999).

78. R. M. Cook, Estimation of the age-specific rate of natural mortality for Shetland sandeels. ICES J. Mar. Sci. 61, 159 (2004).

79. P. M. Walsh et al., Seabird Monitoring Handbook for Britain and Ireland. (Joint Nature Conservation Committee, Peterborough, UK, 1995).

80. R. A. Mavor, M. Parsons, M. Heubeck, S. Schmitt, “Seabird numbers and breeding success in Britain and Ireland, 2006” (UK Nature Conservation Report, Joint Nature Conservation Committee, Peterborough, UK, 2007).

81. M. Frederiksen, R. W. Furness, S. Wanless, Regional variation in the role of bottom-up and topdown processes in controlling sandeel abundance in the North Sea. Mar. Ecol. Prog. Ser. 337, 279 (2007).

82. D. M. Checkley Jr., J. A. Barth, Patterns and processes in the California Current System. Prog. Oceanogr. 83, 49 (2009).

83. K. T. Briggs, E. W. Chu, in Trophic Relationships and Food of California Seabirds, J. P. Croxall, Ed. (Cambridge Univ. Press, Cambridge, 1987), pp. 279-301.

84. D. K. Hyrenbach, R. R. Veit, Ocean warming and seabird communities of the southern California Current System (1987-98): Response at multiple temporal scales. Deep Sea Res. Part II Top. Stud. Oceanogr. 50, 2537 (2003).

85. D. G. Ainley, K. D. Hyrenbach, Top-down and bottom-up factors affecting seabird population trends in the California current system (1985-2006). Prog. Oceanogr. 84, 242 (2010).

86. J. A. Thayer et al., Forage fish of the Pacific Rim as revealed by diet of a piscivorous seabird: Synchrony and relationships with sea surface temperature. Can. J. Fish. Aquat. Sci. 65, 1610 (2008).

87. W. J. Sydeman et al., CCOFI Rep. 50, 82 (2009).

88. J. E. Roth, N. Nur, P. Warzybok, W. J. Sydeman, Annual prey consumption of a dominant seabird, the common murre, in the California Current system. ICES J. Mar. Sci. 65, 1046 (2008).

89. D. G. Ainley, R. L. Veit, S. G. Allen, L. B. Spear, P. Pyle, CCOFI Rep. 36, 72 (1995).

90. W. J. Sydeman et al., Climate change, reproductive performance and diet composition of marine birds in the southern California Current system, 1969-1997. Prog. Oceanogr. 49, 309 (2001).

91. C. L. Abraham, W. J. Sydeman, Ocean climate, euphausiids and auklet nesting: inter-annual trends and variation in phenology, diet and growth of a planktivorous seabird, Ptychoramphus aleuticus. Mar. Ecol. Prog. Ser. 274, 235 (2004).

92. C. L. Abraham, W. J. Sydeman, Prey-switching by Cassin’s auklet Ptychoramphus aleuticus reveals seasonal climate-related cycles of Euphausia pacifica and Thysanoessa spinifera. Mar. Ecol. Prog. Ser. 313, 271 (2006). 
93. W. J. Sydeman, J. F. Penniman, T. M. Penniman, P. Pyle, D. G. Ainley, Breeding performance in the Western Gull: Effects of parental age, timing of breeding and year in relation to food availability. J. Anim. Ecol. 60, 135 (1991).

94. K. M. Sakuma, S. Ralston, V. G. Wespestad, CCOFI Rep. 47, 127 (2006).

95. S. Ralston, D. F. Howard, On the development of year-Class strength and cohort variability in two northern California rockfishes. Fish Bull. 93, 710 (1995).

96. K. L. Mills, T. Laidig, S. Ralston, W. J. Sydeman, Diets of top predators indicate pelagic juvenile rockfish (Sebastes spp.) abundance in the California Current System. Fish. Oceanogr. 16, 273 (2007).

97. L. J. Shannon, C. L. Moloney, A. Jarre, J. G. Field, Trophic flows in the southern Benguela during the 1980s and 1990s. J. Mar. Syst. 39, 83 (2003).

98. R. J. M. Crawford, B. M. Dyer, Responses by four seabird species to a fluctuating availability of Cape anchovy Engraulis capensis off South Africa. Ibis 137, 329 (1995).

99. R. J. M. Crawford, Food, fishing and seabirds in the Benguela upwelling system. J. Ornithol. 148 (suppl. 2), 253 (2007).

100. R. J. M. Crawford, E. Goya, J.-P. Roux, C. B. Zavalaga, Comparison of assemblages and some life-history traits of seabirds in the Humboldt and Benguela systems. Afr. J. Mar. Sci. 28, 553 (2006).

101. R. A. Parrish, A. Bakun, D. M. Husby, C. S. Nelson, Comparative climatology of selected environmental processes in relation to eastern boundary current pelagic fish reproduction. FAO Fish. Rep. 291, 731 (1983).

102. C. L. de Moor, D. S. Butterworth, J. C. Coetzee, Revised estimates of abundance of South African sardine and anchovy from acoustic surveys adjusting for echosounder saturation in earlier surveys and attenuation effects for sardine. Afr. J. Mar. Sci. 30, 219 (2008).

103. T. P. Fairweather, C. D. van der Lingen, A. J. Booth, L. Drapeau, J. J. van der Westhuizen, Indicators of sustainable fishing for South African sardine (Sardinops sagax) and anchovy (Engraulis encrasicolus). Afr. J. Mar. Sci. 28, 661 (2006).

104. C. Roy, C. D. van der Lingen, J. C. Coetzee, J. R. E. Lutjeharms, Abrupt environmental shift associated with changes in the distribution of Cape anchovy Engraulis encrasicolus spawners in the southern Benguela. Afr. J. Mar. Sci. 29, 309 (2007).

105. R. J. M. Crawford, A recent increase of swift terns Thalasseus bergii off South Africa-the possible influence of an altered abundance and distribution of prey. Prog. Oceanogr. 83, 398 (2009).

106. R. J. M. Crawford et al., The influence of food availability on breeding success of African penguins Spheniscus demersus at Robben Island, South Africa. Biol. Conserv. 132, 119 (2006).

107. N. J. Adams, P. J. Seddon, Y. M. Van Hezik, Monitoring of seabirds in the Benguela upwelling system: Can seabirds be used as indicators and predictors of change in the marine environment. S. Afr. J. Mar. Sci. 12, 959 (1992).

108. R. J. M. Crawford et al., Collapse of South Africa's penguins in the early 21st century. Afr. J. Mar. Sci. 33, 139 (2011). 
109. J. M. Bradford, "Systematics and Ecology of New Zealand Central East Coast Plankton Sampled at Kaikoura” (Bulletin 207, Department of Scientific and Industrial Research, New Zealand, 1972).

110. B. Stonehouse, Marine birds and mammal at Kaikoura. Proc. N. Z. Eco. Soc. 12, 13-20 (1965).

111. R. A. Heath, Oceanic circulation in the head of the Hikurangi Trench, east coast, New Zealand. $N$. Z. J. Mar. Freshw. Res. 10, 651 (1976).

112. E. J. Barnes, Eastern Cook Strait region circulation inferred from satellite-derived, sea-surface, temperature data. N. Z. J. Mar. Freshw. Res. 19, 405 (1985).

113. E. J. Murphy et al., Climatically driven fluctuations in Southern Ocean ecosystems. Proc. Biol. Sci. 274, 3057 (2007).

114. E. J. Murphy et al., Interannual variability of the South Georgia marine ecosystem: Biological and physical sources of variation in the abundance of krill. Fish. Oceanogr. 7, 381 (1998).

115. E. J. Murphy, S. E. Thorpe, J. L. Watkins, R. Hewitt, Modeling the krill transport pathways in the Scotia Sea: Spatial and environmental connections generating the seasonal distribution of krill. Deep-Sea Res. Part II-Topical Studies in Oceanography 51, 1435 (2004).

116. E. J. Murphy et al., Southern Antarctic Circumpolar Current Front to the northeast of South Georgia: Horizontal advection of krill and its role in the ecosystem. J. Geophys. Res. Oceans 109, C01029 (2004).

117. E. J. Murphy et al., Spatial and temporal operation of the Scotia Sea ecosystem: a review of largescale links in a krill centred food web. Philos. Trans. R. Soc. Lond. B Biol. Sci. 362, 113 (2007).

118. J. P. Croxall, T. S. McCann, P. A. Prince, P. A. Rothery, Reproductive performance of seabirds and seals at South Georgia and Signy Island, South Orkney Islands 1976-86: Implications for Southern Ocean Monitoring Studies in Antarctic Ocean and Resources Variability, D. Sahrhage, Ed. (Springer-Verlag, Berlin, Germany, 1988), pp. 261-285.

119. K. Reid et al., Krill population dynamics at South Georgia: implications for ecosystem-based fisheries management. Mar. Ecol. Prog. Ser. 399, 243 (2010).

120. J. P. Croxall, P. A. Prince, K. Reid, Dietary segregation of krill-eating South Georgia seabirds. J. Zool. (Lond.) 242, 531 (1997).

121. J. P. Croxall, K. Reid, P. A. Prince, Diet, provisioning and productivity responses of marine predators to differences in availability of Antarctic krill. Mar. Ecol. Prog. Ser. 177, 115 (1999).

122. K. Reid, J. P. Croxall, Environmental response of upper trophic-level predators reveals a system change in an Antarctic marine ecosystem. Proc. R. Soc. B 268, 377 (2001).

123. J. Forcada, P. N. Trathan, K. Reid, E. J. Murphy, J. P. Croxall, Contrasting population changes in sympatric penguin species in association with climate warming. Glob. Change Biol. 12, 411 (2006).

124. J. Forcada, P. N. Trathan, E. J. Murphy, Life history buffering in Antarctic mammals and birds against changing patterns of climate and environmental variation. Glob. Change Biol. 14, 2473 (2008).

125. S. L. Hill, K. Reid, A. W. North, Recruitment of mackerel icefish (Champsocephalus gunnari) at South Georgia indicated by predator diets and its relationship with sea surface temperature. Can. J. Fish. Aquat. Sci. 62, 2530 (2005). 
126. J. P. Croxall, P. N. Trathan, E. J. Murphy, Environmental change and Antarctic seabird populations. Science 297, 1510 (2002).

127. K. H. Kock, K. Reid, J. Croxall, S. Nicol, Fisheries in the Southern Ocean: An ecosystem approach. Philos. Trans. R. Soc. Lond. B Biol. Sci. 362, 2333 (2007).

128. K. Reid, J. P. Croxall, E. J. Murphy, The power of ecosystem monitoring. Aquat. Conserv. 17, S79 (2007).

129. T. Hastie, GAM: Generalized Additive Models. R Package Version 1.04. http://cran.rproject.org/web/packages/gam/index.html) (2011).

130. S. J. Chen, A. K. Gupta, Parametric Statistical Change Point Analysis Birkhäuser, Boston (2000).

131. R. Killick, I. A. Eckley, Changepoint: Contains Functions that Run Various Single and Multiple Changepoint Methods. R package version0.3.; http://cran.rproject.org/web/packages/changepoint/index.html (2011).

132. S. Wood, gamm4: Generalized additive mixed models using mgcv and lme4, R package version 0.1-2, http://cran.r-project.org/web/packages/gamm4/index.html (2011)

133. T. Yee, The VGAM Package for Categorical Data Analysis. J. Stat. Softw. 32, 1 (2010); www.jstatsoft.org/v32/i10/.

134. T. Yee VGAM: Vector Generalized Linear and Additive Models. R package version 0.8-3; http://cran.r-project.org/web/packages/VGAM/index.html (2011).

135. R Development Core Team, R: A language and environment for statistical computing. $\mathrm{R}$ Foundation for Statistical Computing (Vienna, Austria, ISBN 3-900051-07-0, 2010, http://www.R-project.org/).

136. J. Pinheiro, D. Bates, S. DebRoy, D. Sarkar and the R Development Core Team nlme: Linear and Nonlinear Mixed Effects Models. R package version 3.1-101 (2011).

137. D. Oro, R. W. Furness, Influences of food availability and predation on survival of kittiwakes. Ecology 83, 2516 (2002).

138. R. J. M. Crawford, P. S. Sabarros, T. Fairweather, L. G. Underhill, A. C. Wolfaardt, Implications for seabirds off South Africa of a long-term change in the distribution of sardine. Afr. J. Mar. Sci. 30, 177 (2008). 
Acknowledgments: This work was supported by Eur-Oceans Consortium and IRD (Institut de Recherche pour le Développement - France) that funded two workshops. The Lenfest Ocean Program is warmly thanked for being a stimulus for the corresponding authors to undertake the analysis (http://www.oceanconservationscience.org/foragefish/). The authors gratefully acknowledge helpful discussions and interactions with J. Adams, N. Bez, J.M. Durant, J.M. Fromentin, S. Le Goas, P. Gros, S. Hatch, D. Pauly, Y.J. Shin and J. Thayer. We thank P. Lopez (IRD) who drew the figures and A.-C. Gandrillon, L. Vicens (IRD) and A. Cury for editing. $\mathrm{H}$. Österblom was funded by Mistra, the Swedish Environmental Protection Agency and WWF, Sweden and L. Shannon by the South African Research Chair Initiative. We also thank the many contributors who provided datasets or helped collect the long-term data used in this paper. In particular, we thank M. Heubeck, Shetland Oil Terminal Environmental Advisory Group, for the collation of data from Shetland, Dr R. Cook (Fisheries Research Service, Aberdeen) for providing stock assessment data for Shetland sandeels, ICES/WGWIDE for allowing us to use stock statistics for NSS herring, the Department of Agriculture, Forestry and Fisheries (South Africa) for providing information of fish biomass in the southern Benguela system, Department of Environmental Affairs (South Africa) and the National Research Foundation (South Africa) for funding the seabird population surveys in South Africa. Seabird studies on Southeast Farallon Island, Farallon National Wildlife Refuge, California, were conducted and funded by PRBO Conservation Science, in collaboration with the US Fish and Wildlife Service. We thank NOAA-National Marine Fisheries Service, Santa Cruz Laboratory for contributing data on juvenile rockfish abundance. Main support for the long-term studies in the Norwegian Sea was provided by the Norwegian Directorate for Nature Management and the SEAPOP programme. Participation by W.J. Sydeman was supported by NSF award 0929017. The Apex Predator Ecosystem Experiment studies in Alaska were supported by the Exxon Valdez Oil Spill Trustee Council, U.S. Geological Survey and U.S. Fish and Wildlife Service. Any use of trade, product or firm names in this publication is for descriptive purposes only and does not imply endorsement by the U.S. Government. Southern Ocean ecosystem studies were undertaken by the British Antarctic Survey, UK Natural Environment Research Council and we thank all who have contributed as part of the long-term monitoring teams on the Core Programme and for provision of data (for krill particularly Drs J. Watkins and S. Fielding) and the Bird Island Monitoring Programme (for gentoo penguins - particularly P. Trathan). We are also grateful to four anonymous reviewers for suggested improvements to the manuscript. 


\section{Data and codes}

For any questions, remarks, please contact sylvain.bonhommeau@ifremer.fr or philippe.cury@ird.fr

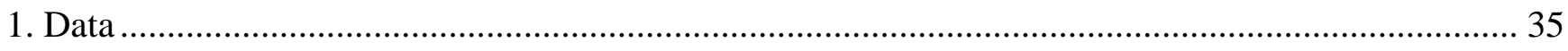

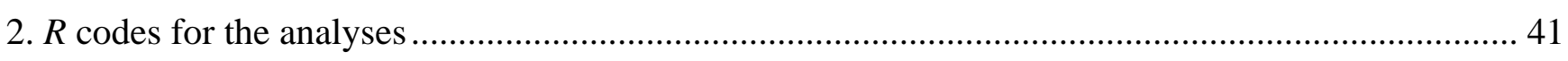

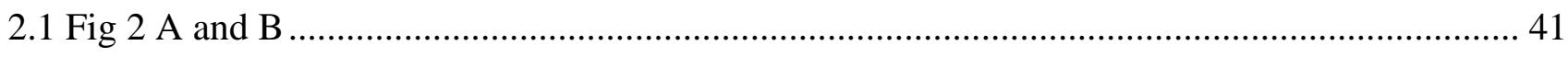

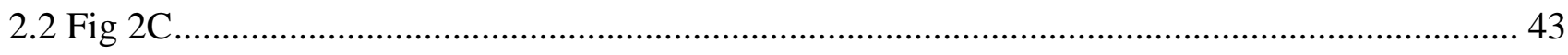

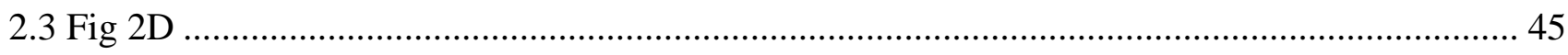

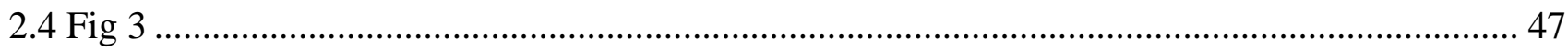

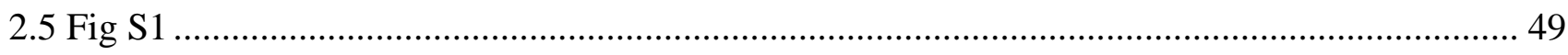

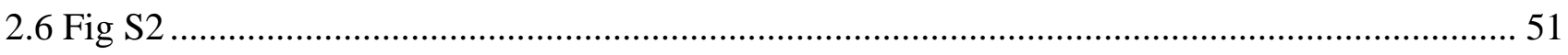

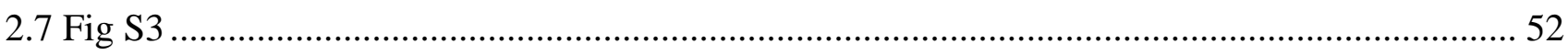

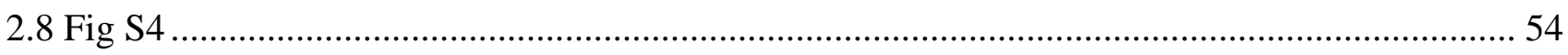

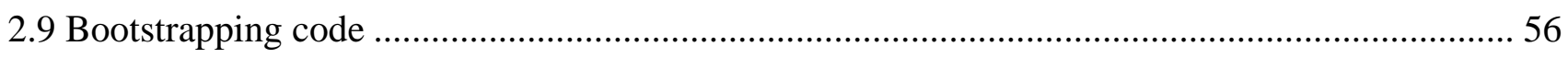




\section{Data}

\section{This is the complete data set that is used throughout the manuscript and in the analyses whose the code is hereinafter. It corresponds to normalized data of the individual data set. See SOM section for further explanations.}

"1983";"0.280251309541968";"-0.8589229749¹02824";"Scotia Sea";"red";"Gentoo penguin";"Krill_biomass";"1" "1986";"-0.228314281424246";"-0.010830717337042";"Scotia Sea";"red";"Gentoo penguin";"Krill_biomass";"1"

"1990";"-0.306555141572894";"0.712943741229647";"Scotia Sea";"red";"Gentoo penguin";"Krill_biomass";"1"

"1991";"-1.67577019417424";"-1.11038397742372";"Scotia Sea";"red";"Gentoo penguin";"Krill_biomass";"1"

"1992";"0.749696470433857";"3.06179670110645";"Scotia Sea";"red";"Gentoo penguin";"Krill_biomass";"1"

"1993";"1.41474378169737";"1.68959190457858";"Scotia Sea";"red";"Gentoo penguin";"Krill_biomass";"1"

"1994";"-1.55840890395127";"-1.05999759676878";"Scotia Sea";"red";"Gentoo penguin";"Krill_biomass";"1"

"1996";"1.37562335162304";"-0.151630042718591";"Scotia Sea";"red";"Gentoo penguin";"Krill_biomass";"1"

"1997";"0.241130879467643";"-0.351762863076979";"Scotia Sea";"red";"Gentoo penguin";"Krill_biomass";"1"

"1998";"-1.7125433984441";"-0.462424540216323";"Scotia Sea";"red";"Gentoo penguin";"Krill_biomass";"1"

"1999";"0.632335180210885";"-0.632419712332507";"Scotia Sea";"red";"Gentoo penguin";"Krill_biomass";"1"

"2000";"0.084649159170347";"-0.792525968619218";"Scotia Sea";"red";"Gentoo penguin";"Krill_biomass";"1"

"2001";"1.33650292154872";"0.137973920858842";"Scotia Sea";"red";"Gentoo penguin";"Krill_biomass";"1"

"2002";"0.358492169690616";"0.39320212941001";"Scotia Sea";"red";"Gentoo penguin";"Krill_biomass";"1"

"2003";"0.084649159170347";"0.303730986190966";"Scotia Sea";"red";"Gentoo penguin";"Krill_biomass";"1"

"2004";"-0.384796001721542";"-0.88811882163746";"Scotia Sea";"red";"Gentoo penguin";"Krill_biomass";"1"

"2004";"-0.697759442316135";"0.100772761309871";"Scotia Sea";"red";"Gentoo penguin";"Krill_biomass";"1"

"2005";"0.984419050879801";"1.05623039073851";"Scotia Sea";"red";"Gentoo penguin";"Krill_biomass";"1"

"2006";"0.475853459913588";"-0.162931660809417";"Scotia Sea";"red";"Gentoo penguin";"Krill_biomass";"1"

"2007";"0.241130879467643";"-0.26605892588821";"Scotia Sea";"red";"Gentoo penguin";"Krill_biomass";"1"

"2009";"-1.6953304092114";"-0.708234733691802";"Scotia Sea";"red";"Gentoo penguin";"Krill_biomass";"1"

"1988";"-0.0162950440570015";"0.067756264519449";"Benguela current";"dark blue";"Cape Gannet";"Sardine_anchovy_w_agulhas";"2"

"1989";"0.320278750186169";"-0.787607346275904";"Benguela current";"dark blue";"Cape Gannet";"Sardine_anchovy_w_agulhas";"2"

"1990";"-0.22384888384029";"-0.938630843735581";"Benguela current";"dark blue";"Cape Gannet";"Sardine_anchovy_w_agulhas";"2"

"1991";"0.469325719934428";"-0.59016878480981";"Benguela current";"dark blue";"Cape Gannet";"Sardine_anchovy_w_agulhas";"2"

"1992";"-0.179064337755176";"-0.0946940359554461";"Benguela current";"dark blue";"Cape Gannet";"Sardine_anchovy_w_agulhas";"2"

"1993";"0.521713066386767";"-0.53866651785871";"Benguela current";"dark blue";"Cape Gannet";"Sardine_anchovy_w_agulhas";"2"

"1994";"-0.0222858399434764";"-0.806992425589805";"Benguela current";"dark blue";"Cape Gannet";"Sardine_anchovy_w_agulhas";"2"

"1995";"0.983584999462725";"-0.645544482286526";"Benguela current";"dark blue";"Cape Gannet";"Sardine_anchovy_w_agulhas";"2"

"1996";"-1.01450010509047";"-1.30921006701159";"Benguela current";"dark blue";"Cape Gannet";"Sardine_anchovy_w_agulhas";"2"

"1997";"0.366097319964825";"-0.0238319774839407";"Benguela current";"dark blue";"Cape Gannet";"Sardine_anchovy_w_agulhas";"2"

"1998";"2.50024338495264";"-0.0888511417239218";"Benguela current";"dark blue";"Cape Gannet";"Sardine_anchovy_w_agulhas";"2"

"1999";"1.38609576528954";"0.107135492334525";"Benguela current";"dark blue";"Cape Gannet";"Sardine_anchovy_w_agulhas";"2"

"2000";"0.197784205988494";"1.61349740228625";"Benguela current";"dark blue";"Cape Gannet";"Sardine_anchovy_w_agulhas";"2"

"2001";"-0.105113128461964";"1.96106001919003";"Benguela current";"dark blue";"Cape Gannet";"Sardine_anchovy_w_agulhas";"2"

"2002";"0.320278750186169";"2.24331799082894";"Benguela current";"dark blue";"Cape Gannet";"Sardine_anchovy_w_agulhas";"2"

"2003";"0.24286677751024";"1.41596958070375";"Benguela current";"dark blue";"Cape Gannet";"Sardine_anchovy_w_agulhas";"2"

"2004";"0.252963991337535";"-0.405188990737276";"Benguela current";"dark blue";"Cape Gannet";"Sardine_anchovy_w_agulhas";"2"

"2005";"-1.9802031334659";"-0.75018769096386";"Benguela current";"dark blue";"Cape Gannet";"Sardine_anchovy_w_agulhas";"2"

"2006";"-1.91793698153091";"-0.205042685831706";"Benguela current";"dark blue";"Cape Gannet";"Sardine_anchovy_w_agulhas";"2"

"2007";"-0.145314998516884";"-0.505282722966904";"Benguela current";"dark blue";"Cape Gannet";"Sardine_anchovy_w_agulhas";"2"

"2008";"-0.655785253119025";"-0.723790345575037";"Benguela current";"dark blue";"Cape Gannet";"Sardine_anchovy_w_agulhas";"2"

"2009";"-1.30088502541844";"1.00495330894308";"Benguela current";"dark blue";"Cape Gannet";"Sardine_anchovy_w_agulhas";"2"

"2010";NA;NA;"Benguela current";"dark blue";"Cape Gannet";"Sardine_anchovy_w_agulhas";"2"

"1988";NA;NA;"Benguela current";"dark blue";"Cape Gannet";"Sardine_anchovy_w_agulhas.1";"3"

"1989";NA;NA;"Benguela current";"dark blue";"Cape Gannet";"Sardine_anchovy_w_agulhas.1";"3"

"1990";NA;NA;"Benguela current";"dark blue";"Cape Gannet";"Sardine_anchovy_w_agulhas.1";"3"

"1991";"0.0801870312027968";"-0.653409844315544";"Benguela current";"dark blue";"Cape Gannet";"Sardine_anchovy_w_agulhas.1";"3"

"1992";"0.750302221254451";"-0.175522787716621";"Benguela current";"dark blue";"Cape Gannet";"Sardine_anchovy_w_agulhas.1";"3"

"1993";"0.057237880858562";"-0.603735735153893";"Benguela current";"dark blue";"Cape Gannet";"Sardine_anchovy_w_agulhas.1";"3"

"1994";"2.09971226149545";"-0.862536972858416";"Benguela current";"dark blue";"Cape Gannet";"Sardine_anchovy_w_agulhas.1";"3"2

"1995";"-0.213562093203408";"-0.706819890206779";"Benguela current";"dark blue";"Cape Gannet";"Sardine_anchovy_w_agulhas.1";"3"

"1996";"-1.72361618585405";"-1.34692757194756";"Benguela current";"dark blue";"Cape Gannet";"Sardine_anchovy_w_agulhas.1";"3"

"1997";"0.915536103732941";"-0.107176094720077";"Benguela current";"dark blue";"Cape Gannet";"Sardine_anchovy_w_agulhas.1";"3"

"1998";"0.667685280015206";"-0.169887296639067";"Benguela current";"dark blue";"Cape Gannet";"Sardine_anchovy_w_agulhas.1";"3"

"1999";"0.0847768612716437";"0.0191424690543027";"Benguela current";"dark blue";"Cape Gannet";"Sardine_anchovy_w_agulhas.1";"3"

"2000";"-0.112585831688775";"1.47203358204047";"Benguela current";"dark blue";"Cape Gannet";"Sardine_anchovy_w_agulhas.1";"3"

"2001";NA;"1.80725889142307";"Benguela current";"dark blue";"Cape Gannet";"Sardine_anchovy_w_agulhas.1";"3"

"2002";"-0.337487505062276";"2.07949765148095";"Benguela current";"dark blue";"Cape Gannet";"Sardine_anchovy_w_agulhas.1";"3"

"2003";"0.268370064025521";"1.28151733581255";"Benguela current";"dark blue";"Cape Gannet";"Sardine_anchovy_w_agulhas.1";"3"

"2004";"0.484092077261328";"-0.474996212694568";"Benguela current";"dark blue";"Cape Gannet";"Sardine_anchovy_w_agulhas.1";"3"

"2005";"-2.40750086611225";"-0.807748615845181";"Benguela current";"dark blue";"Cape Gannet";"Sardine_anchovy_w_agulhas.1";"3"

"2006";NA;"-0.281954430521754";"Benguela current";"dark blue";"Cape Gannet";"Sardine anchovy_w_agulhas.1";"3"

"2007";"0.268370064025521";"-0.571536953044743";"Benguela current";"dark blue";"Cape Gannet";"Sardine_anchovy_w_agulhas.1";"3"

"2008";"-0.337487505062276";"-0.782288287707253";"Benguela current";"dark blue";"Cape Gannet";"Sardine_anchovy_w_agulhas.1";"3"

"2009";"-0.544029858160388";"0.885090763560116";"Benguela current";"dark blue";"Cape Gannet";"Sardine_anchovy_w_agulhas.1";"3"

"2010";NA;NA;"Benguela current";"dark blue";"Cape Gannet";"Sardine_anchovy_w_agulhas.1";"3"

"1988";"-1.06896653834591";"-0.820852219127501";"Benguela current";"dark blue";"African penguin";"Sardine_anchovy_w_agulhas.2";"4"

"1989";"-1.57511885781088";"-0.865546633551083";"Benguela current";"dark blue";"African penguin";"Sardine_anchovy_w_agulhas.2";"4" 
"1990";"-0.14242700193387";"-0.147620606589597";"Benguela current";"dark blue";"African penguin";"Sardine_anchovy_w_agulhas.2";"4" "1991";"-0.149713321225595";"-0.295780830781159";"Benguela current";"dark blue";"African penguin";"Sardine_anchovy_w_agulhas.2";"4" "1992";"-0.438737308927713";"-0.598435920578648";"Benguela current";"dark blue";"African penguin";"Sardine_anchovy_w_agulhas.2";"4" "1993";"-0.908228977733245";"-0.707884447237973";"Benguela current";"dark blue";"African penguin";"Sardine_anchovy_w_agulhas.2";"4" "1994";"-1.23940558482516";"-0.718794107451603";"Benguela current";"dark blue";"African penguin";"Sardine_anchovy_w_agulhas.2";"4" "1995";"0.18772121041361";"-0.923262255326418";"Benguela current";"dark blue";"African penguin";"Sardine_anchovy_w_agulhas.2";"4" "1996";"1.83616117588828";"-0.396431244364975";"Benguela current";"dark blue";"African penguin";"Sardine_anchovy_w_agulhas.2";"4" "1997";"0.679896349642969";"-0.201465058611709";"Benguela current";"dark blue";"African penguin";"Sardine_anchovy_w_agulhas.2";"4" "1998";"-0.0979804560425793";"0.0568475412852183";"Benguela current";"dark blue";"African penguin";"Sardine_anchovy_w_agulhas.2";"4" "1999";NA;NA;"Benguela current";"dark blue";"African penguin";"Sardine_anchovy_w_agulhas.2";"4"

"2000";"1.16908282186935";"2.43656116594873";"Benguela current";"dark blue";"African penguin";"Sardine_anchovy_w_agulhas.2";"4" "2001";"1.4884940722043";"1.58138457500932";"Benguela current";"dark blue";"African penguin";"Sardine_anchovy_w_agulhas.2";"4" "2002";"-0.248252111799936";"1.19989839205527";"Benguela current";"dark blue";"African penguin";"Sardine_anchovy_w_agulhas.2";"4" "2003";"0.507474528626371";"0.401381649322127";"Benguela current";"dark blue";"African penguin";"Sardine_anchovy_w_agulhas.2";"4" "2004";NA;NA;"Benguela current";"dark blue";"African penguin";"Sardine_anchovy_w_agulhas.2";"4" "2005";NA;NA;"Benguela current";"dark blue";"African penguin";"Sardine_anchovy_w_agulhas.2";"4" "2006";NA;NA;"Benguela current";"dark blue";"African penguin";"Sardine_anchovy_w_agulhas.2";"4" "2007";NA;NA;"Benguela current";"dark blue";"African penguin";"Sardine_anchovy_w_agulhas.2";"4" "2008";NA;NA;"Benguela current";"dark blue";"African penguin";"Sardine_anchovy_w_agulhas.2";"4" "2009";NA;NA;"Benguela current";"dark blue";"African penguin";"Sardine_anchovy_w_agulhas.2";"4" "2010";NA;NA;"Benguela current";"dark blue";"African penguin";"Sardine_anchovy_w_agulhas.2";"4" "1976";"1.13139809387772";"0.702633492405968";"North Sea";"dark green";"Arctic skua";"Sandeel";"5" "1977";"1.13139809387772";"1.11847850141808";"North Sea";"dark green";"Arctic skua";"Sandeel";"5" "1978";"1.13139809387772";"0.774578286453312";"North Sea";"dark green";"Arctic skua";"Sandeel";"5" "1979";"1.13139809387772";"0.718231779662386";"North Sea";"dark green";"Arctic skua";"Sandeel";"5" "1980";"1.13139809387772";"1.22041054153131";"North Sea";"dark green";"Arctic skua";"Sandeel";"5" "1981";"1.13139809387772";"1.91714770371289";"North Sea";"dark green";"Arctic skua";"Sandeel";"5" "1982";"0.670856128934279";"1.83884881104598";"North Sea";"dark green";"Arctic skua";"Sandeel";"5" "1983";"0.670856128934279";"1.17892442667324";"North Sea";"dark green";"Arctic skua";"Sandeel";"5" "1984";"0.210314163990838";"0.52143919628673";"North Sea";"dark green";"Arctic skua";"Sandeel";"5"

"1985";"0.210314163990838";"0.16034192086449";"North Sea";"dark green";"Arctic skua";"Sandeel";"5"

"1986";"-0.181146506211087";"-0.0708652805184287";"North Sea";"dark green";"Arctic skua";"Sandeel";"5"

"1987";"-1.14828463259231";"-0.666305812448728";"North Sea";"dark green";"Arctic skua";"Sandeel";"5"

"1988";"-1.28644722207534";"-0.891896810535643";"North Sea";"dark green";"Arctic skua";"Sandeel";"5"

"1989";"-1.33250141856969";"-0.951256389897782";"North Sea";"dark green";"Arctic skua";"Sandeel";"5"

"1990";"-1.42460981155838";"-1.0907186060511";"North Sea";"dark green";"Arctic skua";"Sandeel";"5"

"1991";"0.371503851721042";"1.10849641745767";"North Sea";"dark green";"Arctic skua";"Sandeel";"5"

"1992";"0.901127111405999";"0.196724259734585";"North Sea";"dark green";"Arctic skua";"Sandeel";"5"

"1993";"0.901127111405999";"0.851729341950236";"North Sea";"dark green";"Arctic skua";"Sandeel";"5"

"1994";"0.785991620170139";"0.163170519604813";"North Sea";"dark green";"Arctic skua";"Sandeel";"5"

"1995";"0.440585146462558";"-0.427330213076082";"North Sea";"dark green";"Arctic skua";"Sandeel";"5"

"1996";"0.325449655226698";"-0.506018550497095";"North Sea";"dark green";"Arctic skua";"Sandeel";"5"

"1997";"-0.480498783424323";"0.533634966217833";"North Sea";"dark green";"Arctic skua";"Sandeel";"5"

"1998";"0.440585146462558";"-0.191306194997687";"North Sea";"dark green";"Arctic skua";"Sandeel";"5"

"1999";"-0.250227800952603";"-0.894889386014535";"North Sea";"dark green";"Arctic skua";"Sandeel";"5" "2000";"0.210314163990838";"-1.10057770745758";"North Sea";"dark green";"Arctic skua";"Sandeel";"5" "2001";"-0.480498783424323";"-1.04994988942427";"North Sea";"dark green";"Arctic skua";"Sandeel";"5" "2002";"-1.47066400805272";"-1.22538450260125";"North Sea";"dark green";"Arctic skua";"Sandeel";"5" "2003";"-1.63185369578293";"-1.30741386607062";"North Sea";"dark green";"Arctic skua";"Sandeel";"5" "2004";"-1.63185369578293";"-1.33844646384489";"North Sea";"dark green";"Arctic skua";"Sandeel";"5" "2005";"-1.60882659753575";"-1.29243049158384";"North Sea";"dark green";"Arctic skua";"Sandeel";"5" "1976";"1.54197909199883";"0.702633492405968";"North Sea";"dark green";"Great skua";"Sandeel.1";"6" "1977";"0.976461087598284";"1.11847850141808";"North Sea";"dark green";"Great skua";"Sandeel.1";"6" "1978";"0.976461087598284";"0.774578286453312";"North Sea";"dark green";"Great skua";"Sandeel.1";"6" "1979";"0.410943083197733";"0.718231779662386";"North Sea";"dark green";"Great skua";"Sandeel.1";"6" "1980";"0.128184080997458";"1.22041054153131";"North Sea";"dark green";"Great skua";"Sandeel.1";"6" "1981";"0.410943083197733";"1.91714770371289";"North Sea";"dark green";"Great skua";"Sandeel.1";"6" "1982";"0.693702085398008";"1.83884881104598";"North Sea";"dark green";"Great skua";"Sandeel.1";"6" "1983";"0.693702085398008";"1.17892442667324";"North Sea";"dark green";"Great skua";"Sandeel.1";"6" "1984";"0.693702085398008";"0.52143919628673";"North Sea";"dark green";"Great skua";"Sandeel.1";"6" "1985";"0.693702085398008";"0.16034192086449";"North Sea";"dark green";"Great skua";"Sandeel.1";"6" "1986";"0.693702085398008";"-0.0708652805184287";"North Sea";"dark green";"Great skua";"Sandeel.1";"6"

"1987";"-0.154574921202817";"-0.666305812448728";"North Sea";"dark green";"Great skua";"Sandeel.1";"6"

"1988";"-1.85112893440447";"-0.891896810535643";"North Sea";"dark green";"Great skua";"Sandeel.1";"6"

"1989";"-1.56836993220419";"-0.951256389897782";"North Sea";"dark green";"Great skua";"Sandeel.1";"6"

"1990";"-1.00285192780364";"-1.0907186060511";"North Sea";"dark green";"Great skua";"Sandeel.1";"6"

"1991";"-0.437333923403092";"1.10849641745767";"North Sea";"dark green";"Great skua";"Sandeel.1";"6"

"1992";"-1.00285192780364";"0.196724259734585";"North Sea";"dark green";"Great skua";"Sandeel.1";"6"

"1993";"-0.720092925603367";"0.851729341950236";"North Sea";"dark green";"Great skua";"Sandeel.1";"6"

"1994";"0.128184080997458";"0.163170519604813";"North Sea";"dark green";"Great skua";"Sandeel.1";"6"

"1995";"0.976461087598284";"-0.427330213076082";"North Sea";"dark green";"Great skua";"Sandeel.1";"6"

"1996";"0.976461087598284";"-0.506018550497095";"North Sea";"dark green";"Great skua";"Sandeel.1";"6"

"1997";"0.693702085398008";"0.533634966217833";"North Sea";"dark green";"Great skua";"Sandeel.1";"6"

"1998";"0.693702085398008";"-0.191306194997687";"North Sea";"dark green";"Great skua";"Sandeel.1";"6"

"1999";"0.976461087598284";"-0.894889386014535";"North Sea";"dark green";"Great skua";"Sandeel.1";"6"

"2000";"0.128184080997458";"-1.10057770745758";"North Sea";"dark green";"Great skua";"Sandeel.1";"6"

"2001";"-0.154574921202817";"-1.04994988942427";"North Sea";"dark green";"Great skua";"Sandeel.1";"6"

"2002";"-0.437333923403092";"-1.22538450260125";"North Sea";"dark green";"Great skua";"Sandeel.1";"6" "2003";"-1.85112893440447";"-1.30741386607062";"North Sea";"dark green";"Great skua";"Sandeel.1";"6" "2004";"-2.07733613616469";"-1.33844646384489";"North Sea";"dark green";"Great skua";"Sandeel.1";"6" "2005";"-1.22905912956386";"-1.29243049158384";"North Sea";"dark green";"Great skua";"Sandeel.1";"6" "1976";"1.6733646776366";"0.702633492405968";"North Sea";"dark green";"Arctic tern";"Sandeel.2";"7"

"1977";"-0.215729941019352";"1.11847850141808";"North Sea";"dark green";"Arctic tern";"Sandeel.2";"7" "1978";"-0.530579044128678";"0.774578286453312";"North Sea";"dark green";"Arctic tern";"Sandeel.2";"7"

"1979";"1.56841497660016";"0.718231779662386";"North Sea";"dark green";"Arctic tern";"Sandeel.2";"7"

"1980";"0.938716770381507";"1.22041054153131";"North Sea";"dark green";"Arctic tern";"Sandeel.2";"7" 
"1981";"1.95323054706711";"1.91714770371289";"North Sea";"dark green";"Arctic tern";"Sandeel.2";"7" "1982";"2.26807965017644";"1.83884881104598";"North Sea";"dark green";"Arctic tern";"Sandeel.2";"7" "1983";"0.938716770381507";"1.17892442667324";"North Sea";"dark green";"Arctic tern";"Sandeel.2";"7" "1984";"-0.810444913559189";"0.52143919628673";"North Sea";"dark green";"Arctic tern";"Sandeel.2";"7" "1985";"-0.810444913559189";"0.16034192086449";"North Sea";"dark green";"Arctic tern";"Sandeel.2";"7"

"1986";"-0.810444913559189";"-0.0708652805184287";"North Sea";"dark green";"Arctic tern";"Sandeel.2";"7" "1987";"-0.810444913559189";"-0.666305812448728";"North Sea";"dark green";"Arctic tern";"Sandeel.2";"7"

"1988";"-0.810444913559189";"-0.891896810535643";"North Sea";"dark green";"Arctic tern";"Sandeel.2";"7" "1989";"-0.810444913559189";"-0.951256389897782";"North Sea";"dark green";"Arctic tern";"Sandeel.2";"7" "1990";"-0.810444913559189";"-1.0907186060511";"North Sea";"dark green";"Arctic tern";"Sandeel.2";"7" "1991";"0.239052096805228";"1.10849641745767";"North Sea";"dark green";"Arctic tern";"Sandeel.2";"7" "1992";"0.588884433593368";"0.196724259734585";"North Sea";"dark green";"Arctic tern";"Sandeel.2";"7" "1993";"1.74333114499423";"0.851729341950236";"North Sea";"dark green";"Arctic tern";"Sandeel.2";"7" "1994";"0.0641359284111589";"0.163170519604813";"North Sea";"dark green";"Arctic tern";"Sandeel.2";"7" "1995";"0.413968265199298";"-0.427330213076082";"North Sea";"dark green";"Arctic tern";"Sandeel.2";"7" "1996";"-0.740478446201561";"-0.506018550497095";"North Sea";"dark green";"Arctic tern";"Sandeel.2";"7" "1997";"-0.63552874516512";"0.533634966217833";"North Sea";"dark green";"Arctic tern";"Sandeel.2";"7" "1998";"-0.46061257677105";"-0.191306194997687";"North Sea";"dark green";"Arctic tern";"Sandeel.2";"7" "1999";"0.0641359284111589";"-0.894889386014535";"North Sea";"dark green";"Arctic tern";"Sandeel.2";"7" "2000";"-0.145763473661725";"-1.10057770745758";"North Sea";"dark green";"Arctic tern";"Sandeel.2";"7" "2001";"-0.810444913559189";"-1.04994988942427";"North Sea";"dark green";"Arctic tern";"Sandeel.2";"7" "2002";"-0.810444913559189";"-1.22538450260125";"North Sea";"dark green";"Arctic tern";"Sandeel.2";"7" "2003";"-0.810444913559189";"-1.30741386607062";"North Sea";"dark green";"Arctic tern";"Sandeel.2";"7" "2004";"-0.810444913559189";"-1.33844646384489";"North Sea";"dark green";"Arctic tern";"Sandeel.2";"7" "2005";"-0.810444913559189";"-1.29243049158384";"North Sea";"dark green";"Arctic tern";"Sandeel.2";"7" "1976";"1.49372038447245";"0.702633492405968";"North Sea";"dark green";"Kittiwake";"Sandeel.3";"8" "1977";"1.34283953755604";"1.11847850141808";"North Sea";"dark green";"Kittiwake";"Sandeel.3";"8" "1978";"1.27817631744901";"0.774578286453312";"North Sea";"dark green";"Kittiwake";"Sandeel.3";"8" "1979";"0.86864259010447";"0.718231779662386";"North Sea";"dark green";"Kittiwake";"Sandeel.3";"8" "1980";"0.933305810211503":"1.22041054153131";"North Sea";"dark green";"Kittiwake";"Sandeel.3";"8" "1981";"0.566880896271652";"1.91714770371289";"North Sea";"dark green";"Kittiwake";"Sandeel.3";"8" "1982";"0.976414623616191";"1.83884881104598";"North Sea";"dark green";"Kittiwake";"Sandeel.3";"8" "1983";"0.459108862759931";"1.17892442667324";"North Sea";"dark green";"Kittiwake";"Sandeel.3";"8" "1984";"0.459108862759931";"0.52143919628673";"North Sea";"dark green";"Kittiwake";"Sandeel.3";"8" "1985";"0.459108862759931";"0.16034192086449";"North Sea";"dark green";"Kittiwake";"Sandeel.3";"8"

"1986";"0.200455982331801";"-0.0708652805184287";"North Sea";"dark green";"Kittiwake";"Sandeel.3";"8" "1987";"-1.04969960640416";"-0.666305812448728";"North Sea";"dark green";"Kittiwake";"Sandeel.3";"8" "1988";"-1.69633180747449";"-0.891896810535643";"North Sea";"dark green";"Kittiwake";"Sandeel.3";"8"

"1989";"-1.02814519970182";"-0.951256389897782";"North Sea";"dark green";"Kittiwake";"Sandeel.3";"8"

"1990";"-0.618611472357278";"-1.0907186060511";"North Sea";"dark green";"Kittiwake";"Sandeel.3";"8"

"1991";"-0.0797513047986735";"1.10849641745767";"North Sea";"dark green";"Kittiwake";"Sandeel.3";"8" "1992";"1.29973072415135";"0.196724259734585";"North Sea";"dark green";"Kittiwake";"Sandeel.3";"8"

"1993";"0.286673609141178";"0.851729341950236";"North Sea";"dark green";"Kittiwake";"Sandeel.3";"8" "1994";"0.60998970967634";"0.163170519604813";"North Sea";"dark green";"Kittiwake";"Sandeel.3";"8"

"1995";"0.286673609141178";"-0.427330213076082";"North Sea";"dark green";"Kittiwake";"Sandeel.3";"8"

"1996";"-0.144414524905706";"-0.506018550497095";"North Sea";"dark green";"Kittiwake";"Sandeel.3";"8" "1997";"0.60998970967634";"0.533634966217833";"North Sea";"dark green";"Kittiwake";"Sandeel.3";"8"

"1998";"-0.83415553938072";"-0.191306194997687";"North Sea";"dark green";"Kittiwake";"Sandeel.3";"8" "1999";"0.437554456057587":"-0.894889386014535":"North Sea";"dark green";"Kittiwake";"Sandeel.3";"8" "2000";"0.178901575629457";"-1.10057770745758";"North Sea";"dark green";"Kittiwake";"Sandeel.3";"8" "2001";"-1.69633180747449";"-1.04994988942427";"North Sea";"dark green";"Kittiwake";"Sandeel.3";"8" "2002";"-1.2652436734276";"-1.22538450260125";"North Sea";"dark green";"Kittiwake";"Sandeel.3";"8" "2003";"-1.58855977396277";"-1.30741386607062";"North Sea";"dark green";"Kittiwake";"Sandeel.3";"8" "2004";"-1.48078774045104";"-1.33844646384489";"North Sea";"dark green";"Kittiwake";"Sandeel.3";"8" "2005";"-1.2652436734276";"-1.29243049158384";"North Sea";"dark green";"Kittiwake";"Sandeel.3";"8" "1986";"1.46745051559216";"0.580455962252321";"North Sea";"dark green";"Fulmar";"Shetland_sandeel_TSB";"9" "1987";"1.24398089392838";"-0.211020404736805";"North Sea";"dark green";"Fulmar";"Shetland_sandeel TSB";"9" "1988";"0.126632785609476";"-0.510882328836024";"North Sea";"dark green";"Fulmar";"Shetland_sandeel_TSB";"9" "1989";"1.46745051559216";"-0.589784757710396";"North Sea";"dark green";"Fulmar";"Shetland_sandeel_TSB";"9" "1990";"-1.13969507048528";"-0.775161873063029";"North Sea";"dark green";"Fulmar";"Shetland_sandeel_TSB";"9" "1991";"0.350102407273257";"2.14809682985371";"North Sea";"dark green";"Fulmar";"Shetland_sandeel_TSB";"9" "1992";"1.0205112722646";"0.936143534405265";"North Sea";"dark green";"Fulmar";"Shetland_sandeel_TSB";"9" "1993";"0.797041650600818";"1.80679478340714";"North Sea";"dark green";"Fulmar";"Shetland_sandeel_TSB";"9" "1994";"1.09500114615253";"0.891542955652728";"North Sea";"dark green";"Fulmar";"Shetland_sandeel_TSB";"9" "1995";"0.201122659497403";"0.106632709298521";"North Sea";"dark green";"Fulmar";"Shetland_sandeel_TSB";"9" "1996";"0.722551776712891";"0.00203794947507018";"North Sea";"dark green";"Fulmar";"Shetland_sandeel_TSB";"9" "1997";"-0.0223469621663781";"1.38397475795777";"North Sea";"dark green";"Fulmar";"Shetland_sandeel_TSB";"9" "1998";"-1.13969507048528";"0.420362498141199";"North Sea";"dark green";"Fulmar";"Shetland_sandeel TSB";"9"

"1999";"-0.618265953269794";"-0.514860144656348";"North Sea";"dark green";"Fulmar";"Shetland_sandeel_TSB";"9" "2000";"-0.46928620549394";"-0.788266869019028";"North Sea";"dark green";"Fulmar";"Shetland_sandeel_TSB";"9" "2001";"-0.767245701045648";"-0.720970943839574";"North Sea";"dark green";"Fulmar";"Shetland_sandeel_TSB";"9" "2002";"-0.46928620549394";"-0.954163584977609";"North Sea";"dark green";"Fulmar";"Shetland_sandeel_TSB";"9" "2003";"-0.692755827157721";"-1.06319933095663";"North Sea";"dark green";"Fulmar";"Shetland_sandeel_TSB";"9" "2004";"-1.7356140615887";"-1.10444873610711";"North Sea";"dark green";"Fulmar";"Shetland_sandeel_TSB";"9" "2005";"-1.43765456603699";"-1.04328300654117";"North Sea";"dark green";"Fulmar";"Shetland_sandeel_TSB";"9" "1986";"1.02226112743224";"0.580455962252321";"North Sea";"dark green";"Shag";"Shetland_sandeel_TSB.1";"10" "1987";"0.119409419443652";"-0.211020404736805";"North Sea";"dark green";"Shag";"Shetland_sandeel_TSB.1";"10" "1988";"0.556273149115551";"-0.510882328836024";"North Sea";"dark green";"Shag";"Shetland_sandeel_TSB.1";"10" "1989";"-0.666945293965766";"-0.589784757710396";"North Sea";"dark green";"Shag";"Shetland_sandeel_TSB.1";"10" "1990";"-1.59892125059915";"-0.775161873063029";"North Sea";"dark green";"Shag";"Shetland_sandeel_TSB.1";"10" "1991";"-0.463075553452213";"2.14809682985371";"North Sea";"dark green";"Shag";"Shetland_sandeel_TSB.1";"10" "1992";"0.760142889629104";"0.936143534405265";"North Sea";"dark green";"Shag";"Shetland_sandeel_TSB.1";"10" "1993";"1.2261308679458";"1.80679478340714";"North Sea";"dark green";"Shag";"Shetland_sandeel_TSB.1";"10" "1994";"1.05138537607704";"0.891542955652728";"North Sea";"dark green";"Shag";"Shetland_sandeel_TSB.1";"10"

"1995";"0.498024651825965";"0.106632709298521";"North Sea";"dark green";"Shag";"Shetland sandeel_TSB.1";"10" "1996";"0.672770143694724";"0.00203794947507018";"North Sea";"dark green";"Shag";"Shetland_sandeel_TSB.1";"10" 
"1997";"0.556273149115551";"1.38397475795777";"North Sea";"dark green";"Shag";"Shetland_sandeel_TSB.1";"10" "1998";"0.789267138273897":"0.420362498141199";"North Sea";"dark green";"Shag";"Shetland sandeel_TSB.1";"10" "1999";"-0.230081564293867";"-0.514860144656348";"North Sea";"dark green";"Shag";"Shetland_sandeel_TSB.1";"10" "2000";"-0.34657855887304";"-0.788266869019028";"North Sea";"dark green";"Shag";"Shetland_sandeel_TSB.1";"10" "2001";"0.323279159957205";"-0.720970943839574";"North Sea";"dark green";"Shag";"Shetland_sandeel_TSB.1";"10" "2002";"0.672770143694724";"-0.954163584977609";"North Sea";"dark green";"Shag";"Shetland_sandeel_TSB.1";"10" "2003";"-0.958187780413698";"-1.06319933095663";"North Sea";"dark green";"Shag";"Shetland_sandeel_TSB.1";"10" "2004";"-2.06490922891584";"-1.10444873610711";"North Sea";"dark green";"Shag";"Shetland_sandeel_TSB.1";"10" "2005";"-1.91928798569188";"-1.04328300654117";"North Sea";"dark green";"Shag";"Shetland_sandeel_TSB.1";"10" "1986";NA;"0.580455962252321";"North Sea";"dark green";"Common murre";"Shetland_sandeel_TSB.2";"11" "1987";NA;"-0.211020404736805";"North Sea";"dark green";"Common murre";"Shetland_sandeel_TSB.2";"11" "1988";NA;"-0.510882328836024";"North Sea";"dark green";"Common murre";"Shetland_sandeel_TSB.2";"11" "1989";"0.403094486571605";"-0.589784757710396";"North Sea";"dark green";"Common murre";"Shetland_sandeel_TSB.2";"11" "1990";"-0.199934865339516";"-0.775161873063029";"North Sea";"dark green";"Common murre";"Shetland_sandeel_TSB.2";"11" "1991";"0.512736186919082";"2.14809682985371";"North Sea";"dark green";"Common murre";"Shetland_sandeel_TSB.2";"11" "1992";"0.732019587614035";"0.936143534405265";"North Sea";"dark green";"Common murre";"Shetland_sandeel_TSB.2";"11" "1993";"0.512736186919082";"1.80679478340714";"North Sea";"dark green";"Common murre";"Shetland_sandeel_TSB.2";"11" "1994";"0.732019587614035";"0.891542955652728";"North Sea";"dark green";"Common murre";"Shetland_sandeel_TSB.2";"11" "1995";"0.951302988308989";"0.106632709298521";"North Sea";"dark green";"Common murre";"Shetland_sandeel_TSB.2";"11" "1996";"0.732019587614035";"0.00203794947507018";"North Sea";"dark green";"Common murre";"Shetland_sandeel_TSB.2";"11" "1997";"-0.638501666729423";"1.38397475795777";"North Sea";"dark green";"Common murre";"Shetland_sandeel_TSB.2";"11" "1998";"0.183811085876652";"0.420362498141199";"North Sea";"dark green";"Common murre";"Shetland_sandeel_TSB.2";"11" "1999";"0.293452786224129";"-0.514860144656348";"North Sea";"dark green";"Common murre";"Shetland_sandeel_TSB.2";"11" "2000";"0.457915336745343";"-0.788266869019028";"North Sea";"dark green";"Common murre";"Shetland_sandeel_TSB.2";"11" "2001";"0.238631936050391";"-0.720970943839574";"North Sea";"dark green";"Common murre";"Shetland_sandeel_TSB.2";"11" "2002";"0.128990235702914";"-0.954163584977609";"North Sea";"dark green";"Common murre";"Shetland_sandeel_TSB.2";"11" "2003";"-1.78973952037793";"-1.06319933095663";"North Sea";"dark green";"Common murre";"Shetland_sandeel_TSB.2";"11" "2004";"-2.94097737402643";"-1.10444873610711";"North Sea";"dark green";"Common murre";"Shetland_sandeel_TSB.2";"11" "2005";"-0.309576565686992";"-1.04328300654117";"North Sea";"dark green";"Common murre";"Shetland sandeel_TSB.2";"11" "1975";"-1.08207233136939";"-0.863637459808208";"New Zealand";"light blue";"Red-billed gull";"Euphausiid_availability_index";"12" "1976";"1.53134046983291";"0.829248440551124";"New Zealand";"light blue";"Red-billed gull";"Euphausiid_availability_index";"12" "1977";NA;NA;"New Zealand";"light blue";"Red-billed gull";"Euphausiid_availability_index";"12"

"1978";NA;NA;"New Zealand";"light blue";"Red-billed gull";"Euphausiid_availability_index";"12"

"1979";"-0.18016372329872";"-1.14166085359035";"New Zealand";"light blue";"Red-billed gull";"Euphausiid_availability_index";"12" "1980";"0.689862520109505";"-0.536122990693118";"New Zealand";"light blue";"Red-billed gull";"Euphausiid_availability_index";"12"

"1981";"-0.467772186032564";"-0.633649521496278";"New Zealand";"light blue";"Red-billed gull";"Euphausiid_availability_index";"12" "1982";"0.136511240036191";"-0.440052079752692";"New Zealand";"light blue";"Red-billed gull";"Euphausiid_availability_index";"12" "1983";"0.125268627881074";"0.584704303611857";"New Zealand";"light blue";"Red-billed gull";"Euphausiid_availability_index";"12" "1984";"0.556586184288218";"1.25283382060664";"New Zealand";"light blue";"Red-billed gull";"Euphausiid_availability_index";"12" "1985";"0.950215158090891";"-0.604537124241604";"New Zealand";"light blue";"Red-billed gull";"Euphausiid_availability_index";"12" "1986";"-0.279408267485397";"0.474077194044093";"New Zealand";"light blue";"Red-billed gull";"Euphausiid_availability_index";"12" "1987";"-2.26757890046088";"-1.31779085698113";"New Zealand";"light blue";"Red-billed gull";"Euphausiid_availability_index";"12" "1988";"1.39159704261465";"1.83071490611193";"New Zealand";"light blue";"Red-billed gull";"Euphausiid_availability_index";"12" "1989";NA;NA;"New Zealand";"light blue";"Red-billed gull";"Euphausiid_availability index";"12"

"1990";"0.407431627422935";"0.0752373516550498";"New Zealand";"light blue";"Red-billed gull";"Euphausiid_availability_index";"12" "1991";"0.16409023395201";"1.71572093695597";"New Zealand";"light blue";"Red-billed gull";"Euphausiid_availability_index";"12" "1992";"-0.223085422212181";"-0.399294723596147";"New Zealand";"light blue";"Red-billed gull";"Euphausiid_availability_index";"12" "1993";"-1.45282227336924";"-0.825791343377131";"New Zealand";"light blue";"Red-billed gull";"Euphausiid_availability_index";"12" "1999";"0.0971375840311623";"-1.13241563492793";"Gulf of Alaska";"purple";"Common murre";"biom";"13"

"1996";"0.739945320051718";"-0.963564426712114";"Gulf of Alaska";"purple";"Common murre";"biom";"13"

"1998";"-2.40340613320692";"-0.879208915541513";"Gulf of Alaska";"purple";"Common murre";"biom";"13"

"1995";NA;"-0.809915504938595";"Gulf of Alaska";"purple";"Common murre";"biom";"13"

"1997";"0.344221484045017";"-0.652006122232372";"Gulf of Alaska";"purple";"Common murre";"biom";"13"

"1999";"-1.86106569387736";"-0.595143570052439";"Gulf of Alaska";"purple";"Common murre";"biom";"13"

"1996";"0.731871601161869";"-0.578233835711549";"Gulf of Alaska";"purple";"Common murre";"biom";"13"

"1995";"0.675762568704929";"-0.575778246817638";"Gulf of Alaska";"purple";"Common murre";"biom";"13"

"1997";"1.12463482836045";"0.0082548202190456";"Gulf of Alaska";"purple";"Common murre";"biom";"13"

"1996";"0.151936433548272";"0.077299823345721";"Gulf of Alaska";"purple";"Common murre";"biom";"13"

"1999";"0.731871601161869";"0.639392666922326";"Gulf of Alaska";"purple";"Common murre";"biom";"13"

"1998";"0.227283229381896";"0.979407164394076";"Gulf of Alaska";"purple";"Common murre";"biom";"13"

"1998";"-0.109763885692235";"1.11122609725564";"Gulf of Alaska";"purple";"Common murre";"biom";"13"

"1997";"-0.452883116892314";"1.1261760697059";"Gulf of Alaska";"purple";"Common murre";"biom";"13"

"1995";"0.00245417922164557";"2.24450961509144";"Gulf of Alaska";"purple";"Common murre";"biom";"13"

"1999";"-1.13909137948954";"-1.13241563492793";"Gulf of Alaska";"purple";"Kittiwake";"biom.1";"14"

"1996";"-0.974505181213528";"-0.963564426712114";"Gulf of Alaska";"purple";"Kittiwake";"biom.1";"14"

"1998";"-1.13909137948954";"-0.879208915541513";"Gulf of Alaska";"purple";"Kittiwake";"biom.1";"14"

"1995";"-1.07072922395482";"-0.809915504938595";"Gulf of Alaska";"purple";"Kittiwake";"biom.1";"14"

"1997";"-1.07756543932371";"-0.652006122232372";"Gulf of Alaska";"purple";"Kittiwake";"biom.1";"14"

"1999";"1.25260489181053";"-0.595143570052439";"Gulf of Alaska";"purple";"Kittiwake";"biom.1";"14"

"1996";"1.51882923035852";"-0.578233835711549";"Gulf of Alaska";"purple";"Kittiwake";"biom.1";"14"

"1995";"1.14967359010185";"-0.575778246817638";"Gulf of Alaska";"purple";"Kittiwake";"biom.1";"14"

"1997";"0.00529110530615085";"0.0082548202190456";"Gulf of Alaska";"purple";"Kittiwake";"biom.1";"14"

"1996";"0.712297105243756";"0.077299823345721";"Gulf of Alaska";"purple";"Kittiwake";"biom.1";"14"

"1999";"0.522109001665497";"0.639392666922326";"Gulf of Alaska";"purple";"Kittiwake";"biom.1";"14"

"1998";"0.0327007938345597";"0.979407164394076";"Gulf of Alaska";"purple";"Kittiwake";"biom.1";"14"

"1998";"-0.991429123386874";"1.11122609725564";"Gulf of Alaska";"purple";"Kittiwake";"biom.1";"14"

"1997";"1.082868211154";"1.1261760697059";"Gulf of Alaska";"purple";"Kittiwake";"biom.1";"14"

"1995";"0.116037797383154";"2.24450961509144";"Gulf of Alaska";"purple";"Kittiwake";"biom.1";"14"

"1983";"-2.79931247668128";"-1.19781577550151";"California current";"orange";"Common murre";"all_rockfish";"15"

"1984";"0.155898063266828";"1.40305431501046";"California current";"orange";"Common murre";"all_rockfish";"15"

"1985";"0.455702031087651";"1.18479484730945";"California current";"orange";"Common murre";"all_rockfish";"15"

"1986";"0.155898063266828";"0.405794133405867";"California current";"orange";"Common murre";"all_rockfish";"15"

"1987";"0.669847722388238";"1.35483224581023";"California current";"orange";"Common murre";"all_rockfish";"15"

"1988";"0.841164275428708";"1.81481475551235";"California current";"orange";"Common murre";"all_rockfish";"15"

"1989";"0.669847722388238";"0.672670369307095";"California current";"orange";"Common murre";"all_rockfish";"15"

"1990";"0.541360307607885";"-0.0750383703963453";"California current";"orange";"Common murre";"all_rockfish";"15" 
"1991";"0.798335137168591";"0.596888418106746";"California current";"orange";"Common murre";"all_rockfish";"15" "1992":"-2.62799592364081":"-0.684438616599149":"California current";"orange","Common murre","al__rockfish":"15" "1993";"0.241556339787063";"0.947979192108362";"California current";"orange";"Common murre";"all_rockfish";"15" "1994";"0.541360307607885";"-0.898222532900133";"California current";"orange";"Common murre";"all_rockfish";"15" "1995";"0.584189445868003";"-0.567909703098613";"California current";"orange";"Common murre";"all_rockfish";"15" "1996";"-0.358051595854583";"-0.303071621297395";"California current";"orange";"Common murre";"all_rockfish";"15" "1997";"0.241556339787063";"-0.453757246498088";"California current";"orange";"Common murre";"all_rockfish";"15" "1998";"-1.30029263757717";"-1.38966828830239";"California current";"orange";"Common murre";"all_rockfish";"15" "1999";"0.541360307607885";"-0.543923835898503";"California current";"orange";"Common murre";"all_rockfish";"15" "2000";"0.541360307607885";"-0.267973496197233";"California current";"orange";"Common murre";"all_rockfish";"15" "2001";"0.498531169347768";"0.541834467106493";"California current";"orange";"Common murre";"all_rockfish";"15" "2002";"0.327214616307298";"0.972514230008475";"California current";"orange";"Common murre";"all_rockfish";"15" "2003";"0.11306892500671";"0.246002231205132";"California current";"orange";"Common murre";"all_rockfish";"15" "2004";"0.669847722388238";"0.486954283706241";"California current";"orange";"Common murre";"all_rockfish";"15" "2005";"-0.786342978455758";"-1.91453432490481";"California current";"orange";"Common murre";"all_rockfish";"15" "2006";"-1.25746349931705";"-1.35386379810223";"California current";"orange";"Common murre";"all_rockfish";"15" "2007";"0.541360307607885";"-0.9779158789005";"California current";"orange";"Common murre";"all_rockfish";"15" "1983";NA;"-1.19781577550151";"California current";"orange";"Rhinoceros aucklet";"all_rockfish.1";"16" "1984";NA;"1.40305431501046";"California current";"orange";"Rhinoceros aucklet";"all_rockfish.1";"16"

"1985";NA;"1.18479484730945";"California current";"orange";"Rhinoceros aucklet";"all_rockfish.1";"16"

"1986";"0.0523996413850213";"0.405794133405867";"California current";"orange";"Rhinoceros aucklet";"all_rockfish.1";"16"

"1987";"-0.736352855252666";"1.35483224581023";"California current";"orange";;"Rhinoceros aucklet";"all_rockfish.1";"16"

"1988";"2.29731059335382";"1.81481475551235";"California current";"orange";"Rhinoceros aucklet";"all_rockfish.1";"16"

"1989";"1.44788482774401";"0.672670369307095";"California current";"orange";"Rhinoceros aucklet";"all_rockfish.1";"16"

"1990";"-0.918372662169055";"-0.0750383703963453";"California current";"orange";"Rhinoceros aucklet";"all_rockfish.1";"16"

"1991";"-0.0689468965592383";"0.596888418106746";"California current";"orange";"Rhinoceros aucklet";"all_rockfish.1";"16"

"1992";"1.14451848288336";"-0.684438616599149";"California current";"orange";"Rhinoceros aucklet";"all_rockfish.1";"16"

"1993";"-0.554333048336276";"0.947979192108362";"California current";"orange";"Rhinoceros aucklet";"all_rockfish.1";"16"

"1994";"0.416439255217799";"-0.898222532900133";"California current";"orange";"Rhinoceros aucklet";"all_rockfish.1";"16"

"1995";"-0.129620165531368";"-0.567909703098613";"California current";"orange";"Rhinoceros aucklet";"all_rockfish.1";"16"

"1996";"-0.493659779364146";"-0.303071621297395";"California current";"orange";"Rhinoceros aucklet";"all_rockfish.1";"16"

"1997";"0.0523996413850213";"-0.453757246498088";"California current";"orange";"Rhinoceros aucklet";"all_rockfish.1";"16"

"1998";"-2.49587765544443";"-1.38966828830239";"California current";"orange";"Rhinoceros aucklet";"all_rockfish.1";"16"

"1999";"0.416439255217799";"-0.543923835898503";"California current";"orange";"Rhinoceros aucklet";"all_rockfish.1";"16"

"2000";"0.719805600078448";"-0.267973496197233";"California current";"orange";"Rhinoceros aucklet";"all_rockfish.1";"16"

"2001";"0.598459062134189";"0.541834467106493";"California current";"orange";"Rhinoceros aucklet";"all_rockfish.1";"16"

"2002";"0.477112524189929";"0.972514230008475";"California current";"orange";"Rhinoceros aucklet";"all_rockfish.1";"16"

"2003";"-0.554333048336276";"0.246002231205132";"California current";"orange";"Rhinoceros aucklet";"all_rockfish.1";"16"

"2004";"0.416439255217799";"0.486954283706241";"California current";"orange";"Rhinoceros aucklet";"all_rockfish.1";"16"

"2005";"-1.28241227600183";"-1.91453432490481";"California current";"orange";"Rhinoceros aucklet";"all_rockfish.1";"16"

"2006";"-0.736352855252666";"-1.35386379810223";"California current";"orange";"Rhinoceros aucklet";"all_rockfish.1";"16"

"2007";"-0.0689468965592383";"-0.9779158789005";"California current";"orange";"Rhinoceros aucklet";"all_rockfish.1";"16"

"1983";"-1.54463967619439";"-1.19781577550151";"California current";"orange";"Pigeon guillemot";"all_rockfish.2";"17"

"1984";"0.673948476605139";"1.40305431501046";"California current";"orange";"Pigeon guillemot";"all_rockfish.2";"17"

"1985";"1.05068986104279";"1.18479484730945";"California current";"orange";"Pigeon guillemot";"all_rockfish.2";"17"

"1986";"-1.50277952236798";"0.405794133405867";"California current";"orange";"Pigeon guillemot";"all_rockfish.2";"17"

"1987";"1.36464101474084";"1.35483224581023";"California current";"orange";"Pigeon guillemot";"all_rockfish.2";"17"

"1988";"0.485577784386311";"1.81481475551235";"California current";"orange";"Pigeon guillemot";"all_rockfish.2";"17"

"1989";"-0.519065907447436";"0.672670369307095";"California current";"orange";"Pigeon guillemot";"all_rockfish.2";"17"

"1990";"-1.00045767645111";"-0.0750383703963453";"California current";"orange";"Pigeon guillemot";"all_rockfish.2";"17"

"1991";"1.0925500148692";"0.596888418106746";"California current";"orange";"Pigeon guillemot";"all_rockfish.2";"17"

"1992";"-0.895807291885092";"-0.684438616599149";"California current";"orange";"Pigeon guillemot";"all_rockfish.2";"17"

"1993";"-0.581856138187046";"0.947979192108362";"California current";"orange";"Pigeon guillemot";"all_rockfish.2";"17"

"1994";"-0.519065907447436";"-0.898222532900133";"California current";"orange";"Pigeon guillemot";"all_rockfish.2";"17"

"1995";"0.234416861427875";"-0.567909703098613";"California current";"orange";"Pigeon guillemot";"all_rockfish.2";"17"

"1996";"-0.581856138187046";"-0.303071621297395";"California current";"orange";"Pigeon guillemot";"all_rockfish.2";"17"

"1997";"-0.121394446096578";"-0.453757246498088";"California current";"orange";"Pigeon guillemot";"all_rockfish.2";"17"

"1998";"-1.43998929162837";"-1.38966828830239";"California current";"orange";"Pigeon guillemot";"all_rockfish.2";"17"

"1999";"0.841389091910764";"-0.543923835898503";"California current";"orange";"Pigeon guillemot";"all_rockfish.2";"17"

"2000";"0.925109399563576";"-0.267973496197233";"California current";"orange";"Pigeon guillemot";"all_rockfish.2";"17"

"2001";"1.21813047634842";"0.541834467106493";"California current";"orange";"Pigeon guillemot";"all_rockfish.2";"17"

"2002";"1.51115155313326";"0.972514230008475";"California current";"orange";"Pigeon guillemot";"all_rockfish.2";"17"

"2003";"0.380927399820296";"0.246002231205132";"California current";"orange";"Pigeon guillemot";"all_rockfish.2";"17"

"2004";"1.34371093782764";"0.486954283706241";"California current";"orange";"Pigeon guillemot";"all_rockfish.2";"17"

"2005";"-0.665576445839858";"-1.91453432490481";"California current";"orange";"Pigeon guillemot";"all_rockfish.2";"17"

"2006";"-1.08417798410392";"-1.35386379810223";"California current";"orange";"Pigeon guillemot";"all_rockfish.2";"17"

"2007";"-0.665576445839858";"-0.9779158789005";"California current";"orange";"Pigeon guillemot";"all_rockfish.2";"17"

"1964";"1.12688984619738";"0.182463692039307";"Norwegian Sea";"black";"Atlantic puffin";"herring_vpa_0";"18"

"1965";"1.12688984619738";"-0.57385214376296";"Norwegian Sea";"black";"Atlantic puffin";"herring_vpa_0";"18"

"1966";"1.12688984619738";"-0.193878926173975";"Norwegian Sea";"black";"Atlantic puffin";"herring_vpa_0";"18"

"1967";"1.12688984619738";"-0.614054390508567";"Norwegian Sea";"black";"Atlantic puffin";"herring_vpa_0";"18"

"1968";"1.12688984619738";"-0.603074041177168";"Norwegian Sea";"black";"Atlantic puffin";"herring_vpa_0";"18"

"1969";"-0.704803896738293";"-0.562429038410134";"Norwegian Sea";"black";"Atlantic puffin";"herring_vpa_0";"18"

"1970";"-0.704803896738293";"-0.643178881598061";"Norwegian Sea";"black";"Atlantic puffin";"herring_vpa_0";"18"

"1971";"-0.704803896738293";"-0.646942307780194";"Norwegian Sea";"black";"Atlantic puffin";"herring_vpa_0";"18"

"1972";"-0.704803896738293";"-0.640557765951211";"Norwegian Sea";"black";"Atlantic puffin";"herring_vpa_0";"18"

"1973";"-0.704803896738293";"-0.534801062673065";"Norwegian Sea";"black";"Atlantic puffin";"herring vpa_0";"18"

"1974";"1.12688984619738";"-0.572612426902964";"Norwegian Sea";"black";"Atlantic puffin";"herring_vpa_0";"18"

"1975";"-0.966474431443389";"-0.622732408528544";"Norwegian Sea";"black";"Atlantic puffin";"herring_vpa_0";"18"

"1976";"-0.1814628273281";"-0.559595399872998";"Norwegian Sea";"black";"Atlantic puffin";"herring_vpa_0";"18"

"1977";"-0.966474431443389";"-0.603871002015738";"Norwegian Sea";"black";"Atlantic puffin";"herring_vpa_0";"18"

"1978";"-0.940307377972879";"-0.594130369544335";"Norwegian Sea";"black";"Atlantic puffin";"herring_vpa_0";"18"

"1979";"-0.940307377972879";"-0.538343110844484";"Norwegian Sea";"black";"Atlantic puffin";"herring_vpa_0";"18"

"1980";"-0.966474431443389";"-0.636015089171366";"Norwegian Sea";"black";"Atlantic puffin";"herring_vpa_0";"18"

"1981";"-0.966474431443389";"-0.639291483729929";"Norwegian Sea";"black";"Atlantic puffin";"herring_vpa_0";"18"

"1982";"-0.966474431443389";"-0.628311134398529";"Norwegian Sea";"black";"Atlantic puffin";"herring_vpa_0";"18" 
"1983";"1.33622627396146";"2.38827419079056";"Norwegian Sea";"black";"Atlantic puffin";"herring_vpa_0";"18" "1984";"0.263377081670564";"-0.547198231273032";"Norwegian Sea";"black";"Atlantic puffin";"herring_vpa_0";"18" "1985";"1.04838868578585";"-0.324934708516482";"Norwegian Sea";"black";"Atlantic puffin";"herring_vpa_0";"18" "1986";"-0.966474431443389";"-0.595547188812902";"Norwegian Sea";"black";"Atlantic puffin";"herring_vpa_0";"18" "1987";"-0.966474431443389";"-0.568539071505832";"Norwegian Sea";"black";"Atlantic puffin";"herring_vpa_0";"18" "1988";"-0.338465148151158";"-0.392366450579873";"Norwegian Sea";"black";"Atlantic puffin";"herring_vpa_0";"18" "1989";"1.33622627396146";"0.00235939764307308";"Norwegian Sea";"black";"Atlantic puffin";"herring_vpa_0";"18" "1990";"1.12688984619738";"0.317663670742374";"Norwegian Sea";"black";"Atlantic puffin";"herring_vpa_0";"18" "1991";"1.4408944878435";"2.19163738655423";"Norwegian Sea";"black";"Atlantic puffin";"herring_vpa_0";"18"

"1992";"1.54556270172554";"2.75472563948515";"Norwegian Sea";"black";"Atlantic puffin";"herring_vpa_0";"18"

"1993";"0.368045295552603";"0.42690043634894";"Norwegian Sea";"black";"Atlantic puffin";"herring vpa 0";"18"

"1994";"-0.91414032450237";"-0.280021537702888";"Norwegian Sea";"black";"Atlantic puffin";"herring_vpa_0";"18"

"1995";"-0.966474431443389";"-0.475516031403937";"Norwegian Sea";"black";"Atlantic puffin";"herring_vpa_0";"18" "1996";"-0.312298094680648";"-0.130573670230286";"Norwegian Sea";"black";"Atlantic puffin";"herring_vpa_0";"18" "1997";"-0.966474431443389";"-0.269545930235916";"Norwegian Sea";"black";"Atlantic puffin";"herring_vpa_0";"18" "1998";NA;NA;"Norwegian Sea";"black";"Atlantic puffin";"herring_vpa_0";"18"

"1999";"0.891386364962796";"1.14812342989287";"Norwegian Sea";"black";"Atlantic puffin";"herring_vpa_0";"18" "2000";"-0.91414032450237";"-0.07841701090614";"Norwegian Sea";"black";"Atlantic puffin";"herring_vpa_0";"18" "2001";"1.23155806007942";"-0.290780509023573";"Norwegian Sea";"black";"Atlantic puffin";"herring_vpa_0";"18" "2002";"1.41472743437299";"3.34253738865259";"Norwegian Sea";"black";"Atlantic puffin";"herring_vpa_0";"18"

"2003";"-0.0506275599755514";"0.883744954378149";"Norwegian Sea";"black";"Atlantic puffin";"herring_vpa_0";"18" "2004";"1.33622627396146";"1.98417077003378";"Norwegian Sea";"black";"Atlantic puffin";"herring_vpa_0";"18" "2005";"-0.757138003679312";"-0.221374075104616";"Norwegian Sea";"black";"Atlantic puffin";"herring_vpa_0";"18" "2006";"1.33622627396146";"-0.118459865484033";"Norwegian Sea";"black";"Atlantic puffin";"herring_vpa_0";"18" "2007";"-0.966474431443389";"-0.501009923117726";"Norwegian Sea";"black";"Atlantic puffin";"herring_vpa_0";"18" "2008";"-0.966474431443389";"-0.380757387698047";"Norwegian Sea";"black";"Atlantic puffin";"herring_vpa_0";"18" "2009";"-0.966474431443389";"-0.0398883819215285";"Norwegian Sea";"black";"Atlantic puffin";"herring_vpa_0";"18" "2010";"-0.966474431443389";NA;"Norwegian Sea";"black";"Atlantic puffin";"herring_vpa_0";"18"

"1964";NA;"0.182463692039307";"Norwegian Sea";"black";"Kittiwake";"herring_vpa_0.1";"19"

"1965";NA;"-0.57385214376296";"Norwegian Sea";"black";"Kittiwake";"herring_vpa_0.1";"19"

"1966";NA;"-0.193878926173975";"Norwegian Sea";"black";"Kittiwake";"herring_vpa_0.1";"19"

"1967";NA;"-0.614054390508567";"Norwegian Sea";"black";"Kittiwake";"herring_vpa_0.1";"19"

"1968";NA;"-0.603074041177168";"Norwegian Sea";"black";"Kittiwake";"herring_vpa_0.1";"19"

"1969";NA;"-0.562429038410134";"Norwegian Sea";"black";"Kittiwake";"herring_vpa_0.1";"19"

"1970";NA;"-0.643178881598061";"Norwegian Sea";"black";"Kittiwake";"herring_vpa_0.1";"19"

"1971";NA;"-0.646942307780194";"Norwegian Sea";"black";"Kittiwake";"herring_vpa_0.1";"19"

"1972";NA;"-0.640557765951211";"Norwegian Sea";"black";"Kittiwake";"herring_vpa_0.1";"19"

"1973";NA;"-0.534801062673065";"Norwegian Sea";"black";"Kittiwake";"herring_vpa_0.1";"19"

"1974";NA;"-0.572612426902964";"Norwegian Sea";"black";"Kittiwake";"herring_vpa_0.1";"19"

"1975";NA;"-0.622732408528544";"Norwegian Sea";"black";"Kittiwake";"herring_vpa_0.1";"19"

"1976";NA;"-0.559595399872998";"Norwegian Sea";"black";"Kittiwake";"herring_vpa_0.1";"19"

"1977";NA;"-0.603871002015738";"Norwegian Sea";"black";"Kittiwake";"herring_vpa_0.1";"19"

"1978";NA;"-0.594130369544335";"Norwegian Sea";"black";"Kittiwake";"herring_vpa_0.1";"19"

"1979";NA;"-0.538343110844484";"Norwegian Sea";"black";"Kittiwake";"herring vpa_0.1";"19"

"1980";NA;"-0.636015089171366";"Norwegian Sea";"black";"Kittiwake";"herring_vpa_0.1";"19"

"1981";"0.623592227014251";"-0.639291483729929";"Norwegian Sea";"black";"Kittiwake";"herring_vpa_0.1";"19"

"1982";"-0.294644457222745";"-0.628311134398529";"Norwegian Sea";"black";"Kittiwake";"herring_vpa_0.1";"19"

"1983";"0.0745912416044578";"2.38827419079056";"Norwegian Sea";"black";"Kittiwake";"herring vpa_0.1";"19"

"1984";NA;"-0.547198231273032";"Norwegian Sea";"black";"Kittiwake";"herring_vpa_0.1";"19"

"1985";NA;"-0.324934708516482";"Norwegian Sea";"black";"Kittiwake";"herring_vpa_0.1";"19"

"1986";NA;"-0.595547188812902";"Norwegian Sea";"black";"Kittiwake";"herring_vpa_0.1";"19"

"1987";NA;"-0.568539071505832";"Norwegian Sea";"black";"Kittiwake";"herring_vpa_0.1";"19"

"1988";"0.318992994701286";"-0.392366450579873";"Norwegian Sea";"black";"Kittiwake";"herring_vpa_0.1";"19"

"1989";"0.614961316731738";"0.00235939764307308";"Norwegian Sea";"black";"Kittiwake";"herring_vpa_0.1";"19"

"1990";"0.955882300803384";"0.317663670742374";"Norwegian Sea";"black";"Kittiwake";"herring_vpa_0.1";"19"

"1991";"-0.287718266779788";"2.19163738655423";"Norwegian Sea";"black";"Kittiwake";"herring_vpa_0.1";"19"

"1992";"1.60132531557119";"2.75472563948515";"Norwegian Sea";"black";"Kittiwake";"herring_vpa_0.1";"19"

"1993";"1.26684894191737";"0.42690043634894";"Norwegian Sea";"black";"Kittiwake";"herring_vpa 0.1";"19"

"1994";"1.09919223508129";"-0.280021537702888";"Norwegian Sea";"black";"Kittiwake";"herring_vpa_0.1";"19"

"1995";"0.588614328077878";"-0.475516031403937";"Norwegian Sea";"black";"Kittiwake";"herring_vpa_0.1";"19"

"1996";"0.32877848006495";"-0.130573670230286";"Norwegian Sea";"black";"Kittiwake";"herring_vpa_0.1";"19"

"1997";"-1.26983421485433";"-0.269545930235916";"Norwegian Sea";"black";"Kittiwake";"herring_vpa_0.1";"19"

"1998";"-0.487172461810914";NA;"Norwegian Sea";"black";"Kittiwake";"herring_vpa_0.1";"19"

"1999";"-0.236784897843269";"1.14812342989287";"Norwegian Sea";"black";"Kittiwake";"herring_vpa_0.1";"19"

"2000";"-0.299547970090363";"-0.07841701090614";"Norwegian Sea";"black";"Kittiwake";"herring_vpa_0.1";"19"

"2001";"-0.916669981845307";"-0.290780509023573";"Norwegian Sea";"black";"Kittiwake";"herring_vpa_0.1";"19"

"2002";"1.5998622490338";"3.34253738865259";"Norwegian Sea";"black";"Kittiwake";"herring_vpa_0.1";"19"

"2003";"0.645957907434902";"0.883744954378149";"Norwegian Sea";"black";"Kittiwake";"herring_vpa_0.1";"19"

"2004";"-0.221491162253215";"1.98417077003378";"Norwegian Sea";"black";"Kittiwake";"herring_vpa_0.1";"19"

"2005";"-0.666728955921049";"-0.221374075104616";"Norwegian Sea";"black";"Kittiwake";"herring_vpa_0.1";"19"

"2006";"1.02440904535042";"-0.118459865484033";"Norwegian Sea";"black";"Kittiwake";"herring_vpa_0.1";"19"

"2007";"-1.74435420176974";"-0.501009923117726";"Norwegian Sea";"black";"Kittiwake";"herring_vpa_0.1";"19"

"2008";"-2.00008198352061";"-0.380757387698047";"Norwegian Sea";"black";"Kittiwake";"herring_vpa_0.1";"19"

"2009";"-1.4090504497637";"-0.0398883819215285";"Norwegian Sea";"black";"Kittiwake";"herring_vpa_0.1";"19"

"2010";"-0.908929579711898";NA;"Norwegian Sea";"black";"Kittiwake";"herring_vpa_0.1";"19" 


\section{$2 R$ codes for the analyses}

\subsection{Fig $2 A$ and $B$}

\#\#\#\#\#\# PURPOSE: Relationship between normalized annual breeding success of seabirds and normalized prey abundance (Fig. 2A) and Change in variance across the range of normalized food abundance ranging from -1.5 to 2 standard deviations in 8 classes.

\#\#\#\#\#\# INSTRUCTIONS: set the path where you downloaded and saved the global dataset

\#\#\#\#\#\# REQUIREMENTS: you need the script bootstrapping.R and to have the R packages 'gam',

'changepoint', and 'time' installed

\#\#\#\#\#\# INPUTS: the global_dataset.csv file

\#\#\#\#\#\# OUTPUTS: Figs. 2A and B

\#\#\#\#\#\# MISCELLANEOUS:

\#\#\#\#\#\# AUTHORS: Sylvain Bonhommeau \& Philippe Cury (Last update 23rd of August 2011)

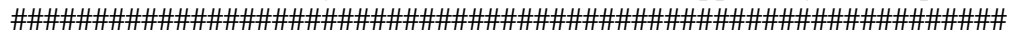

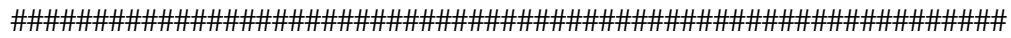

\#\#\# LOAD the required packages

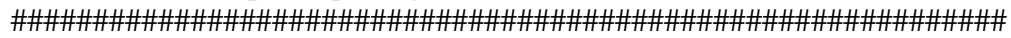

library(gam)

library(changepoint) \# package version 0.3

library(time)

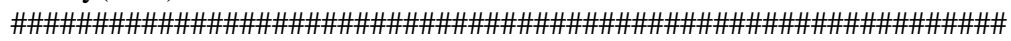

\#\#\# !!!! SET the path to the data (download the global_dataset.csv file and paste it in the repository you want to work in)!!!

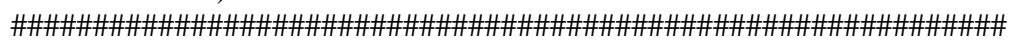

setwd('XXX')

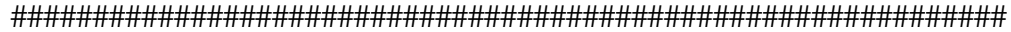

\#\#\# LOAD the data

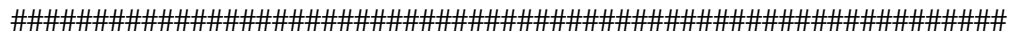

t_glob <- read.table('./global_dataset.csv', header=F, sep=";")

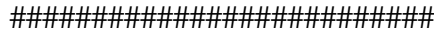

\#\#\# Script to boostrap

bootstrap_size $<-1000$

smoother_size $<-3$

source('./bootstrapping.R')

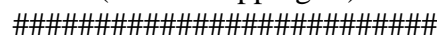

\#\#\# Figure (set png_figure to 1) or not (any other value)

png_figure $<-0$

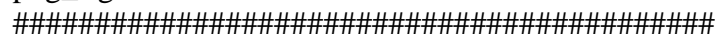

\#\#\#\#\#\# GLOBAL DATASET FIGURE (Fig 2A) \#\#\#

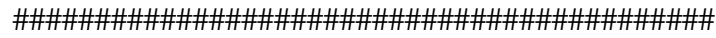

if (png_figure $==1)\{$

png('./Fig2A.png', width=1200, height=1200)

\}

$\operatorname{par}(\operatorname{mar}=c(5,5,3,1))$

plot(min(prey),min(bird), col="transparent" ,main="'",ylab="Breeding success (-)", xlab="Prey

abundance $(-) "$, cex.lab=2.5, cex.axis=2.5, $p c h=16$, cex.main $=2, x \lim =c(-2,3.5), y \lim =c(-3.5,3))$

lines(titu, lwd=2)

$\mathrm{xd}<-\mathrm{c}(\mathrm{fds}[\mathrm{fds} 2,2], \mathrm{rev}(\mathrm{fds}[\mathrm{fds} 2,2]))$

up.sd<-prediction\$fit[fds2]+1.96*prediction\$se.fit[fds2]

down.sd<-prediction\$fit[fds2]-1.96*prediction\$se.fit[fds2]

yd<-c(up.sd,rev(down.sd))

polygon(xd,yd,col="grey81",lty=1,border="transparent")

lines(titu\$y titu\$x, lwd=4)

for (i in 1:length(data[,1])) \{

$$
\text { points(data[i,2] data[i,3],pch=16, col=paste(data[i,5]), cex=2) }
$$


\#\#\# Identify the threshold

data2 <- cbind(titu\$y[1:150],1,titu\$x[1:150])

change_point $<$ - cpt.reg(data2,penalty="SIC")

threshold <- titu\$x[cpts(change_point)[1]]

abline(v=threshold, lwd=4, col="orange")

percentage_threshold <- (threshold+abs(min(prey)) $) /(\max ($ prey $)+$ abs(min(prey) $))$

text(threshold,-3.2, paste(signif(threshold,2), "\ni.e.",paste(signif(percentage_threshold*100,2)),"\% of

max prey abundance" ), pos=4, cex=2.5)

text(2.5,2.5, paste("AIC=",signif(AIC(gam.object),5),sep=" "), pos=4, cex=2.5)

legend("bottomright", pch=16, col=unique(paste(t_glob[,5])), legend=unique(t_glob[,4]), bty="n",

cex=2)

\#\#\# plot the confidence interval

IC<-quantile(thresh, c $(0.025,0.975))$

abline $(v=\mathrm{IC}[1]$, lwd=3, lty=2, col="black")

abline (v=IC[2], lwd=3, lty=2, col="black")

if (png_figure $==1)\{$

dev.off()

\}

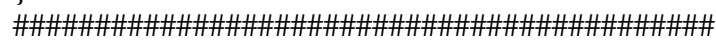

\#\#\#\#\#\#\#\#\# VARIANCE FIGURE (Fig 2B) \#\#\#\#\#\#

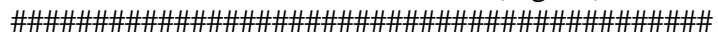

min_prey $<-\min ($ prey)

max_prey $<-\max$ (prey)

diff_prey <- max_prey-min_prey

variance $<-0$

count $<-0$

for (i in seq(-2,3, by=0.5)) \{

$$
\mathrm{j}<-\mathrm{i}+0.5
$$

variance <- c(variance,var(bird[which(prey>i \& prey <= j )], na.rm=T))

\} count $<-$ c(count,length(bird[which(prey $>$ i \& prey $<=$ j )]))

variance $<$ - variance[-1]

count $<$ - count [-1]

\#\#\# Figure (set png_figure to 1) or not (any other value)

png_figure $<-0$

if (png_figure $==1)\{$

png('./Fig2B.png', width=1200, height=1200)

\}

$\operatorname{par}(\operatorname{mar}=\mathrm{c}(6,6,1,1))$

plot(smooth(variance[2:9]) seq(-1.5,2,by=0.5), type="l", ylab="Variance of seabird breeding success", xlab="Prey abundance $(-) "$, cex.axis=3, cex.lab=3, lwd=3)

abline(v=threshold, lwd=3, col="orange")

legend("topright", legend=c("Threshold value as identified $\backslash n$ in the global analysis"), col="orange",

lwd=3, bty="n", cex=3)

if (png_figure $==1)\{$

dev.off()

\}

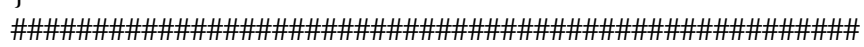

\#\#\#\#\#\#\#\#\#\#\#\#\# Test for difference in variance \#\#

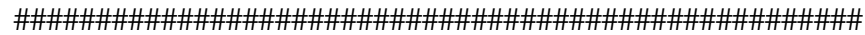

\#\#\# Bartlett test for variance

first_var $<$ - bird[which(prey $<-0.092)$ ]

second_var $<-$ bird[which(prey $>$-0.092)]

var.test(first_var,second_var) 


\subsection{Fig 2C}

\#\#\#\#\#\# PURPOSE: Script to fit the parametric model (see Table S2) to the global dataset for each ecosystem \#\#\#\#\#\# INSTRUCTIONS: set the path where you downloaded and saved the global dataset \#\#\#\#\#\#\# INPUTS: the global_dataset.csv file \#\#\#\#\#\# OUTPUTS: Fig. 2C \#\#\#\#\#\# AUTHORS: Sylvain Bonhommeau \& Philippe Cury (Last update 23rd of August 2011)

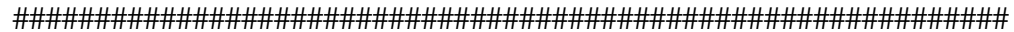

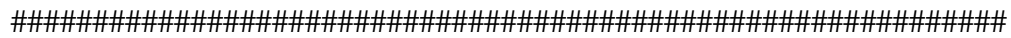
\#\#\# !!!! SET the path to the data !!!!

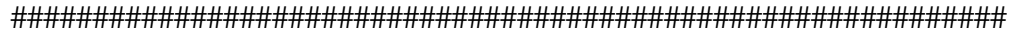
setwd('XXX')

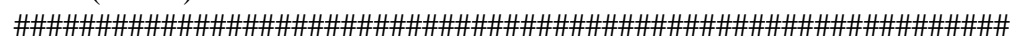

\#\#\# LOAD the data

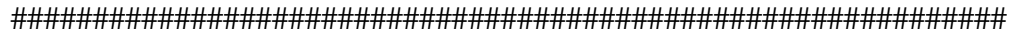

t_glob <-read.table('./global_dataset.csv', header=F, sep=";")

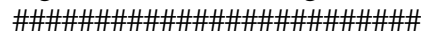

\#\#\#\#\# CONTROL PARAMETERS

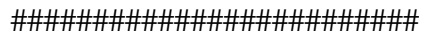

\#\#\# for nls to enable larger number of iterations and decrease the minFactor

nls_cont $<$ - nls.control $($ maxiter $=500$, tol $=1 \mathrm{e}-05$, minFactor $=1 /(1024 * 20)$, printEval $=$ FALSE, warnOnly $=$ FALSE)

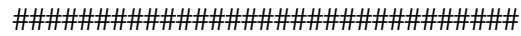

\#\#\#\#\# PARAMETER ESTIMATION \#\#\#

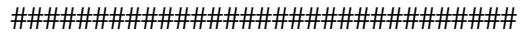

\#\#\# Initialization for the first ecosystem

toto $<$ - unique (t_glob[,4])

$\mathrm{j}<-1 ; \mathrm{i}<-1$

data $<-$ subset(t_glob, V4==toto[j])

\#\#\# The global data set contains some holes in the times series. We first select the years we have both a breeding success and an abundance estimate for the prey

bird<-as.numeric(data[,2])

prey<-as.numeric(data[,3])

req1<-which(is.na(bird)==T)

if (length(req1) >0) \{bird<-bird[-req1];prey<-prey[-req1] \}

req $2<$-which(is.na(prey) $==\mathrm{T}$ )

if (length(req2) $>0$ ) \{bird<-bird[-req2];prey<-prey[-req2] $\}$

model3 <- nls(bird $\sim \mathrm{c}+\mathrm{a}^{*}(1-\exp (-\mathrm{b} *$ prey $))$, start=list( $\left.\mathrm{a}=1, \mathrm{~b}=1, \mathrm{c}=0\right)$, control=nls_cont)

x_prey <- seq(min(prey), $\max ($ prey),by=(max(prey)-min(prey))/200)

y_bird <- coef(model3)[3]+coef(model3)[1]*(1-exp(-coef(model3)[2]*x_prey))

\#\#\# Figure (set png_figure to 1) or not (any other value)

png_figure $<-0$

if (png_figure $==1)\{$

png('./Fig2C.png', width=1200, height=1200)

\}

$\operatorname{par}(\operatorname{mar}=\mathrm{c}(5,5,3,1))$

plot(bird prey, xlim=c(-2,3.5), ylim=c(-2,2) ,ylab="Breeding success (-)", xlab="Prey abundance (-)", cex.lab=2.5, cex.axis $=2.5$, pch=16, cex.main=2, col="transparent", main="'", cex.main=2.5)

lines(smooth(y_bird) x_prey,col=paste(data[i,5]), lwd=4)

for (j in 2: length(toto) ) \{

data <- subset(t_glob, V4==toto[j])

bird<-as.numeric(data[,2])

prey<-as.numeric(data[,3])

req $1<$-which(is.na(bird) $==\mathrm{T}$ )

if (length(req1) $>0$ ) \{bird<-bird[-req1];prey<-prey[-req1] \}

req $2<$-which(is.na(prey) $==\mathrm{T}$ )

if (length(req2) $>0$ ) \{bird<-bird[-req2];prey<-prey[-req2] $\}$

model3 <- nls(bird c+a*(1-exp(-b*prey)), start=list(a=1, b=1, c=0),control=nls_cont)

x_prey <- seq(min(prey), $\max ($ prey),by=(max(prey)-min(prey) $) / 200)$ 
y_bird <- coef(model3)[3]+coef(model3)[1]*(1-exp(-coef(model3)[2]*x_prey))

lines(smooth(y_bird) x_prey,col=paste(data[i,5]), lwd=4)

\}

legend("bottomright", pch=16, col=unique(paste(t_glob[,5])), legend=unique(t_glob[,4]), bty="n", cex=2)

if (png_figure==1) \{

dev.off()

\} 


\subsection{Fig 2D}

\#\#\#\#\#\# PURPOSE: Script to fit the parametric model to the global dataset for each species \#\#\#\#\#\# INSTRUCTIONS: set the path where you downloaded and saved the global dataset \#\#\#\#\#\# INPUTS: the global_dataset.csv file \#\#\#\#\#\# OUTPUTS: Fig. 2D

\#\#\#\#\#\# AUTHORS: Sylvain Bonhommeau \& Philippe Cury (Last update 23rd of August 2011)

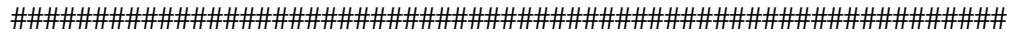

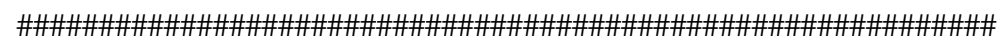

\#\#\# !!!! SET the path to the data (download the global_dataset.csv file and paste it in the repository you want to work in) !!!

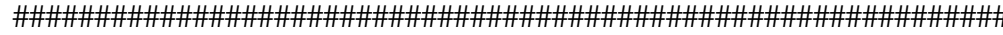

setwd('XXX')

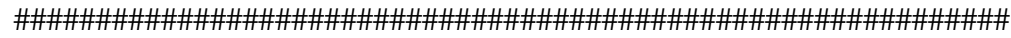

\#\#\# LOAD the data

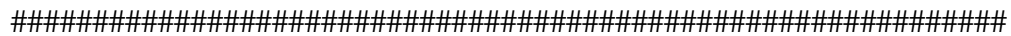

t_glob <- read.table('./global_dataset.csv', header=F, sep=";")

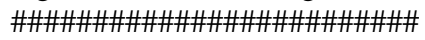

\#\#\#\# CONTROL PARAMETERS

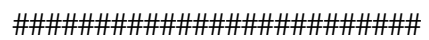

\#\#\# for nls to enable larger number of iterations and decrease the minFactor

nls_cont $<$ - nls.control (maxiter $=500$, tol $=1 \mathrm{e}-05$, minFactor $=1 /(1024 * 20)$,

printEval $=$ FALSE, warnOnly $=$ FALSE)

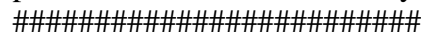

\#\#\#\#\# Model FITS

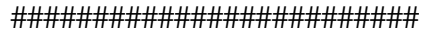

colors $<$ - rainbow $(18)$

data $<-$ t_glob

un_data <- unique(paste(t_glob[,6])) \# Get the tag for each data sea

\#\#\# Initialization for the first species

$\mathrm{i}<-1$

subset_data <- subset(t_glob,subset=c(t_glob[,6]==paste(un_data[i])))

\#\#\# The global data set contains some holes in the times series. We first select the years we have both a breeding success and an abundance estimate for the prey

bird<-as.numeric(subset_data[,2])

prey<-as.numeric(subset_data[,3])

req $1<$-which(is.na(bird) $==\mathrm{T}$ )

if (length(req1) >0) \{bird<-bird[-req1];prey<-prey[-req1] $\}$

req2 $<$-which(is.na(prey) $==\mathrm{T}$ )

if (length(req2) $>0$ ) \{bird<-bird[-req2]; prey<-prey[-req2] $\}$

model3 <- nls(bird $\sim \mathrm{c}+\mathrm{a} *(1-\exp (-\mathrm{b} *$ prey $))$, start=list(a=1, b=1, c=0), control=nls_cont)

x_prey <- seq(min(prey), $\max ($ prey),by=(max(prey)-min(prey))/200)

y_bird <- coef(model3)[3]+coef(model3)[1]*(1-exp(-coef(model3)[2]*x_prey))

\#\#\# Figure (set png_figure to 1 ) or not (any other value)

png_figure $<-0$

if (png_figure $==1)\{$

png('./Fig2D.png', width=1200, height=1200)

\}

$\operatorname{par}(\operatorname{mar}=\mathrm{c}(5,5,3,1))$

plot(bird prey, xlim=c(-2,3.5), ylim=c(-2,2) ,main="',ylab="Breeding success (-)", xlab="Prey

abundance $(-)$ ", cex.lab=2.5, cex.axis=2.5, pch=16, cex.main=2, col="transparent")

lines(smooth(y_bird) $\sim$ _prey,col=colors[i], lwd=4)

legend_text $<$ - paste(subset_data[1,6])

counter $<-1$

for (i in 2:length(un_data)) \{

$$
\begin{aligned}
& \text { if }(\mathrm{i}<6)\{\mathrm{i} 2<-\mathrm{i}\} \text { else }\{\mathrm{i} 2<-\mathrm{i}-1\} \\
& \text { if }(\mathrm{i} !=6)\{ \\
& \text { subset_data }<- \text { subset(t_glob,subset=c(t_glob[,6]==paste(un_data[i])) }
\end{aligned}
$$




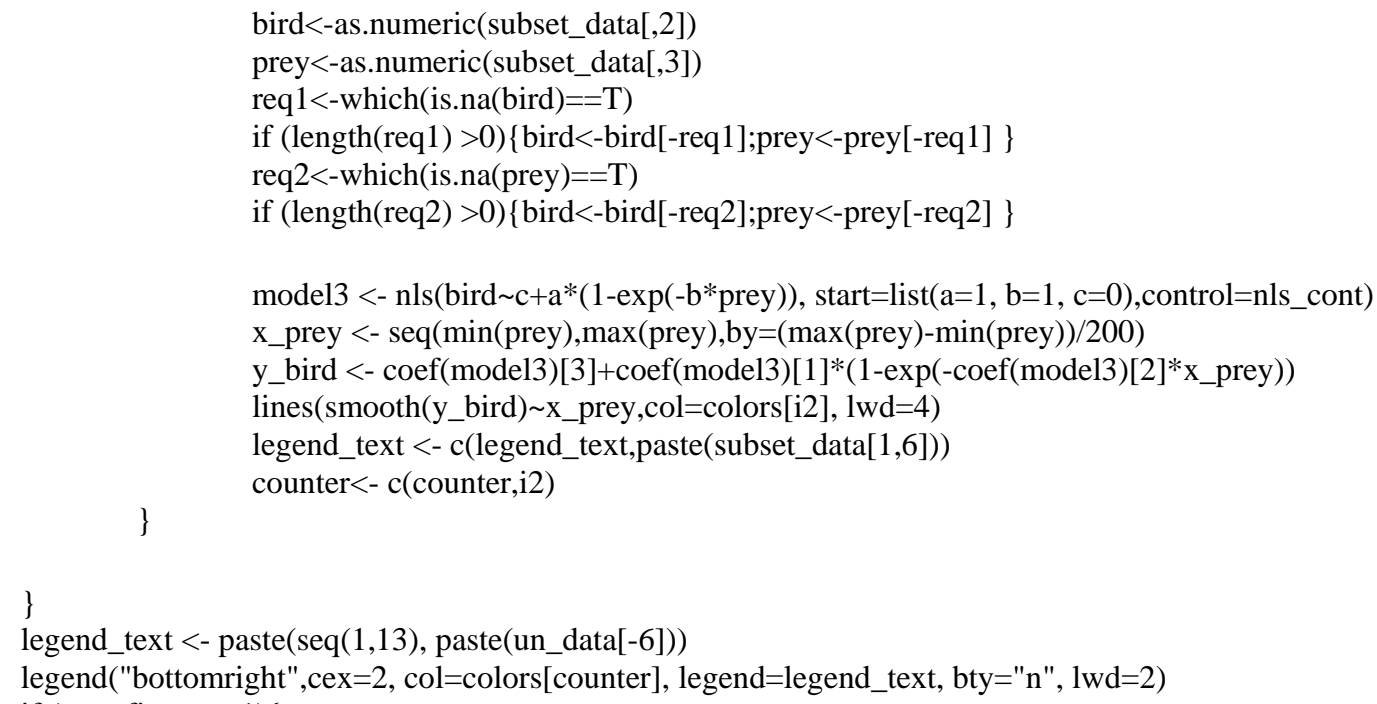




\subsection{Fig 3}

\#\#\#\#\#\# PURPOSE: Script to fit the parametric model to the global dataset for each ecosystem with the data overplotted \#\#\#\#\#\# INSTRUCTIONS: run this script to

\#\#\#\#\#\# INSTRUCTIONS: set the path where you downloaded and saved the global dataset, install the package splines, quantreg and VGAM

\#\#\#\#\#\# INPUTS: the global_dataset.csv file

\#\#\#\#\#\# OUTPUTS: Fig. 3

\#\#\#\#\#\# AUTHORS: Sylvain Bonhommeau \& Philippe Cury (Last update 23rd of August 2011)

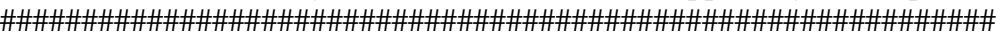

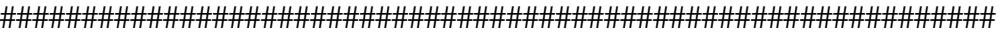

\#\#\# LOAD the required packages

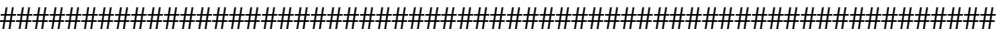

library(gam)

library(changepoint)

library(time)

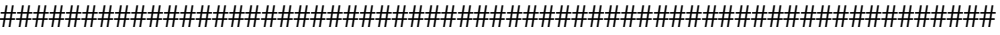

\#\#\# SET the path to the data

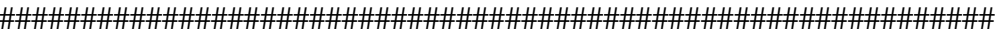

setwd('XXX')

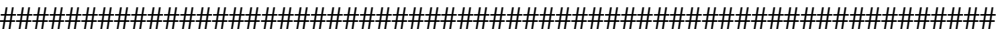

\#\#\# LOAD the data

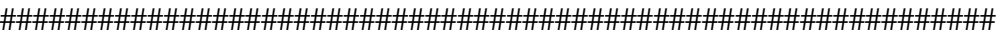

t_glob <- read.table('./global_dataset.csv', header=F, sep=";")

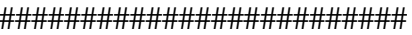

\#\#\#\# CONTROL PARAMETERS

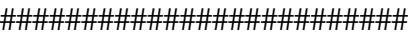

\#\#\# for nls to enable larger number of iterations and decrease the minFactor

nls_cont $<-$ nls.control $($ maxiter $=500$, tol $=1 \mathrm{e}-05$, $\operatorname{minFactor}=1 /(1024 * 20)$, printEval $=$ FALSE, warnOnly $=$ FALSE)

\#\#\# Initialization for the first ecosystem

toto $<-$ unique (t_glob[,4])

$\mathrm{j}=1 ; \mathrm{i}=1$

data <- subset(t_glob, V4==toto[j])

\#\#\# The global data set contains some holes in the times series. We first select the years we have both a breeding success and an abundance estimate for the prey

bird<-as.numeric(data[,2])

prey<-as.numeric(data[,3])

req1<-which(is.na(bird)=-T)

if (length(req1) >0) \{bird<-bird[-req1];prey<-prey[-req1] $\}$

req2<-which(is.na(prey) $==\mathrm{T}$ )

if (length(req2) $>0$ ) \{bird<-bird[-req2];prey<-prey[-req2] $\}$

model3 <- nls(bird $\sim \mathrm{c}+\mathrm{a} *(1-\exp (-\mathrm{b} *$ prey $))$, start=list(a=1, b=1, c=0), control=nls_cont)

x_prey <- seq(min(prey), $\max ($ prey),by=(max(prey)-min(prey))/200)

y_bird <- coef(model3)[3]+coef(model3)[1]*(1-exp(-coef(model3)[2]*x_prey))

\#\#\# Figure (set png_figure to 1) or not (any other value)

png_figure $<-0$

if (png_figure $==1)\{$

png('./Fig3.png', width=1200, height=1200)

\}

$\operatorname{par}(\operatorname{mar}=\mathrm{c}(5,5,3,1), \operatorname{mfrow}=\mathrm{c}(3,3))$

plot(bird prey, xlim=c(-2,3.5), ylim=c(-2,2) ,ylab="Breeding success (-)", xlab="Prey abundance (-)", cex.lab=2.5, cex.axis=2.5, pch=16, cex.main=2, col="transparent", main=toto[j], cex.main=2.5)

lines(smooth(y_bird) $\sim$ __prey,col=paste(data[i,5]), lwd=4)

points(bird prey, pch=17,col=paste(data[i,5]), lwd=4) 
for (j in 2: length(toto) ) \{

data $<$ - subset(t_glob, V4==toto[j])

bird $<$-as.numeric(data[,2])

prey<-as.numeric(data[,3])

req $1<$-which(is.na(bird) $==\mathrm{T}$ )

if (length(req1) $>0$ ) \{bird<-bird[-req1];prey<-prey[-req1] $\}$

req $2<$-which(is.na(prey) $==\mathrm{T}$ )

if (length(req2) $>0$ ) \{bird<-bird[-req2];prey<-prey[-req2] $\}$

model3 <- nls(bird c $+a^{*}\left(1-\exp \left(-b^{*}\right.\right.$ prey)), start=list(a=1, b=1, c=0), control=nls_cont)

$\mathrm{x} \_$prey $<$- seq(min(prey), $\max ($ prey),by $=(\max ($ prey)$)-\min ($ prey $)) / 200)$

y_bird <- coef(model3)[3]+coef(model3)[1]*(1-exp(-coef(model3)[2]*x_prey))

plot(bird prey, $x \lim =c(-2,3.5)$, ylim $=c(-2,2)$,ylab="Breeding success $(-) "$ ", xlab="Prey

abundance (-)", cex.lab=2.5, cex.axis=2.5, pch=16, cex.main=2, col="transparent", main=toto[j], cex.main $=2.5$ )

lines(smooth(y_bird) $\sim$ __prey,col=paste(data[i,5]), lwd=4)

\}

points(bird prey, pch=17,col=paste(data[i,5]), lwd=4)

legend("bottomright", pch=16, col=unique(paste(t_glob[,5])), legend=unique(t_glob[,4]), bty="n", cex=2)

if (png_figure $==1)\{$

dev.off()

\} 


\subsection{Fig S1}

\#\#\#\#\#\# PURPOSE: Script to estimate the minimum of number of years required to estimate the threshold

\#\#\#\#\#\# INSTRUCTIONS: set the path where you downloaded and saved the global dataset

\#\#\#\#\#\# INPUTS: the global_dataset.csv file

\#\#\#\#\#\# OUTPUTS: Fig. S1

\#\#\#\#\#\# AUTHORS: Sylvain Bonhommeau \& Philippe Cury (Last update 23rd of August 2011)

\#\#\#\#\#\# WARNINGS: this is a bootstrap procedure. It will repeat 100 times this procedure (100

bootstraps...) so get some coffee.

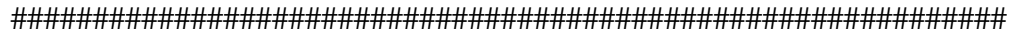

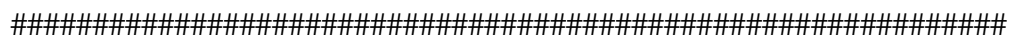

\#\#\# LOAD the required packages

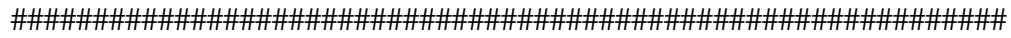

library(gam)

library(changepoint)

library(time)

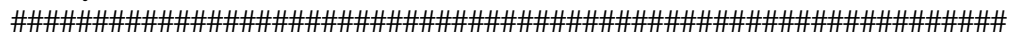

\#\#\# !!!! SET the path to the data (download the global_dataset.csv file and paste it in the repository you want to work in) !!!

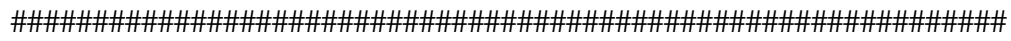

setwd('XXX')

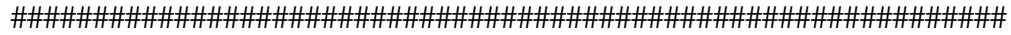

\#\#\# LOAD the data

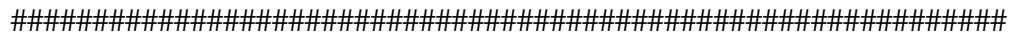

t_glob <- read.table('./global_dataset.csv', header=F, sep=";")

\#\#\# GAM

nb_boot $<-100$

year_est $<$-rep(0,nb_boot)

threshold <- array(0,dim=c(nb_boot,38,nb_boot))

years <- 1964:2010

for ( $\mathrm{j}$ in 1:nb_boot) \{

prev <- progressBar()

for (year_size in 5:42) \{

prev2 <- progressBar()

for (i in 1:nb_boot) \{

prev2 <- progressBar(i/nb_boot, prev2)

year_start <- sample(years[1:(length(years)-year_size)], size=1)

t_glob[,1]<(year_start+year_size $))$ )

bird <- as.numeric(data[,2])

prey $<$ - as.numeric(data[,3])

req $1<-$ which(is.na(bird) $==\mathrm{T}$ )

if (length(req1) >0) \{bird<-bird[-req1];prey<-prey[-req1] $\}$

req $2<$-which(is.na(prey) $==\mathrm{T}$ )

if (length(req2) >0) \{bird<-bird[-req2];prey<-prey[-req2] $\}$

gam.object $<$-gam(bird $\sim$ (prey,3), na.action='na.omit')

prediction<-predict.gam(gam.object, se.fit $=\mathrm{T}$ )

fds<-cbind(prediction\$fit,prey,prediction\$se.fit,0,0)

fds2<-order(fds[,2])

titu <- spline(prediction\$fit[fds2] prey[fds2],n=200)

data2 <- cbind(titu\$y[1:150],1,titu\$x[1:150])

change_point $<$ - cpt.reg(data2,penalty="SIC")

\}

threshold[i,(year_size-4),j] <- titu\$x[cpts(change_point)[1]]

\}

year_est <-rep(0,nb_boot)

year_mean <-rep $(0,38)$ 


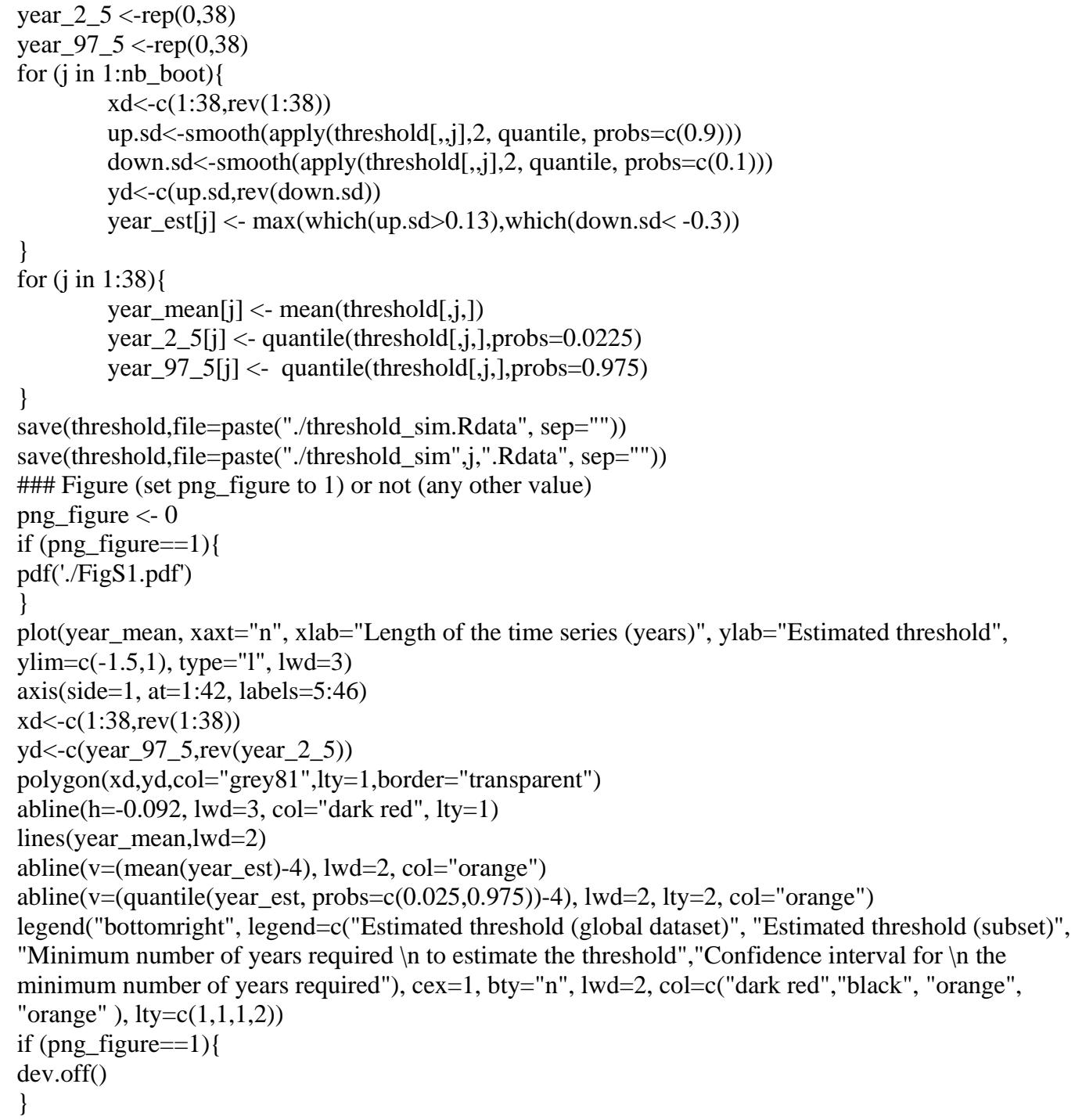




\subsection{Fig S2}

\#\#\#\#\#\# PURPOSE: Script to estimate when the maximum prey biomass is observed in the global dataset

\#\#\#\#\#\# INSTRUCTIONS: set the path where you downloaded and saved the global dataset

\#\#\#\#\#\# INPUTS: the global_dataset.csv file

\#\#\#\#\#\# OUTPUTS: Fig. S2

\#\#\#\#\#\# AUTHORS: Sylvain Bonhommeau \& Philippe Cury (Last update 23rd of August 2011)

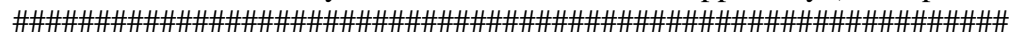

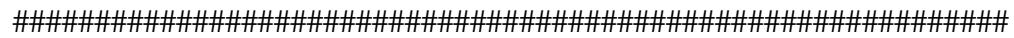

\#\#\# SET the path to the data (download the global_dataset.csv file and paste it in the repository you want to work in)

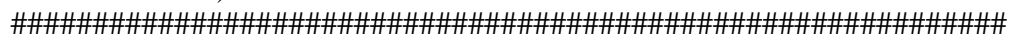

setwd('XXX')

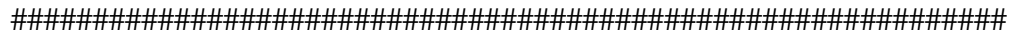

\#\#\# LOAD the data

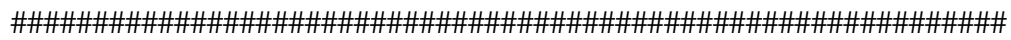

data <- read.table('./global_dataset.csv', header=F, sep=";")

year $<$ - rep $(0,19)$

for (i in 1:19) \{

data2 $<-$ subset $($ data, subset $=\mathrm{c}($ data[,8]=-i) $)$

iwh <- which(data2[,3]==max(data2[,3], na.rm=T))

\} year[i] <- data2[iwh,1]-data2[1,1]+1

names <- c("Krill_biomass", rep("Sardine_anchovy_w_agulhas",3),

rep("Sandeel",4),rep("Shetland_sandeel_TSB",3),"Euphausiid_availability_index",rep("biom",2),rep(" all_rockfish",3),rep("herring_vpa_0",2))

max_bio <- as.data.frame(cbind(year,names))

index <- max_bio[1:(length(max_bio[,1])-1),2]!=max_bio[2:length(max_bio[,1]),2]

year2 <- year[index][year[index]>0]

\#\#\# Figure (set png_figure to 1) or not (any other value)

png_figure $<-0$

if (png_figure $==1)\{$

png('./FigS2.png')

\}

$\operatorname{par}(\operatorname{mar}=\mathrm{c}(5,5,1,4))$

titi<-lowess(density(year2)\$y density(year2)\$x, f=0.56)

plot(titi, type="l", xlab="Years after the beginning of data collection", ylab="Probability", cex.axis=2.5, cex.lab $=1.7, x \lim =c(0,50)$, lwd=2)

abline $(v=\operatorname{round}($ titi $\$ x[$ which(titi\$y==max(titi\$y))] $)$ lwd=3)

text(5.,0.006, paste(round(titi $\$ x[$ which(titi\$y==max(titi\$y))])," years", sep="'"), pos=1, cex=2)

if (png_figure $==1)\{$

dev.off() 


\subsection{Fig S3}

\#\#\#\#\#\# PURPOSE: Script to run the generalized additive mixed model (GAMM) analysis on the data set

\#\#\#\#\#\# INSTRUCTIONS: set the path where you downloaded and saved the global dataset, install the package gamm4 \#\#\#\#\#\# INPUTS: the global_dataset.csv file \#\#\#\#\#\# OUTPUTS: Fig. S3

\#\#\#\#\#\# AUTHORS: Sylvain Bonhommeau \& Philippe Cury (Last update 23rd of August 2011)

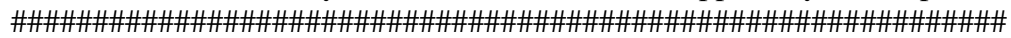

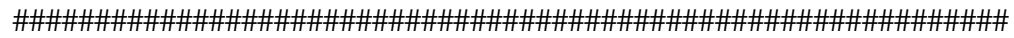

\#\#\# LOAD the required packages

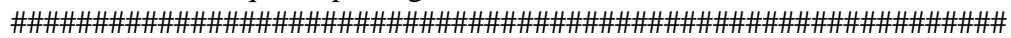

library(gam)

library(changepoint)

library(time)

library(gamm4)

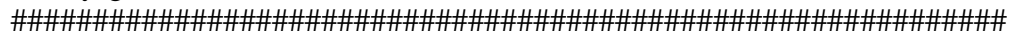

\#\#\# !!!! SET the path to the data (download the global_dataset.csv file and paste it in the repository you want to work in)!!!

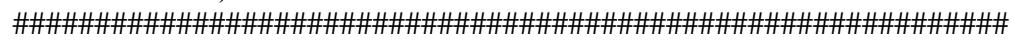

setwd('XXX')

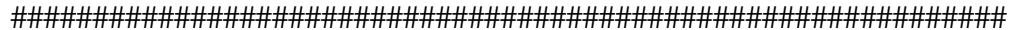

\#\#\# LOAD the data

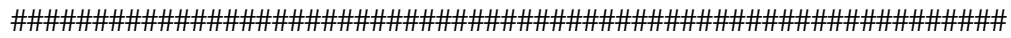

t_glob <- read.table('./global_dataset.csv', header=F, sep=";")

data $<-$ t_glob

\#\#\# The global data set contains some holes in the times series. We first select the years we have both a breeding success and an abundance estimate for the prey

bird <- as.numeric(data[,2])

prey $<-$ as.numeric(data[,3])

Eco $<$ - as.numeric(data[,4])

req1 $<-$ which(is.na(bird) $==$ T)

if (length(req1) >0) \{bird<-bird[-req1];prey<-prey[-req1]; Eco<-Eco[-req1] $\}$

req $2<$-which(is.na(prey) $==\mathrm{T}$ )

if (length(req2) >0) \{bird<-bird[-req2];prey<-prey[-req2] ; Eco<-Eco[-req2]

\#\#\# GAMM

gam.object <- gamm4(bird s(prey), random = (1|Eco), na.action="na.omit")

prediction <- predict.gam(gam.object\$gam, se.fit=T)

fds <- cbind(prediction\$fit,prey,prediction\$se.fit,0,0)

fds2 <- order(fds[,2])

titu <- spline(prediction\$fit[fds2] prey[fds2],n=200)

\#\#\# Figure (set png_figure to 1 ) or not (any other value)

png_figure $<-0$

if (png_figure $==1)\{$

png('./FigS3.png', width=1200, height=1200)

\}

plot(min(prey),min(bird), col="transparent" ,main="'"ylab="Breeding success (-)", xlab="Prey abundance $(-) "$, cex.lab=2.5, cex.axis=2.5, $p c h=16$, cex.main $=2, x \lim =c(-2,3.5), y \lim =c(-3.5,3))$ lines(titu, lwd=2)

$\mathrm{xd}<-\mathrm{c}(\mathrm{fds}[\mathrm{fds} 2,2], \mathrm{rev}(\mathrm{fds}[\mathrm{fds} 2,2]))$

up.sd<-prediction\$fit[fds2]+1.96*prediction\$se.fit[fds2]

down.sd<-prediction\$fit[fds2]-1.96*prediction\$se.fit[fds2]

yd<-c(up.sd,rev(down.sd))

polygon(xd,yd,col="grey81",lty=1,border="transparent")

lines(titu\$y titu\$x, lwd=4)

for (i in 1:length(data[,1]))\{

points(data[i,2] data[i,3],pch=16, col=paste(data[i,5]), cex=2)

\}

\#\# Identify the threshold 
data2 <- cbind(titu\$y[1:150],1,titu\$x[1:150])

change_point $<$ - cpt.reg(data2,penalty="SIC")

threshold $<-$ titu\$x[cpts(change_point)[1]]

abline(v=threshold, lwd=4, col="orange")

percentage_threshold <- (threshold+abs(min(prey)))/(max(prey)+abs(min(prey)))

text(threshold,-3.2, paste(signif(threshold,2), "Ini.e.",paste(signif(percentage_threshold*100,2)),"\% of

max prey abundance" ), pos $=4$, cex $=2.5$ )

legend("bottomright", pch=16, col=unique(paste(t_glob[,5])), legend=unique(t_glob[,4]), bty="n", $\mathrm{cex}=2)$

if (png_figure $==1)\{$

dev.off()

\} 


\subsection{Fig S4}

\#\#\#\#\#\# PURPOSE: Script to run the quantile regression analyses on the global dataset \#\#\#\#\#\# INSTRUCTIONS: set the path where you downloaded and saved the global dataset, install the package splines, quantreg and VGAM

\#\#\#\#\#\# INPUTS: the global_dataset.csv file

\#\#\#\#\#\# OUTPUTS: Fig. S4

\#\#\#\#\#\# REQUIREMENTS: you need the script bootstrapping.R

\#\#\#\#\#\# AUTHORS: Sylvain Bonhommeau \& Philippe Cury (Last update 23rd of August 2011)

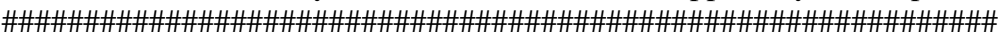

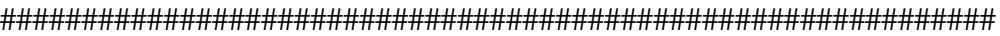

\#\#\# LOAD the required packages

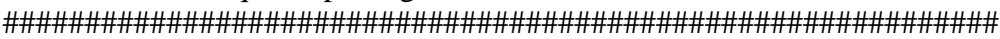

library(gam)

library(changepoint)

library(time)

library(splines)

library(quantreg)

library(VGAM)

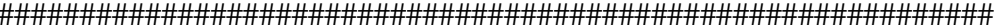

\#\#\#!!!! SET the path to the data (download the global_dataset.csv file and paste it in the repository you want to work in) !!!

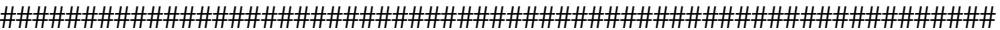

setwd('XXXX')

t_glob <- read.table('./global_dataset.csv', header=F, sep=";")

data $<-$ t_glob

\#\#\# The global data set contains some holes in the times series. We first select the years we have both a breeding success and an abundance estimate for the prey

bird $<$ - as.numeric $($ data[,2])

prey $<-$ as.numeric $($ data[,3])

req1 $<-$ which(is.na(bird) $==$ T)

if (length(req1) $>0$ ) \{bird<-bird[-req1];prey<-prey[-req1] $\}$

req2 $<$-which(is.na(prey) $==\mathrm{T}$ )

if (length(req2) >0) \{bird<-bird[-req2];prey<-prey[-req2] \}

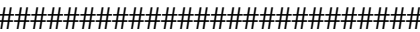

\#\#\# Script to boostrap to plot as in Fig 2A

bootstrap_size $<-1000$

smoother_size $<-3$

source('./bootstrapping.R')

\#\#\# Classic GAM as for the Figure 1A of the manuscript

gam.object<-gam(bird s(prey,3), na.action='na.omit')

prediction $<$-predict.gam(gam.object, se.fit $=\mathrm{T}$ )

fds $<$-cbind(prediction\$fit,prey,prediction\$se.fit,0,0)

fds2 $<-$ order(fds[,2])

titu <- spline(prediction\$fit[fds2] prey[fds2],n=200)

\#\#\# Fit a "quantile" gam on the data (with an offset of 10 since vgam requires that the response variable is positive (then offset substracted for the plot)

fit <- vgam(bird+10 s(prey), lms.bcn(zero=c(1,3)),trac=TRUE)

\#\#\#quantile regression with GAM

qtreg_gam <- qtplot.lmscreg(fit, percentiles=c(10,90), main="Quantiles",pch=16, las=1,

ylab="Bredding success (-)", xlab="Prey abundance $(-)$ ", lwd=2, lcol=4, yaxt="n")

quant_matrix $<-$ cbind(prey,qtreg_gam\$fitted.values-10)

order_quant_matrix <- order(quant_matrix[,1])

titu95 <- spline(quant_matrix[order_quant_matrix,3] quant_matrix[order_quant_matrix,1],n=200)

titu5 <- spline(quant_matrix[order_quant_matrix,2] quant_matrix[order_quant_matrix,1],n=200)

\#\#\# Figure (set png_figure to 1) or not (any other value)

png_figure $<-0$

if (png_figure==1) \{

png('./FigS4.png', width=1200, height=1200) 


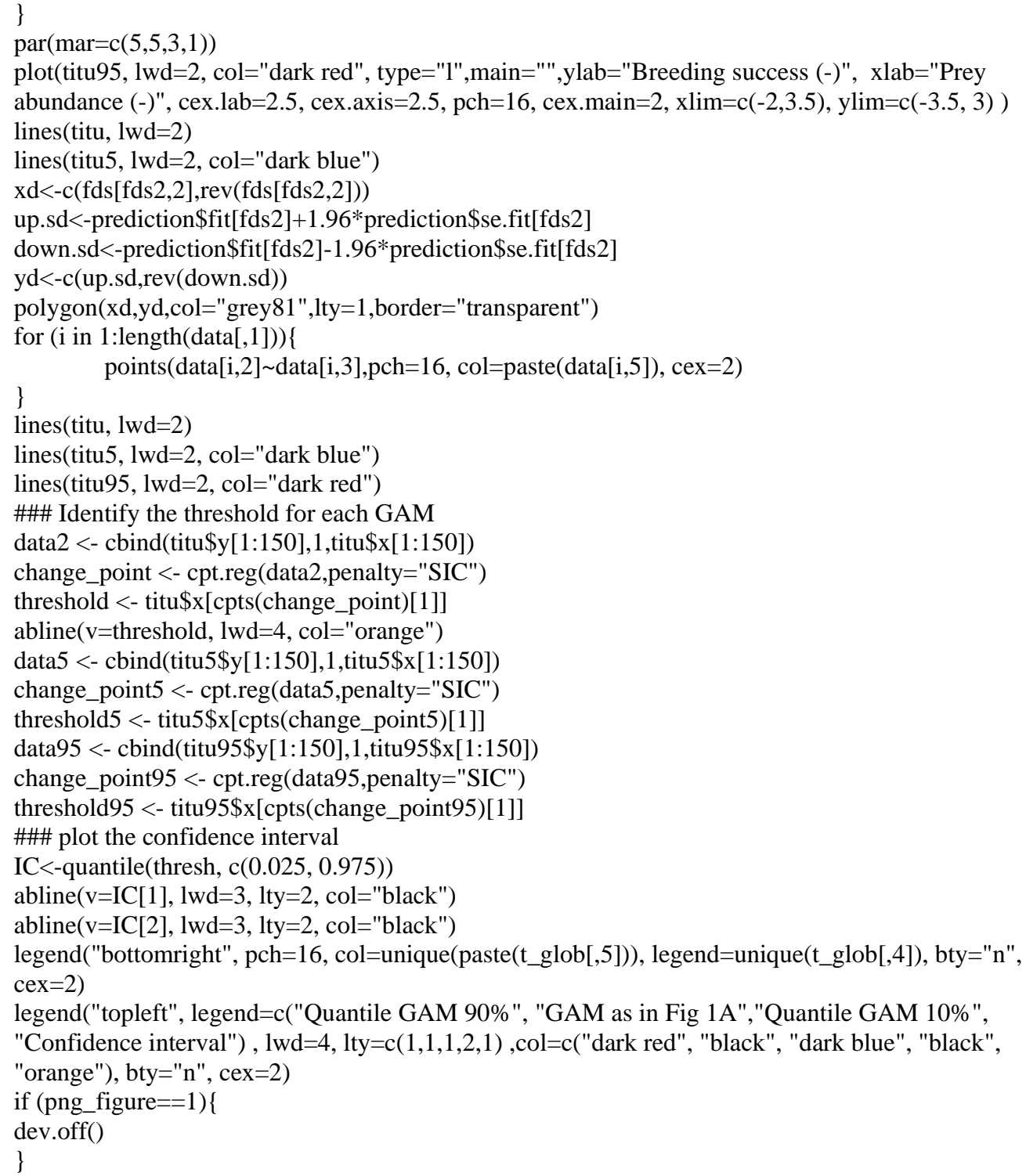




\subsection{Bootstrapping code}

\#\#\#\#\#\# PURPOSE: Script to bootstrap on the data set to find the confidence interval for the threshold estimate (for Fig 2A)

\#\#\#\#\#\# INSTRUCTIONS: set the bootstrap sample size you want to do in the Fig2A_B.R script \#\#\#\#\#\# INSTRUCTIONS: set the path where you downloaded and saved the global dataset \#\#\#\#\#\# REQUIREMENTS: you need the script bootstrapping.R and to have the R packages 'gam', 'changepoint', and 'time' installed \#\#\#\#\#\# INPUTS: the global_dataset.csv file \#\#\#\#\#\# OUTPUTS: Figs. 2A and B \#\#\#\#\#\#\# MISCELLANEOUS:

\#\#\#\#\#\# AUTHORS: Sylvain Bonhommeau \& Philippe Cury (Last update 23rd of August 2011)

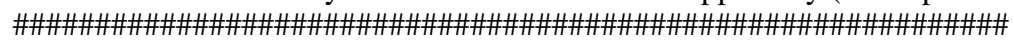

\#\#\# The global data set contains some holes in the times series. We first select the years we have both a breeding success and an abundance estimate for the prey

data $<-$ t_glob

bird $<$ - as.numeric(data[,2])

prey $<-$ as.numeric(data[,3])

req1 $<-$ which(is.na(bird) $==$ T)

if (length(req1) >0) \{bird<-bird[-req1];prey<-prey[-req1] $\}$

req2 $<$-which(is.na(prey) $==\mathrm{T}$ )

if (length(req2) >0) \{bird<-bird[-req2];prey<-prey[-req2] $\}$

\#\#\#\#\#\# RESAMPLING \#\#\#\#\#\#\#\#

nb $<$ - bootstrap_size

thresh $<$ - vector(length=nb) \#\# create a vector to be filled with the estimated threshold

prev <- progressBar() \#\# just to display how long it remains for the bootstrap

for (i in 1:nb) \{

prev $<$ - progressBar(i/nb, prev)

bootsample $<$ - sample(1:length(bird), replace $=$ T)

birdi <- bird[bootsample]

preyi <- prey[bootsample]

\#\#\#\#\#\#Computing threshold on new sample \#\#\#\#\#\#

gam.object <- gam(birdi s(preyi, smoother_size), na.action='na.omit')

prediction <- predict.gam(gam.object, se.fit=T)

fds <- cbind(prediction\$fit,preyi,prediction\$se.fit,0,0)

fds2 $<$ - order(fds[,2])

titu $<$ - spline(prediction\$fit[fds2] preyi[fds2],n=200)

data <- cbind(titu\$y[1:150],1,titu\$x[1:150])

change_point <- cpt.reg(data,penalty="SIC") \#\# Calculate the position of the threshold (see

changepoint package)

\}

thresh[i] <- titu\$x[cpts(change_point)[1]]

\#\#\# Reset the values to initial values

data $<-$ t_glob

bird<-as.numeric(data[,2])

prey<-as.numeric(data[,3])

req1 $<$-which(is.na(bird) $==\mathrm{T}$ )

if (length(req1) $>0$ ) $\{$ bird<-bird[-req1];prey<-prey[-req1] \}

req $2<$-which(is.na(prey) $==\mathrm{T}$ )

if (length(req2) $>0$ ) \{bird<-bird[-req2];prey<-prey[-req2] $\}$

gam.object<-gam(bird s(prey,smoother_size), na.action='na.omit')

prediction<-predict.gam(gam.object, se.fit=T)

fds $<$-cbind(prediction\$fit,prey,prediction\$se.fit,0,0)

fds2<-order(fds[,2])

titu <- spline(prediction\$fit[fds2] prey[fds2],n=200) 